Pediat Res. 16: 886-907 (1982)

Abstracts

\title{
21ST ANNUAL MEETING
}

\section{EUROPEAN SOCIETY FOR PAEDIATRIC ENDOCRINOLOGY}

\author{
Helsinki, Finland, June 28-July 1, 1982
}

\author{
President: Jaakko Perheentupa, Finland \\ Secretary: Raphaël Rappaport, France \\ Treasurer: Pierre C. Sizonenko, Switzerland \\ Council: Albert Aynsley-Green, United Kingdom \\ Giuseppe Chiumello, Italy \\ W. G. Sippel, Germany \\ Magda Vanderschueren-Lodeweyckx, Belgium
}

\begin{abstract}
1 J. TAPANAINEN ${ }^{\star}$, H. MARTIKAINEN ${ }^{\star}$, L. DUNKEL ${ }^{*}$, J, PERHEENTUPA and R. VIHKO ${ }^{*}$. Department of CIinical Chemistry, University of Oulu, and Children's Hospital, University of Helsinki, Finland.

Pubertal change in testicular steroidogenic response to a single dose of hCG.

The response patterns of plasma steroids to a single i.m. dose of $5000 \mathrm{IU} / 1.7 \mathrm{~m}^{2}$ of hCG was studied in prepubertal and early pubertal boys, and compared with the response of young adult men (Martikainen et al, Clin. Endocrinol. 1980:13:157). The rapid (at approximately $2 \mathrm{~h}$ ) testosterone $(\mathrm{T})$ response was absent in all boys, but the slow response (at 2-5 d) appeared constantly. The relative $T$ response (maximal stimulated vs. basal concentration) was 70 -fold in prepuberty, and 6-fold at early puberty, against 2.4-fold in adult men. Plasma estradiol (E2) and 17hydroxyprogesterone (17-OHP) showed no increase in prepuberty, but responded at early puberty in a pattern similar to adult but

In conclusion the testicular responses of E2 and 17-OHP to hCG appear later than the $T$ response, and the relative $T$ response is highest in the absence of the $\mathrm{E} 2$ response. It is suggested that the testicular E2 response to LH/hCG appears only in the course of puberty and results in an intratesticular short-loop feed-back inhibition of androgen production.
\end{abstract}

\section{2} F. BIDLINGMAIER, W. EISENMENGER*, U. KUHNLE*, and D. KNORR. University of Munich, Children's Hospital and Institute for Forensic Pathology, Munich (FRG)

Testicular and epldidymal concentrations of testosterone $(T)$ and androstenedione $(A)$ during infancy.

$T$ and $A$ were measured in testicular and epididymal tissue of 24 infants deceased by sudden infant death. In most cases elevated plasma levels of cortisol and $A$ suggested predeath stress. Plasma $T$ levels, however, did not differ from healthy infants indicating an unchanged gonadal situation. Testicular $T$ concentrations were maximal in boys from 1 to 3 months of age (mean: 65.5; range 7-370 $\mathrm{ng} / \mathrm{g}$ wet tissue) with peak values corresponding to concentrations reported for pubertal or even adult testes (PASQUALINI et al., Clin. Endocr. 15, 535 (1981). Thereafter testicular $T$ concentrations decreased and after the age of 6 months all values were below $8 \mathrm{ng} / \mathrm{g}$ (low prepub, range). P1asma and testicular $T$ correlated significantly. On an average the concentrations in the testes were 26 times higher than in the corresponding plasma sample. Testicular A was low (mean: 5.5 $\mathrm{ng} / \mathrm{g}$ ) and varied 1ittle. Epididymal $T$ concentrations were surprisingly high. In 1 to 3 months old boys they averaged $40 \%$ of the testicular $T$ concentrations ranging from 5 to $42 \mathrm{ng} / \mathrm{g}$. These concentrations are much higher than those reported for androgens in prostatic tissue of infants, boys, and adults (HAMMOND, J. Endocr. 78, 7 (1978)). Our findings suggest that high local $T$ concentrations during infancy are important not only for the testicle itself but also for the developing epididymis.
3 J.M. GARAGORRI* J.C. JOB, P. CANLORBE, J.E. TOUBLANC, J.L. CHAUSSAIN, HOpi tal Sainivincent de paul, 75014 paris, France. Early treatment of cryptorchidism with human chorionic gonadotropin hCG.

153 children with common cryptorchidism (109 uni and 44 bilateral) excluding cases with associated malformation or demonstrable abnormalities, were treated at age 6-59 months using hCG IM injections of 500 to 1500 IU on alternate days. Treatment before 3 years resulted in $81 \%$ complete failures; at $3-4$ years, $55 \%$ failures, $19 \%$ complete testicular descent and $26 \%$ partial. The \% of failures was increased when the dose of hCG was lower than $1000 \mathrm{IU} / \mathrm{m}^{2} /$ injection and when the cryptorchid testis was in very high situation.

Previous endocrine investigation had been obtained in 78 : 33 with postnatal follow-up of $L H$ and testoste rone, 45 with LHRH test. No correlation was found between the endocrine data such obtained and the clinical results. Measurement of the plasma testosterone after the $3 \mathrm{~d}$ injection of hCG showed no overall significant difference between successfully and unsignificant difference between successfully and unly lower $(p<0.01)$ in patients treated at 36-59 months than before this age, contrasting with the significant iy $(\mathrm{p}<0.01)$ better clinical results in the older group

4 J. MULLER* and N.E. SKAKKEBAKK (Intr. by K.W. Kastrup). Laboratory of Reproductive Biology, Dept. of Obstetrics and Gynecology, and Dept. of Pediatrics G, Rigshospitalet, Copenhagen.

Stereological investigation of testicular germ cells in the normal child.

Quantitation of histological structures in the infantile testis has usually been carried out using arbitrary or relative units. In order to obtain further information on the quantitative changes of infantile germ cells during childhood a stereological study was carried out. Testicular material was obtained from 48 boys (age 0-18 years) who died from sudden death. The testicular material was embedded in paraffin, re-embedded in Spurr's resin and sectioned at 0.54 . Quantitation was carried out on a Reichert Visopan projection microscope using point and profile counting. The study showed that the total number of germinal cells per individual was decreasing during the first four years of life. Hereafter a slight increase took place until puberty, when a 20 -fold increase was observed. The nuclear diameter was steadily decreasing during childhood, which indicates that the large foetal germ cells gradually are replaced by the smaller adult spermatogonia. Thus, it appears that the population of germinal cells in the testis is not quiescent during childhood. 

Enfants-Malades, Paris. France.

Association of facial malformations with primary hypopituitarism as possible evidence for a common developmental defect of prosencephalic neural crest derivatives.

Recent studies have shown that nasofrontal facial structures, total anterior pituitary and hypothalamic area are derived from the prosencephalic neural crest. Although hypopituitarism has already been described in holoprosencephaly, the purpose of the present study was to identifiy less severe clinical and radiological signs, which could be taken as evidence for a developmental defect. Nineteen consecutive patients were examined by one fo us (G.C.). They presented with isolated $\mathrm{GH}(\mathrm{n}=9)$ or multiple pituitary deficiences $(n=10)$. Abnormalities were classified according to their embryonic postulated origin along the anterior neural crest. Six patients had prosencephalic derived defects such as : cartilaginous microrhiny of Binder $(n=4)$, frontoparietal angioma $(n=1)$, and lateral incisors microdontia $(n=1)$. In four other cases facial dysplasia referred respectively to mesencephalic or rhombencephalic locations : mandibular dysostosis with ear defect $(n=3)$ or tongue hemihypertrophy $(n=1)$. These findings could indicate a high frequency of prosencephalic neural crest derived abnornalities suggesting the possible role of an embryonic developmental defect as a cause of so called primary hypopituitarism.

\section{6} California, San Francisco.

Synthesis of growth hormone (GH), prolactin (Pr1) and pro-opiomelanocortin (POMC) during ovine fetal development. Effect of cortisol infusion.

Glucocorticoids are given to mothers having a premature delivery to prevent the respiratory distress syndrome. We decided to study the effect of glucocorticoids on the synthesis of ovine fetal GH, $\operatorname{Pr} 1$ and POMC. Chronically cathetrized fetuse of 118-125 days of gestation were infused with cortisol, $1 \mathrm{mg} /$ hour for 48 hours. Controls were infused with $0.9 \%$ saline. Another control group were the twins of cortisol infused fetuses. Fetuses were delivered by cesarean section. Pituitary glands were immediately dissected and used for short-term incubation in a tissue culture system supplied by $35 \mathrm{~s}-$ methionine. Newly synthetized hormones were displayed by a two-directional SDS/ polyacrylamide gel electrophoresis system. Hormone synthesis was quantitated by comparing spot sizes of hormones to an internal control. During the cortisol infusion synthesis of GH was increased. No change was detected in the synthesis of Prl or POMC. The synthesis of POMC in the neurointermediate lobes was not changed either. Negative feed-back regulation of cortisol secretion is not fully developed at this stage of gestation.
2. HOCHBERG T. CHEN A. BENDERLI* S. SHANI* C. CONE* and D. FELDMAN* (Intr. by Stanford University, CA USA.

Vitamin $D$ resistent rickets with deficient skin fibroblasts receptors to $1,25(\mathrm{OH})_{2} \mathrm{D} 3$.

Severe rickets, alopecia, high circulating levels of $1,25(\mathrm{OH}) 2 \mathrm{D} 3$ and refractoriness to treatment with vit. has been described in 4 patients so far. We report 4 additional patients with this disorder: 2 pairs of sibs, 1-7 years of age of 2 unrelated families. Onset of rachitic signs occured within the first year of life. Partial alopecia was apparent on diagnosis and became gradually complete. Serum analysis revealed: Ca $6.6-7.6 \mathrm{mg}$ dl $(\mathrm{N} 9.5 \pm 0.7)$, $12.8-4.1 \mathrm{mg} / \mathrm{dl}$ (N $5.0 \pm 1.0)$, alkaline

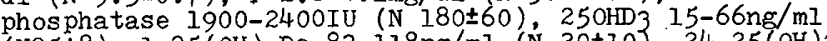

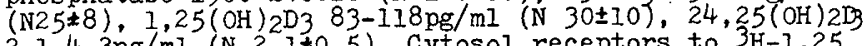
$2.1-4.3 \mathrm{ng} / \mathrm{mI}$ (N $2,1 \pm 0.5)$. Cytosol receptors to $3 \mathrm{H}-1,25$ $(\mathrm{OH}) 2 \mathrm{D} 3$ were studied in skin fibroblasts cultured from the forearm of one patient, and compared to that of 5 normal individuals. Affinity (Kd) of normal cytosol was 0.1-0.2nM and maximal binding was 20-30fmol/looug DNA. cytosol of an affected patient showed negligible specific binding of $3 \mathrm{Hl}, 25(\mathrm{OH}) 2 \mathrm{D} 3$. Sucrose density gradient analysis showed a $3.2 \mathrm{~S}$ peak in control cytosol. That of the patient was devoid of a binding peak. We conclude that this child has defective $1,25(0 \mathrm{H})_{2} \mathrm{D} 3$ receptors.

\section{7 \\ R.P.WILLIG, I.LAGENSTEIN* D.KOHNE* \\ Dept. of Pediatrics, University of Hamburg, FRG Morphological and Functional Brain Alterations Due to ACTH Treatment.}

ACTH and glucocorticoids are potent drugs for treating infantile spasms. ACTH was thought to act by adrenal stimulation. However, our findings suggest, that ACTH produces a direct effect upon brain. This was found out by $a_{2}$ prospective study of 28 children receiving depot ACTH $\left(160 \mathrm{IU} / \mathrm{m}^{2} /\right.$ day) and subsequently dexamethasone $(0,3 \mathrm{mg} / \mathrm{kg} /$ day) because of intractable convulsions.

1. Following lo days ACTH treatment serial cortjsol determinations resulted in elevated plasma levels $(101,0-14,2($ SEM) $\mu \mathrm{g} / \mathrm{d} 1)$. Similar high levels were induced by 15 IU ACTH, too. Such low ACTH dosage exerts maximal adrenal stimulating but no anticonvulsive effect. - 2. Spasms of 2 children with adrenal insufficiency were treated successfully by ACTH, al though plasma cortisol levels did not increase. Similar effects were observed in adrenalectomised animals treated with ACTH. - 3. ACTH caused reversible brain shrinkage demonstrated by computerized cranial tomography (CCT). Cerebral al terations subsided when ACTH was discontinued and replaced by dexamethasone. - ACTH dose dependency, its effectiveness despite adrenal insufficiency, and morphological brain changes induced by ACTH indicate an extraadrenal, direct action of ACTH upon neural tissue. To make use of the anticonvulsive ACTH efficacy but to avoid side effects due to hypercortisolaemia we suggest anticonvulsive treatment with ACTH fragments without adrenal stimulating actions.
9 J.P. BOURGUIGNON, A. GERARD" and P. FRANCHIMONT: Pediatric Clinic, University of Liège, Hôpital de Bavière, B 4020 Liège, Belgium.

Castration of prepubertal male rats does not affect hypothalamic maturation at puberty.

After castration of adult (75 days) male rats, mean serum $L H$ increased from 20 to $168 \mathrm{ng} I R P-1 / \mathrm{ml}$ + within $24 \mathrm{~h}$, whereas mean total hypothalamic LHRH content fell from 4.22 to $1.14 \mathrm{ng}$ twithin 15 days, confirming other observations. Prepubertal male rats, intact or castrated at 21 days, were studied $0.3,1,2,7,15$ and 21 days afterwards. A first rise in serum LH from 3.8 to $93 \mathrm{ng} /$ $m l+o c c u r e d 1$ and 2 days after castration whereas neither serum $L H$ in intact rats nor hypothalamic LHRH content in both intact and castrated rats changed at that time. From 23 to 28 days of age, at the time of the onset of puberty, mean serum $L H$ increased from 4.9 to $15.7 \mathrm{ng} / \mathrm{ml}$ t and from 93 to $209 \mathrm{ng} / \mathrm{ml}$ + in intact and castrated rats respectively. During the same period, mean hypothalamic LHRH content increased from 1.08 to $2.29 \mathrm{ng}$ t and from 0.94 to $1.95 \mathrm{ng}+$ in intact and castrated rats respectively. The pubertal increase of hypothalamic LHRH content occured similar in intact and castrated rats up to 42 days of age. In conciusion, castration of adult male rats resulted in a decrease in hypothalamic LHRH content whereas prepubertal castrated rats showed a normal increase in hypothalamic LHRH content during puberty and a concomitant secondary rise in serum $\mathrm{LH}$. This might suggest that, in male rats, hypothalamic maturation at puberty can proceed in the absence of gonads.

$+p<0.01$

10

P.J. SMAIL*, C. FAYMAN*, W.C. HOBSON*, G.B. FULLER* and J.S.D. WINTER* University of Manitoba, Winnipeg and Primate Research Institute, New Mexico State University (Intr. by CoC. Forsyth)

Studies on adrenarche in non-human primates.

Previous investigators have reported that chimpanzees demonstrate an adrenarchal rise in serum concentrations of adrenal C-19 steroids but that this phenomenon is absent in lower primates. We have measured serum levels of dehydroepiandrosterone (DHA), DHA-sulphate (DHAS) and cortisol in 52 chimpanzees $(0.5-10 \mathrm{yr}$ ), 76 Macaca mulatta $(0.2-5 \mathrm{yr})$ and $80 \mathrm{M}$. nemastrina $(0.5-9 \mathrm{yr})$. Concomitant studies in $10 \mathrm{M}$. mulatta showed that venepuncture stresscaused parallel increases in serum levels of all 3 steroids. Thus adrenarche was defined as an age-related rise in levels of DHA and DHAS relative to cortisol. The chimpanzees showed such a rise beginning before puberty (age 7-10 $\mathrm{yr}$ in this species), exactly like human adrenarche. In M. mulatta, DHA showed no change with age up to $5 \mathrm{yr}$ while DHAS levels declined. In M. nemastrina the pattern was similar but a later postpubertal rise of DHA and DHAS was seen as 6-9 yrs (puberty occurring at 2.5-4 yrs in macaques). These data indicate that adrenarche occurs at $6 \div 9 \mathrm{yr}$ in all primates and is completely independent of the age of sexual maturation. It seems likely that adrenarche reflects progressive adrenal growth and the resulting impact of changing intra-adrenal steroid concentrations upon steroidogenesis in the zona reticularis. 
Failure of DHEA-oenenthate to promote growth.

It has frequently been suggested that ađrenal androgens may promote pubertal growth. In order to assess this effect, we administered DHEA-oenenthate (Schering AG, BERLIN) in monthly IM injections $\left(70 \mathrm{mg} / \mathrm{m}^{2}\right.$ ) over 1 year to 5 boys with constitutional short stature (aged 10-12 4/12 yr) and 1 boy (aged $124 / 12$ ) with panhypopituitarism (coincidently receiving thyroxine and $\mathrm{hGH}$ ). All showed bone age delay of at least 3 yrs, and all had sub-normal levels of DHEA and DHEA-S. Pre-treatment growth velocity ranged from 3-5 cm/yr. Following DHEA-oenenthate injection, DHEA increased 10-fold after 8 days, 2.6-fold after 15 days, and 1.8fold after 22 days. Plasma DHEA-S levels increased 14-fold on day 8,6 -fold on day 15 , and 4 -fold on day 22 . There was no rise in plasma testosterone or androstenedione, which remained at prepubertal levels. During therapy, and during one year of followup post-therapy, there was no significant change in growth velocity. The rate of skeletal maturation assessed by $\mathrm{X}$-ray was not affected. One of 4 boys entered puberty during the post-treatment year. These results demonstrate that this long-acting form of DHEA, administered over $1 \mathrm{yr}$, did not raise plasma testosterone values, and did not accelerate either growth or skeletal maturation. This does not lead support to the suggestion that adrenal androgens play a role in the regulation of normal growth. This study was approved by the Ethical Committee of the Department. 12 M. CRAEN*, M.V.L. DU CAJU, J.P. BOURGUTGNON,

$R$. WOLTER, M. VANDERSCHUEREN-LODEWEYCKX.

Departments of Paediatrics and Internal Medicine ${ }^{1}$, Universities of Ghent, Antwerp, Liège, Louvain, Brussels and Leuven, Belgium.

Effects of oral treatment with DHEAS in girls with hypopituitarism.

Six girls with multiple pituitary hormone deficiencies, aged 19-22 years, were studied longitudinally before and during treatment with DHEAS ( $\left.15 \mathrm{mg} / \mathrm{m}^{2} / \mathrm{d} \mathrm{p} .0.\right)$. Plasma levels of DHEAS, DHEA and $\Delta_{4}$ were measured by RIA; pubic (P) and axillary (A) hair development was scored according to Tanner. At the beginning of therapy BA ranged from 11 to 13.8 years and biochemical adrenarche was absent in all patients. Replacement therapy with hGH and thyroxine with or without cortisone was already given for several years. Breast development was achieved by oral administration of ethinyloestradiol $10 \mu \mathrm{g}$ $3 / 4$ weeks. Treatment with DHEAS resulted in a net increase in plasma levels of DHEAS. $P_{2}$ was achieved in all girls after 6-28 months and $\mathrm{P}_{3}$ or $\mathrm{P}_{4}$ in some. Withdrawal bleeding occurred in all cases; no signs of virilization were found. In conclusion, these data suggest that treatment with DHEAS is effective to promote the development of pubic hair in hypopituitary girls without spontaneous adrenarche.

\section{S.E.OBERF IELD, E.STONER, L.S.LEVINE, D.LAURENCE SR.} M.I.New. Cornell Univ Med Col, NYC 10021 USA. Unilateral macronodular hyperplasia causing hyperaldosteronism.

We present the first report of primary hoperaldosteronism in chilchood due to unilateral macronodular hyperplasia. A 10 y o white male with severe hypertension $(150 / 100 \mathrm{~mm} / \mathrm{tg})$, hypokalemia $(1.4 \mathrm{mEg} / 1)$, and suppressed plasma renin activity (PRA) $(<0.1 \mathrm{ng} / \mathrm{ml} / \mathrm{hr}$ ) demonstrated fixed PRA and aldosterone (aldo) levels with alteration of dietary sodium. The paradoxical decrease in aldo on assumption of upright posture suggested a tunor. Prolonged ACTH administration produced a continuous rise in blood pressure, but a transient rise in aldo. A minimal decrease in urinary aldo with dexamethasone was noted excluding dexamethasone suppressible hyperaldosteronism. Blood pressure nomal ized with spironolactone. CT, iodocholesterol scanning, and adrenal venography were not diagnostic of a discrete adrenal lesion

Adrenal vein homone sampling with ACTH stimulation however, lateral ized aldosterone secretion unequivocally to the left adrenal gland:

\begin{tabular}{|c|c|c|c|c|c|}
\hline & Aldo(ng/dl) & $D O C(\mathrm{ng} / \mathrm{dl})$ & $B(\mu g / d l)$ & $F(\mu \mathrm{g} / \mathrm{dl})$ & $\frac{\text { Aldo/F }}{3 \Omega}$ \\
\hline $\begin{array}{l}\text { Left adrenal vein } \\
\text { Ridht adrenal vein }\end{array}$ & 5795.0 & $16,034.0$ & 90.0 & 1896.0 & $\begin{array}{l}3.06 \\
0.05\end{array}$ \\
\hline IVC below adrenal veins & 89.2 & 1929 & 2.352 & 22 & 4.0 \\
\hline Periphe & 62.3 & 187.0 & 3.4 & 25.0 & \\
\hline
\end{tabular}

Although hyperplasia as a cause of hyperaldosteronism in childhood is more cormon than an adenama, a tumor was predicted since adrenal vein sampling lateral ized aldo secretion to the left adrenal. However, left adrenalectany revealed macronodular hyperplasia, adrenal pathology consistent with the patient's young age. Post operatively, there was hyperkalemia, hypoaldosteronism, and reversal of hypertension. Thus in childhood, hyperaldosteronism due to unilateral hypersecretion may result from nodular hyperplasia, rather than a discrete adenoma.
O. ANDERSEN ${ }^{*}$ and B. BROCK JACOBSEN. Department of Pediatrics G,Rigshospitalet, University of Copenhagen, Denmark.

The renin-aldosterone-system (R-A-S) in nephrogenic diabetes insipidus (NDI) without treatment and during treatment with thiazide (T) and indomethacin (I).

$\mathrm{R}-\mathrm{A}-\mathrm{S}$ has not previously been studied in NDI. A family with apparently $\mathrm{x}$-linked NDI is presented: The proband, $\mathrm{a}$ boy, his mother and adult halfbrother suffered from NDI. His adult halfsister and maternal grandmother were healthy carriers of the gene. as judged from their urine concentrating capacities. All the adults had normal values of serum-aldosterone ( $S-A)$ and serumrenin (s-R). The mother and the halfbrother managed well without medical treatment. The proband was studied from 3 to 15 months of age. Before treatment $\mathrm{s}-\mathrm{A}$ and $\mathrm{s}-\mathrm{R}$ activity were normal for age (235 pmol/l and $32 \mathrm{ng} / \mathrm{ml} / \mathrm{h}$ ) in spite of hypertonic dehydration (s-Na 156-161 mEq/1, s-Osm $316 \mathrm{mosm} / \mathrm{kg}$ ). As expected $\mathrm{R}-\mathrm{A}-\mathrm{S}$ was stimulated during treatment with $\mathrm{T}$ ( $\mathrm{s}-\mathrm{A} 560 \mathrm{pmol} / 1, \mathrm{~s}-\mathrm{R}$ activity $104 \mathrm{ng} / \mathrm{ml} / \mathrm{h}$ ). T lowered $\mathrm{s}-\mathrm{Na}$ to $147 \mathrm{mEg} / \mathrm{l}$ and considerably improved the clinical condition although polyuria persisted unchanged. Addition of I caused a short term increase of $\mathrm{s}-\mathrm{A}$ (peakvalue 1730 pmol/l) followed by a decrease to normal values $(<450$ pmol/1). S-R was depressed immediately (from 990 to $<300 \mathrm{mIU} / 1$ ). Treatment with I alone depressed both $s-A$ and $s-R$. The effect of I on polyuria and $\mathrm{s}-\mathrm{Na}$ was only transient and disappeared within 2 weeks. Conclusions: $1 . \mathrm{R}-\mathrm{A}-\mathrm{S}$ is not activated in NDI during hypertonic dehydration and offers no information in the control of this disorder. 2. The effect of $I$ in NDI is of short duration.

Contribution of adrenal cortex for development and maintenance of essential hypertension.

Spontaneously hypertensive rats (SHR) were used as a model for essential hypertension. Prehypertensive (6 weeks) and early hypertensive ( 10 weeks) male SHR underwent complete bilateral adrenalectomy (ADNEX) and kept on $0,9 \% \mathrm{NaCl}$. Blood pressure (BP) was measured by the tail cuff method. The rats were ether stressed at various intervals to assess adrenal steroid release. Following ADNEX of prehypertensive SHR two distinct groups of SHR could be distinguished. In the first group the development of hypertension depended on the presence of increasing releasable amounts of corticosterone, aldosterone and DOC. Adrenal regeneration was confirmed histologically at autopsy. The second group remained normotensive and adrenal steroids released were unmeasurable. ADNEX of hypertensive ( $>150 \mathrm{mmHg}$ ) SHR lead to a similar dichotomy. Following ADNEX fell precipitously and the recovery of high BP depended on the development of adrenal regeneration. The analysis of the steroids released following ether stress demonstrates the dependence of high BP on mineralcorticoid and especially glucocorticoid activity. The capacity of regenerates to release steroids, measured in vitro, confirmes the in vivo results. It is concluded that adrenal cortical activity is critically involved in the development and maintenance of hypertension.

16 Z. HOCHBERG and A. BENDERLI* (Intr. by R. Kauli). Department of Pediatrics, Rambam Medical Center, Haifa, Israel. Normal osmotic threshold for vasopressin release in the hyponatremia of hypothyroidism.

To explore a possible downward resetting of the hypothalamic osmoreceptors in the hyponatremia of hypothyroidism, 4 children, aged $11-15$ years, with primary hypothyroidism were studied. Serum T4 were $<3 \mathrm{ug} / \mathrm{dl}$ (Normal 5.5-10.5) and TSH were $>55 \mathrm{uU} / \mathrm{ml}$ (Normal 2.56.5). Plasma and urine osmolality ( $P /$ Uosm) were measured on random paired simultaneous samples, and following a $20 \mathrm{ml} / \mathrm{kg}$ water load. The osmotic threshold (OT) was determined by an isovolemic infusion of $3 \%$ $\mathrm{NaCl}$, and compared to the OT of 6 normal volunteers. Random measurements revealed hyponatremia and inappropriately high Uosm for the given Posm. A water load diluted the urine normally to Uosm of $62-88 \mathrm{~m} 0 \mathrm{sm} / \mathrm{kg}$. or of the hypothyroid patients was detected a Posm of $286-287 \mathrm{m0sm} / \mathrm{kg}$, compared to $286.7 \pm 1.0$ in the control group. It is concluded that patients with hypothyroidism have normal osmoreceptors with normal of and that none of the subtypes of the syndrome of inappropriate secretion of $\mathrm{ADH}$ could account for the hyponatremia of hypothyroidism. 
A. LARSSON, L. HACENFELDT* and L. BLIJ1*. The Department of Paediatrics, Karolinska Institute, St. Göran's Children's Hospital, The Department of Clinical Chemistry, Karolinska Hospital, and the Department of Paediatrics, Sachsska Barnsjukhuset, Stockholm, Sweden.

Serum $\alpha$-fetoprotein - a biochemical indicator of prenatal hypothyroidism.

Congenital hypothyroidism $(\mathrm{CH})$ is a heterogenous group of disorders. Infants with severe prenatal hypothyroidism have increased risk for neuropsychological sequelae, Bone age estimates and thyroid scintigrams have been used to identify these $\mathrm{CH}$ patients neonatally. We have analysed serum $\alpha$-fetoprotein (AFP) in 79 infants with positive TSH screening tests; 45 infants with $\mathrm{CH}$ and 34 with false positive tests. The serum samples were collected at $12 \pm 3$ days in $\mathrm{CH}$ infants and $17 \pm 6$ days in false positive infants. Serum was analysed for AFP (RIA-Gnost, Behringwerke) TSH and thyroid hormones. Skeletal maturation index was estimated according to Sénécal et al. S-AFP (mg/l) in $\mathrm{CH}$ infants was $47 \pm 56$ (mean \pm SD; range 3-208) and in false positive infants $6.3 \pm 5.5$ (range $0.1-26$ ); the difference was significant $(p<0,01)$. S-AFP in false positive infants was within the reference range whereas about half of the $\mathrm{CH}$ infants had elevated levels. S-AFP in $\mathrm{CH}$ infants was inversely correlated to the skeletal maturation index. It is suggested that thyroid hormones are needed for the repression of fetal hepatic AFP synthesis. The results indicate that analyses of S-AFP may be used neonatally to assess the degree and duration of fetal hypothyroidism, i.e., to identify infants with $\mathrm{CH}$ who are at risk for neurological sequelae. This study was approved by the ethical comnittee of the Karolinska Institute.

18

P. CZERNICHOW, M. SCHLUMBERGER*, R. POMAREDE* P. FRAGU* and R. RAPPAPORT

Hôpital des Enfants-Malades and Institut Gustave Roussy, Paris and Villejuif, France. Diagnostic value of plasma thyroglobulin measurement to determine the type of thyroid defect in congenital hypothyroidism.

The aim of this study was to evaluate the diagnostic value of plasma thyroglobulin $(\mathrm{Tg})$ measurement in patients with congenital hypothyroidism and to see if it could be of value in the classification of thyroid defect. Twenty hypothyroid patients were examined before 50 days of age. Plasma thyroxine $\left(\mathrm{T}_{4}\right) \quad 3,5,3^{\prime}$ triiodothyronine $\left(\mathrm{T}_{3}\right)$, thyroid stimulating hormone (TSH) and $T g$ were measured and thyroid scanning performed on all the infants. On the basis of the clinical evaluation and thyroid scans patients were divided into 3 groups : Group I ectopic or eutopic hypoplastic glands $(n=11)$, Group II goiters $(n=3)$, Group III athyrosis $(n=6)$. There was no differences among the TSH values of the 3 groups. Plasma $T_{4}$ and $T_{3}$ were lower in Group III patients than other groups. Plasma Tg was undetectable in all 6 patients with athyrosis and varied from 15 to $600 \mathrm{ng} / \mathrm{ml}$ in Group I patients. It was undetectable in one patient with congenital goiter. In conclusion : Tg measurement is of considerable help in the classification of patients among the different types of thyroid defects.

\section{9}

F. DELANGE, P. BOURDOUX" C. THILLY", R. LAGASSE*, P. COURTOIS", P. HENNART " and A.M. ERMANS". Univ. of Brussels, Belgium, IRS-CEMUBAC goiter program, Zaire. Neonatal thyroid screening in the presence of dietary goitrogens. We have shown that in severe endemic goiter, alterations of thyroid function are more important in newborns than in adults. Therefore we tested the hypothesis that increased serum thyrotropin (TSH) in the newborn could constitute a more sensitive index of the presence of dietary goitrogens in a population than the prevalence of goiter and elevated TSH in adults. Serum TSH was determined in cord blood in 674 newborns, in 637 of the mothers at delivery and in 894 euthyroid adults in 3 rural areas in Zaire (Bas Zaire, Kivu and Ubangi) with markedly different prevalence of goiter, and in Kinshasa used as control area. Exposure of the mothers to dietary goitrogens was assessed by the urinary concentration of iodine (I), thiocyanate ( $\mathrm{SCN}$ ), and by the urinary I/SCN ratio at delivery. The $1 / \mathrm{SCN}$ ratio decreased'from 12.1 in Kinshasa to 7.0 in Bas Zaire (NS), 3.5 in Kivu $(P<0.001)$ and 2.3 in Ubangi $(P<0.001)$. The prevalence of goiter was normal in Bas Zaire $(2 \%)$, slightly elevated in Kivu $(13 \%)$ and extremely high in Uban$g i(77 \%)$. TSH in adults and mothers at delivery was slightly higher than in the controls only in Ubangi. In contrast, cord TSH was already higher in Bas Zaire than in the controls (9.8 v.s. 7.8 $\mu \mathrm{U} / \mathrm{ml}, \mathrm{P}<0.05)$. It was also elevated in $\mathrm{Kivu}(10.1 \mu \mathrm{J} / \mathrm{m} 1, \mathrm{P}<0.001)$ and as high as $69.8 \mu \mathrm{U} / \mathrm{ml}$ in Ubangi $(\mathrm{P}<0.001)$. In conclusion, screening for congenital hypothyroidism based on the determination of TSH in cord blood is the most sensitive index of the presence of goitrogenic factors in the environment.
M. VANDERSCHUEREN-LODEWEYCKX, F. DEBRUYNE ${ }^{* 1}$,

P. BASTYNS ${ }^{* 1}$, L. SNOECK ${ }^{\mathbf{*}}$, L. DOOMS ${ }^{\boldsymbol{*}}$, E. EGGERMONT ${ }^{\boldsymbol{\pi}}$, R. EECKEL $\mathrm{S}^{*}$ and J. TYBERGHEIN ${ }^{*}$.

Departments of Paediatrics and of Otorhinolaryngology ${ }^{1}$, University of Leuven, Belgium.

Hearing acuity in children with congenital hypothyroidism (CH). Hearing acuity assessment was carried out in 45 patients with CH (36 girls and 9 boys), aged $110 / 12$ to $132 / 12$ years, during adequate long term therapy. Otoscopy was performed in all cases with additional microotoscopy and tympanometry if required. Secretory otitis media was found in 6 patients $(138)$ and treated either medically or by the insertion of grommets in the eardrum. In these children, hearing assessment was performed after complete cure of the otitis. Hearing acuity was measured either by conventional monoaural pure-tone audiometry $(250-8000 \mathrm{~Hz})$ or by binaural free field testing according to Suzuki according to the patient's age (above and below 4 yrs). Auditory perception was normal in 36 patients $(80 \%)$; in the remaining 9 patients, a sensorineural hearing loss of variable degree was detected involving preferentially the higher frequencies. Pexception deafness required the use of a hearing aid in 4 cases $(98)$. This frequency is far higher than in a normal population. No relation could be found between hearing acuity and CA or BA at diagnosis of $\mathrm{CH}$, aetiology of thyroid hypofunction and neuropsychological sequelae. In conclusion, sensorineural hearing loss occurs at a higher than normal frequency in patients with $\mathrm{CH}$ and should be searched for carefully in order to prevent additional difficulties.

21 R. KAULI, M. KARP, E. LUBIN* and Z. LARON. Inst. Pediat. \& Adolesc. Endocrinol. \& Inst. Nuclear Med. Beilinison Medical Ctr. \& Sackler Sch. of Medicine, Tel Aviv University, Israel.

Asymptomatic thyreotoxicosis.

Laboratory evidence for thyreotoxicosis without clinical expression was found upon routine testing of serum $T_{4}$ in 2 young women aged 17 and 24 with juvenile diabetes and in an apparently healthy prepubertal girl aged 8 . Serum $\mathrm{T}_{4}$ levels
fluctuated between $9.5-14.2 \mathrm{ug} / \mathrm{dl}$ and $\mathrm{T}_{3}$ levels from $2.2-3.3$ $\mathrm{ng} / \mathrm{ml}$; TSH was suppressed $(1.5 \mathrm{uU} / \mathrm{ml})$ and did not respond to TRH stimulation in repeated tests. Microsomal thyroid antibodies were found in the 2 diabetics but were undetectable in the nondiabetic girl. During close follow-up of 5 to 6 yrs they remained clinically euthyroid with persistent laboratory evidence of hyperthyroidism; then the elder diabetic and the non-diabetic developed overt thyreotoxicosis which responded to ant $i$-thyroid therapy. The younger diabetic remains asymptomatic so far. These findings indicate that a state of asymptomatic thyreotoxicosis can exist for a long time. The fact that 2 of 3 patients had diabetes may suggest an autoimmune pathogenesis. It is debatable whether such patients should be treated while clinically asymptomatic.

22 A. MIETTINEN* P. AHONEN*, and J. PERHEENTUPA.

Department of Bacteriology and Immunology and The Children's Hospital, University of Helsinki, Finland. Parathyroid and other autoantibodies (AAb) in patients with autoimmune polyendocrinopathy-candidosis-ectodermal dystrophy (APECED) APECED is a recessively inherited disease manifested as a variable combination of superficial candidosis, hypoparathyroidism (HP), adrenal insufficiency, gonadal atrophy, pernicious anaemia, diabetes, hypothyroidism (HT), hepatitis, alopecia, and nail and enamel dystrophy. We have studied the prevalences of various $\mathrm{AAb}$ in the sera of the patients, their uneffected siblings and their parents. The results are shown below:

\begin{tabular}{|c|c|c|c|c|c|c|c|c|}
\hline & & & ralen & ce of & autc & antik & bodies & $(\%)$ \\
\hline & $\mathrm{N}$ & PA & ICA & $\mathrm{AA}$ & $\mathrm{OA}$ & $\mathrm{TA}$ & $T g A$ & MsA \\
\hline Patients & $\overline{40}$ & 29 & 18 & 72 & 62 & 58 & 18 & 30 \\
\hline Siblings & 27 & 0 & 0 & 0 & 0 & 0 & 0 & 7 \\
\hline Parents & 28 & 0 & 7 & 0 & 0 & 0 & 14 & 18 \\
\hline
\end{tabular}

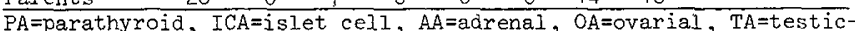
ular, TgA=thyroglobulin, MsAzthyroid microsomal antibodies.

Correlation between the presence of $\mathrm{AAb}$ and the corresponding endocrine deficiency was only partial. 10 of 34 patients with HP and 1 of 6 patients without HP had PA. Some patients have had ICA or AA for years without so far developing the deficiency, whereas others developed the deficiency without $\mathrm{AAb}$ finding. A few patients had PA or ICA temporarily but no disease. In case of thyroid the correlation is at this stage strikingly poor: only 1 patient has HT. 

23 M.MANNS, B.WEBER, W.ARNOID, W.BURGER ${ }^{\star}{ }^{*}$ T.H.HUTTIEROTH,

KinderkTinik der Freien Universität Berl in (West), and I.Medizinische Klinik der Johannes Gutenberg Universität Mainz, W.Germany.

Humoral immune phenomena in juvenile insul in dependent diabetes mellitus (IDDM)

Sera from 295 children ( 148 male,147 female) with IDDM were tested for several autoantibodies and circulating immune complexes (CIC) (Raji cell technique). Thyroglobul in antibodies (TAK) were detected in $15 \%$ of patients, parietal cell antibodies of the stomach in $22 \%$, smooth muscle antibodies and antinuclear antibodies in $2 \%$, whereas all sera were negative for mitochondrial antibodies, liver membrane antibodies and rheumatoid factor. The mean age of diabetes onset was higher in patients with thyrogastric antibodies than in those negative for these antibodies. Islet cell antibodies were only positive in a small proportion of the 295 sera; specificity testing will be completed by March 1982. CIC were found in $4 \%$; these CIC were not restricted to freshiy manifested cases nor were they correlated with one of the antibody specificities detected. An age and sex matched control group was negative for all immune phenomena.

These data demonstrate an increased prevalence of organspecific auto-antibodies in IDDM. They may indicate a genetically determined predisposition for autoimmunity in a subgroup of IDDM. CIC in IDDM are unlikely to be composed of these organ-specific antibodies and their corresponding tissue antigens.

24 F. MUSTONEN ${ }^{\star}$, M. KNIP* and H.K. AKERBLOM, Department of Pediatrics, University of Oulu, Oulu and The Children's Hospital, University of Helsinki, Helsinki, Finland. A positive association between complement-fixing islet-cell antibodies and endogenous insulin secretion in IDRM.

It has been suggested that CF-ICA are particularly related to the actual damage of beta-cells in IDDM. We report here an association between CF-ICA and endogenous insulin secretion (EIS) in the beginning of IDDM. The study included 184 patients. Their mean

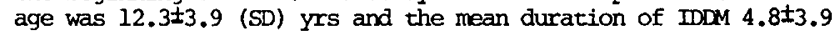
yrs. ICA were determined by both the conventional IFL and the CFT methods. An individual mean serum C-peptide (MCP) was calculated on the basis of all determinations $(n=2-8)$ of each subject during 1980. A 24-hr urine sample was collected once for the measurement of urinary C-peptide (UCP) excretion. The patients were divided into three groups according to the duration of IDDM ( $I \underline{1}_{2} \mathrm{yrs}$, II 2.1-5 yrs, III>5 yrs). The ICA-IgG positive patients had a slightly higher MCP and UCP than the negative patients in all groups. The difference was significant in group II when comparing UCP $(p<0.05)$. MCP was higher $(p<0.05)$ among the patients having CF-ICA in group I. The fact that no difference was found between ICA-IgG positive and negarive parients in group I combined with the finding of a higher EIS in CF-ICA positive diabetics indicates that ICA-IgG and CF-ICA are separate types of cyroplasmic ICA. Further it supports the hypothesis that CF-ICA are markers of active beta-cell damage. Finally our findings indicate a relation between an autoimmune process in the beta-cells and EIS.
M.O.SAVAGE, H.R.JENKINS, M.MALONE, E。R。WOZNIAK ${ }^{*}$ atid G.F.BOTTAZZO Hospital for Sick Children, Great Ormond Street, Dept of Immunology, The Middlesex Hospital, London.

POLYENDOCRINOPATHY ASSOCIATED WITH SEVERE PROTRACTED DIARRHOEA AND SPECIF IC DUODENAL AUTOANTIBODIES IN A MALE INFANT.

We report the rare association of atrophic autoimmune thyroiditis, Type 1 diabetes and aucoimmune duodenitis in the first year of life. A 4 month old male infant developed severe protracted diarrhoea, not improved by exclusion of common food allergens, which necessitated prolonged intravenous feeding. Proximal small intestinal biopsy showed subtotal villous atrophy. Aged 6 months, he became clinically and biochemically hypothyroid without a goitre. Aged 7 months, he developed diabetes. Autoantibody tests at 9 months showed high titres of thyroid microsomal and thyroglobulin antibodies(abs) by haemagglutination。Gastric parietal cell abs were weakly positive. Islet cell abs were positive until 6 months after the onset of diabetes but were not complement fixing. Sections of human duodenum stained by direct immunofluorescent technique showed strong positive reaction on the microvilli and in the cytoplasm of the enterocytes. The HLA phenotype was $\mathrm{A} 2$, AW24/BW51, B7/CW1, CW7/BW4, BW6//DRW6, DR5. The infant died aged 16 months and post mortem histology confirmed atrophic autoimmune thyroiditis with no lymphocytic infiltration in the pancreatic islet cells.

\section{7} E.J.SCHOENLE*, J.ZAPF* and E.R.FROESCH ${ }^{*}$
(Intr. by A. Prader) Metabolic Unit, Dept. Medicine,
University Hospital, Zurich, Switzerland

Stimulation of Growth in Hypophysectomized Rats by Insulin-like Growth Factors (ICF) I and II

The growth hormone $(\mathrm{CH})$ dependent polypeptides ICF I and II are the only structurally characterized somatomedins. These peptides have been suggested 25 years ago to be mediators of $\mathrm{GH}$.

In this study pure IGF 1 and IGF 11 were administered to hypophysectomized rats during six days by continuous infusion from subcutaneously implanted Alzet minipumps. Both hormones stimulated the metabolic indices of growth: body weight, DNA synthesis of the costal cartilage and the width of the proximal tibial epiphysis. IGF II was less active than IGF I. These effects were comparable with the effects of $\mathrm{GH}$. Another in vivo effect of $\mathrm{GH}$ recently described by our group, the control of basal glucose transport in adipocytes, was not mediated by IGF. Thus, our study validates the concept, that longitudinal growth is not directly dependent on $\mathrm{GH}$, but is mediated by the $\mathrm{GH}$-dependent insulinlike growth factors 1 and II, whereas the adipocyte glucose transport seems to be controlled by $\mathrm{GH}$ itself or by unknown mediators. Supported by the Swiss National Science Foundation (Grant No. 3. 380-0.78)

28 S. DROP1*, D. KOFTLEVE $1 *$, H. GUYDA $2 *$, (Intr. by. H.K. A. Visser ${ }^{1}$ ). Dept. Pediatrics, Erasmus Univ.Rotterdam; Dept. Pediatrics, McGill, Univ., Montreal.

Isolation of a Somatomedin binding protein in human amniotic fluid; development of a radioimmunoassay.

Amniotic Fluid Binding Protein (AFBP), a heat labile, acid stable protein (M.W. +40.000 ), reactive in a radioreceptorassay for somatomedin (SM), inhibits SM activity in SM bioassays (Acta Endocrinol. 90: 505, 1979). AFBP was purified from midgestation amniotic fluid (AF) by acid-ethanol extraction, Sephadex G-150 chromatography, high performance liquid chromatography and gelelectrophoresis. AFBP activity was quantitated by incubation studies with labeled SM (Insulin-Like-Activity), followed by dextrancoated charcoal separation. Protein recovery: $+0,01 \%$. Rabbits were immunized with AFBP in complete freund adiuvant. AFBP was labeled by the chloramin $T$ method. The antiserum was cleared of anti-albumin antibodies by affinity-chromatography (HSA coupled to $\mathrm{CN}-$ Br activated Sepharose-4B). A double anti body radioimmunoassay (RIA) was developed. At a final dilution of 1: 5000 of the antibody the specific binding was $32 \%$. Dilutions of semipurified AFBP in an effective range of $0.5-5 \mathrm{ug} / \mathrm{ml}$ (protein; biorad) were designated as standards. No cross-reactivity was observed with the following at $1-4 \mathrm{mg} / \mathrm{ml}$ : human, bovine and ovine albumin; $\alpha-f e-$ to-protein; transferrin; $\alpha$-glycoprotein; $\alpha{ }_{1}$-antitrypsin; 1actoglobulin $A$ and $B$; HCG; LH; FSH. The mean AFBP - RIA level in midgestation $A F$ was $160 \pm 60$ yg equiv/m1 $(n=30)$. After Seph. G-150 chromatography ( $\mathrm{pH} 2 . \overline{2}$ ) AFBP activity was discovered in fractions of cord and adult serum at Kav 0.5 . 
Presence in normal serum of a low molecular weight fraction inhibiting somatomedin activity.

Gel chromatography of whole normal human serum demonstrates a low molecular weight fraction, which strongly decreases the ability of normal serum to stimulate the in vitro incorporation of $35 \mathrm{~S}$-sulphate and $3 \mathrm{H}$-thymidine into porcine rib cartilage. Gels are equilibrated with $0,05 \mathrm{M} \mathrm{NH}_{4} \mathrm{HCO}_{3}$ buffer, $\mathrm{pH}$ 7.9. With Sephadex G200-columns, the inhibitory material is recovered from the fractions between the cytochrome- $C$ marker and those preceding the $\mathrm{NaCl}$ elution volume. Gel filtration of normal serum (or of its ultrafiltrate passed through YM10 Diaflo membranes) on Biogel $\mathrm{P}_{4}$ permits a more accurate evaluation of the molecular weight of this inhibitory fraction, which is estimated between 1000 and 1500 daltons. Comparable elution profiles are obtained with uraemic serum.

This somatomedin inhibitory fraction (SmIF) contains no detectable amounts of cortisol, is thermo-labile at $90^{\circ} \mathrm{C}$ for 60 minutes but is stable over a $\mathrm{pH}$ range between $\mathrm{pH} 2$ and $\mathrm{pH} 8$.

These observations demonstrate the presence in normai human serum of a fraction, which inhibits the action of somatomedin in vitro and is probably associated with a peptide with a molecular weight between 1000 and 1500 daltons.

30 P. MAYER* and D.S. SCHALCH* (Intr. by D. SCHOENBERG) University of Colorado Health Sciences Center Denver, Colorado 80262

Chromatographic evidence for a precursor of rat Insulin-like Growth Factor-II.

Polypeptide hormones are synthesized in higher molecular weight forms which undergo post-translational processing, resulting in the secretion of the mature hormones. Thus far, nothing is known about the existence of a precursor of Insulin-like Growth Factor-II (IGFII), but theoretically it should exist. To investigate this assumption, we used as a model for IGF-II biosynthesis an established line of Buffalo rat liver cells (BRL), which produce rat IGF-II. Serum free "conditioned" medium was chromatographed on a Bio-gel $\mathrm{P}-10$ column in $\mathrm{M}$ acetic acid. Cells were lysed in $5 \mathrm{M}$ acetic acid and processed in a manner similar to medium. IGF-II activity from cel1 lysates, quantitated in a competitive protein binding assay, eluted in two area: peak I at $34 \%$ bed volume (BV) and peak II at $42 \%$ BV (apparent MW 15000 and 8500 daltons respectively). The appearance of peak II was prevented by cell incubation with colchicine. The elution pattern of IGF-II in medium was totally different: ratio of peak $\mathrm{I}$ and II was reversed and a third peak appeared at $62 \%$ BV which contained the major portion of IGF-II activity (apparent MW 7500 daltons). Incubation with trypsin-inhibitor prevented the appearance of peak II. In conclusion: rat IGF-II might be synthesized as a precursor, which is converted intra- and extracellutarly in at least two enzymatic cleavage steps to the mature peptide hormone.

\section{R.E. JOHNSONBAUGH*, E.M. RITZÉN, and K. HALL} Pediatric Endocrinology Unit and Department of Endocrinology, Karol inska Hospital, Stockholm, Sweden. Hormonal influences on the growth of lectin-stimulated 7ymphocytes. Recently a plasma factor which stimulates the incorporation of thymidine into lectin-stimulated lymphocytes has been demonstrated to be a GH-dependent factor. We were interested in evaluating known growth factors in this system. The plasma-stimulated thymidine uptake of lectin-activated lymphocytes was measured in the presence of various growth factors and compared to a standard curve. Testosterone $(T)\left(10^{-6}, 10^{-7}, 10^{-8} \mathrm{M}\right)$, cortisol (C) $\left(10^{-6}, 10^{-7}, 10^{-8}\right.$ Sterone (T) estradiol (E) $\left(10^{-8}, 10^{-9}, 10^{-10} \mathrm{M}\right), \mathrm{hGH}(1000,100,33.3,10$ $\mathrm{ng} / \mathrm{ml})$, insul in (I) $(640,320,80,20 \mathrm{mU} / \mathrm{ml})$, and IGF-1 $(4,2,1$, $0.5,0.25,0.125 \mathrm{ng} / \mathrm{ml}$ ) were evaluated. The results showed that $\mathrm{T}$, $\mathrm{C}, \mathrm{E}, \mathrm{hGH}$, and I did not influence the thymidine incorporation. IGF-1 significantly reduced the activity found in reference plasma. In addition the void volume after G25 M Sephadex separation showed a significant reduction in thymidine uptake. In conclusion, we found that the plasma factor is (a) not affected by T,C, E, hGH, or I, (b) it presumably has a smali molecular weight, (c) it is not IGF-1, and (d) IGF-1 inhibits the activity of reference plasma. M.I.NEW. Cornel1 Univ Med Col, NYC 10021; Shadair Childrens Hosp, Helena, MT 59601

Non salt losing form of congenital adrenal hyperpla. sia (CAH) due to $3 \beta$-hydroxysteroid dehydrogenase (3BHSD) defiwith normal aldosterone production.

In studies of a 6 y 0 boy and his non-HLA identical 8 y 0 sister, we have demonstrated $3 B \mathrm{BHS}$ deficiency in the zona fasciculata, and intact 3BHSD activity in the zona glomerulosa. The sister did not manifest abnormal genital development at birth, but developed premature adrenarche at the age of 4 yrs, with clitoromegaly and advanced bone age. The brother had $4^{\circ}$ hypospadias at birth. In both sibs, the basel ine and ACTH stimula-
ted $\triangle 5$-steroids (pregnenolone, dehydroepiandrosterone (DHA), and ted $\Delta 5$-steroids (pregnenolone, dehydroepiandrosterone (DHA), and 1 ine and ACTH stimulation, the ratio of $\Delta 5 / \Delta 4$ steroids remained extremely high demonstrating the $3 \beta H S D$ deficiency in the zona fasciculata. All steroids suppressed with dexamethasone (DEX). Norma 1 plasma and urinary aldosterone rose appropriately to stimulation with ACTH and low $\mathrm{Na}$ diet with normal $\mathrm{Na}$ conservation. Plasma renin activity (PRA) was normal, increased with dependent mineralocorticoid antagonist. HCG administration did not stimulate testosterone $(T)$ in the brother, indicating a deficiency of $3 B \mathrm{HSD}$ in the gonad. Following $3 \mathrm{H}$-DHA infusion, $3 \mathrm{H}-\mathrm{T}$ conjugate was detectable in a 24 -hour urine sample, suggesting peripheral 3 BHSD activity. We propose that in these sibs, there is a deficiency of 3 BHSD in the gonad and in the adrenal zona fasciculata, whereas in the zona glomerulosa $3 \beta \mathrm{HSD}$ is intact. enzyme in the fasciculata and glomerulosa, as has been suggested

in the 21- and 11B-hydroxylase deficiency forms of CAH.

33 H.G.DÖRR*,W.G.SIPPELL, S.L.S.DROP*,F.BIDLINGMAIER and D.KNORR (Divs.of Paed.Endocrin., Depts.of Paediat.,Univ. Hosp of Munich, Kiel, FRG, and Rotterdam, Netherlands) Deficient 11B-hydroxylation in childhood adrenocortical tumours. In search of a marker for the differentiation of adrenocortical carcinoma(AC) from adenoma(AA), we studied plasma corticoster oids in 5 children(age 3-6 yrs) with isosexual precocious puberty due to adrenocortical tumours (histo1.: $4 \mathrm{AC}, 1 \mathrm{AA}$ ). Among various hormonal parameters,plasma levels of 11-deoxycorticosterone(DOC), corticosterone(B),11-deoxycortisol(S) and cortisol(F) were simultaneously determined by automated LH-20 chromatography and RIAs, both pre- and postoperatively.Preop., DOC- and S-levels were elevated in all children when compared with age-matched controls (C) whereas $B$ and $F$ were normal. Results (pre/postop. in $\mathrm{ng} / \mathrm{ml}$ ):

\begin{tabular}{lllll} 
Patient & DOC & B & S & $F$ \\
\hline 1,AC & $1.01 /-$ & $7.80 /-$ & $3.76 /-$ & $130 /-$ \\
$2, \mathrm{AC}$ & $0.78 / 0.03$ & $3.21 / 1.51$ & $3.90 / 0.50$ & $177 / 171$ \\
$3, \mathrm{AC}$ & $0.32 / 0.06$ & $1.88 / 1.04$ & $3.60 / 0.19$ & $194 / 158$ \\
4, AA & $0.29 / 0.06$ & $4.71 / 0.41$ & $2.72 / 0.35$ & $62 / 29$ \\
$5, \mathrm{AC}$ & $0.44 / 0.06$ & $0.84 / 0.46$ & $5.50 / 0.24$ & $38 / 58$ \\
\hline Normal & $0.03-0.28$ & $0.29-9.37$ & $0.21-1.50$ & $32-136$ (range)
\end{tabular}

$B / D O C$-ratios were markedly decreased in a11 AC-patients (mean:4.9 vs 16.9 in $C$ ), but normal in the $A A-c a s e(16.2)$. F/S-ratios were decreased in all cases (mean:32.7 vs 104 in $C$ ). Since $B / D O C$ and $F / S-$ ratios reflect adrenal $11 \beta$-hydroxylase activity, our data indicate a deficient 11ß-hydroxylation. High DOC-levels and, particularly, decreased B/DOC-ratios may indicate malignancy and could be helpful in monitoring the postop. course of such diseases.

34 M.ZACHMANN, T, KUSTER* and B.ZAGALAK* Department of Pediatrics, University of Zurich, Switzerland.

Studies with deuterated pregnenolone $(\mathrm{Pd} 4)$ and $170 \mathrm{H}$-progesterone $(17 \mathrm{Pd} 8)$ in man.

8 adult volunteers $(7 \mathrm{~m}, 1 \mathrm{f})$ and $1 \operatorname{girl}(16 \mathrm{yr})$ with $3 \beta$-hydroxysteroid dehydrogenase deficiency (3ßHD) were given $10 \mathrm{mg}$ of $\mathrm{Pd} 4(\mathrm{n}=4)$ or 17Pd8(5) iv(6) or im(3) with(7) or without(2) ACTH-stimulation, and the occurrence of labelled steroids in urine was studied by

$\mathrm{GC}-\mathrm{MS}$. The following quantities $(\mu \mathrm{mol} / \mathrm{d})$ and labelled percentages $(\%)$ were found:

subject route ACTH PD $\%$ PD $\%$ alloPD $\div$ THE

$\mathrm{Pd} 4: 3 \beta \mathrm{HD} 1$ iv $+\begin{array}{llllllll}1.0 & 85.6 & 0.9 & 73.9 & 0.2 & 86.2 & 3.2 & 0\end{array}$

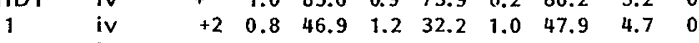

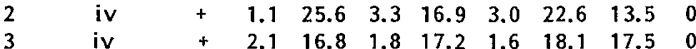

17Pd8. 4 PT $\frac{\circ}{0}$ THS $\%$ THE

17Pd8: 4 iv $+5.449 .3 \quad 1.2 \quad 0 \quad 9.7 \quad 0$

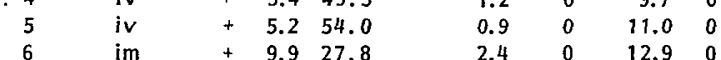

$\begin{array}{lllllll}6 & \mathrm{im}+9.9 & 27.8 & 2.4 & 0 & 12.9 & 0\end{array}$

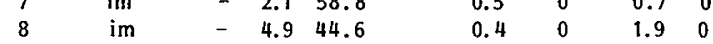

$\mathrm{PD}^{\prime}=$ pregnenediol, $\mathrm{PD}=$ pregnanediol, $\mathrm{PT}=$ pregnanetriol

It is concluded that $\mathrm{Pd} 4$ is $3 \beta$-dehydrogenated, but $17 \mathrm{Pd} 8$ is not 21 -hydroxylated by human adrenals in vivo.

1 :Zachmann etal. .Horm. Res. 11, 292, 1979; 2 : short-acting. Supported by Swiss National Science Foundation (Grant No. 3.959.080). 
Home saliva $170 \mathrm{OH}$-progesterone(17P)monitoring as an index of control in congenital adrenal hyperplasia(CAH).

Daily profiles of saliva $17 \mathrm{p}$ concentrations were performed in 16 treated CAH patients (present age 3.0-18.5 yr.) on 2 consecutive days at frequent intervals. prepubertal patients received hydrocortisone (F) in 3 divided doses, at approximately $0800-0900$, 1600 and $2100-2200 \mathrm{hrs}$, whereas postpubertal patients received single dose dexamethasone (D), usually at bedtime. Typical daily profiles of saliva 17P levels obtained in CAH patients who showed variable degrees of control are shown in the table:-

\begin{tabular}{|l|c|c|c|}
\hline \multicolumn{4}{|c|}{ Saliva 17P pmol/L } \\
\hline Time & Under-treated & Adequately-treated & over-treated \\
\hline $0800-0900$ & 5000 & 1600 & $<400$ \\
1200 & 2500 & 1400 & $<400$ \\
1600 & 2600 & 1300 & $<400$ \\
$2100-2200$ & 1000 & 400 & $<400$ \\
\hline Mean \pm SEM saliva 17P in normal children 370 +9.6 pmol/L \\
\hline
\end{tabular}

Changes in daily steroid dose or readjustments in the proportion of divided doses were reflected in the patterns of saliva 17P levels when profiles were repeated. Hourly saliva sampling provided detailed information on the length of action of each $F$ and $D$ doses together with the crest and nadir of the intrinsic 17p diurnal rhythm. Home saliva 17 profiling offers an additional useful
biochemical parameter to determine the appropriate glucocorticoid replacement dose in the individual $\mathrm{CAH}$ patient.

\section{M.M. ILONDO ${ }^{*}$, M. VANDERSCHUEREN-LODEWEYCKX, M. PIZARRO ${ }^{*}$, R. VLIETINCK ${ }^{* 2}$ P. MALVAUX,} M. PIZARRO ${ }^{*}$ R. VLIETINCK ${ }^{*}{ }^{\text {P. }}$.

Departments of Paediatrics and Human Genetics ${ }^{2}$, and Steroid Labo-

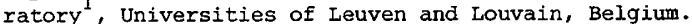

Plasma androgens as an index of adequacy of treatment in CAH.

Plasma levels of DHEA-S, DHEA, $\Delta 4$ and $T$ were measured by RIA in 75 samples collected in 24 patients with CAH due to $21-\mathrm{OH}-$ lase deficiency. $C A$ in these patients ranged between $O$ and 14 years, BA between 0 and 15 years. They were treated with hydrocortisone $\left(18-30 \mathrm{mg} / \mathrm{m}^{2} / \mathrm{d}\right)$ and, when salt-wasters, salt and/or $9 \alpha$-fludrocortisone. The results were analyzed in relation to CA, BA, body surface, pubertal development and degree of control, the latter evaluated by well-defined clinical and biochemical criteria. In untreated newborn infants, androgen levels are high and decrease with glucocorticoid treatment. Except for plasma $T$ in girls, none of the four androgens appears to be useful in establishing the diagnosis of CAH. During long-term treatment, the most clear distinction between the children with good control (GC) and those with poor control is found for DHEA-S, the levels being significantly lower than normal in GC $(p<0 . \infty 1)$. The same applies to a lesser extent to $T$ levels, which are particularly helpful in girls and in prepubertal boys. DHEA and $\Delta 4$ levels show a marked dispersion and a great overlap. Thus, DHEA-S proves to be the most indicative test of adequacy of treatment when patients of both sexes and all ages are considered.

\section{7}

H.BUCHER, J.ZAPF, T.TORRESANI, A.PRADER, R.ILLIG Departments of Pediatrics and Internal Medicine, University of Zurich, Switzerland.

Growth hormone (GH), insulin, IGF I, IGF II, and prolactin (PRL) in 18 children with excessive, normal or decreased linear growth after surgery for craniopharyngeoma.

Patients (age 1.7-13.6 yrs.) are grouped acc. to growth rate (SDS) during the $1^{\text {st }}$ postoperative year. Hormones were determined by RIA.

Results $(\bar{x}+$ SEM):

\begin{tabular}{|c|c|c|c|c|c|c|}
\hline group & n & growth & insulin & IGF I & IGF II & \multicolumn{1}{|c|}{ PRL } \\
\hline A & 6 & $>+2$ & $50.6 \pm 11.5$ & $109 \pm 31$ & $806 \pm 154$ & $658 \pm 224$ \\
B & 6 & -2 to +2 & $9.4 \pm 1.9$ & $80 \pm 23$ & $564 \pm 143$ & $1042 \pm 468$ \\
C & 6 & $<-2$ & $7.0 \pm 1.1$ & $40 \pm 18$ & $460 \pm 132$ & $157 \pm 111$ \\
\hline contr. & $>15$ & & $12.5 \pm 1.3$ & $143 \pm 13$ & $641 \pm 27$ & $208 \pm 23$ \\
\hline
\end{tabular}

Peak $\mathrm{GH}$ values after arginine and insul in were $<3.0 \mathrm{mU} / \mathrm{/}$ in all 3 groups (contr. $>25 \mathrm{mU} / \mathrm{I}$ ). Insulin after arginine (area under curve) was higher than normal in $A(p<0.001)$ and lower than normal in $B$ and $C(p<0.02)$. IGF I $(\mathrm{ng} / \mathrm{ml})$ was normal in $A$ and $B$ and low in $C(p<0.002)$. It correlates with growth rate in $B$ and $C$, but not in $A$. IGF II was normal in all 3 groups. Basal PRL values were high in $A$ and $B(p<0.05)$ and low in $C(p<0.05)$.

It is suggestive to assume that excessive growth rate in $A$ is due to hyperinsulinemia which may be attributed to the hyperphagia and obesity usually present in $A$, and absent in $B$ and $C$.

Supported by the Swiss National Science Foundation Grant No. 3,894,080.
M.BINOUX,M.GOURMELEN and F.GIRARD-INSERM U 142-Paris Laron's syndrome : serum IGFs detectable by proteinbinding assay ( $P B A$ ) but not radioimmunoassay (RIA). In a 9-year-old child with Laron's syndrome, we studied the nature of the serum IGFs and the effects of hGH and hCS (the latter because of its stimulatory effect on the in vitro production of IGFs by foetal human liver-unpublished data). $10 \mathrm{mg}$ of each hormone were given over 3 days. IGFs were separated from their carriers by acidic gel filtration and assayed by RIA (SMC antiserum from the NIAMDD) and PBA (binding proteins from rat liver culture medium ; these recognize the various SMs but preferentially IGF I). The tracer was IGF I and the standard a mixture of IGF (gifts from Dr Zapf, Zürich). For the RIA the displacement curves for the serum extracts ( 3 dilutions) pointed towards small amounts of IGF-Iike material, but no estimation was possible since the curves were not parallel with the standard. For the PBA, all the curves were parallel and the following estimations were made :

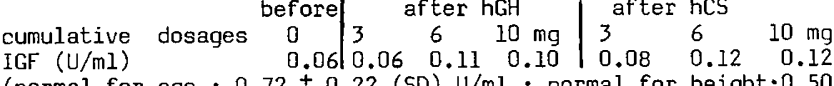
(normal for age : $0.72 \pm 0.22$ (SD) $\mathrm{U} / \mathrm{ml}$; normal for height: 0.50 \pm 0.16 ; total GH deficiency : $0.21 \pm 0.14$ ). Titration curves obtained with fractions containing IGF carrier proteins were not parallel with that of normal serum, although the slope was similar to that of the curve obtained with carriers extracted from cerebrospinal fluid which have a greater affinity for IGF II. The results indicate an overall deficiency of IGF and especially of SMC/IGF I. They also suggest that the response of the IGFproducing cells to hormonal stimulation was not completely lost.

G. THIERIOT-PREVOST*, R.M. SCHIMPFF J.I. CHAUSSAIN with technical assistance of B. LEDUC, INSERM U. 188, Hopital SaintVincent de Paul, Paris, France.

Sulfation and Thymidine activities in the plasma of diabetic children and adolescents.

sulfation (chick embryo cartilage assay) and Thymidine (lectin-activated human lymphocytes assay) activities were measured in 14 insulin-treated diabetic children aged 4 to 16 years. Mean plasma sulfation activity was $0.85 \pm \mathrm{SEM} 0.09 \mathrm{U} / \mathrm{ml}$, values being highly significantly negatively correlated with $\mathrm{Hb} \mathrm{AI}_{\mathrm{C}}(r=0.663, \mathrm{p}<0.01)$ and with 24 hours glucosuria $(r=0.764, p<0.001)$ but not with blood glucose Mean plasma thymidine activity was $1.045 \pm$ SEM 0.131 $\mathrm{U} / \mathrm{ml}$ values being significantly correlated with age $(r=0.699, p<0.01)$ but not with the other parameters. No relationship was found between sulfation and thymidine activities and insulin concentrations in the same samples. Additionnally mean plasma transferrin concentration was $2.732 \pm \mathrm{SEM} 0.152 \mathrm{U} / \mathrm{ml}$, not significantly different from normal values.

These data demonstrate that, in diabetic children treated by insulin, sulfation factor level is closely correlated to the quality of the control of the metabolic disorder. In contrast, thymidine activity of plasma appears to be unaffected by the level of glycemic regulation.

\section{0}

M. MAES and J.-M. KETELSLEGERS*. Unité de Diabète et Croissance, University of Louvain, Brussels, Belgium.

Liver somatogenic $(\mathrm{GH})$ and lactogenic (PRL) binding sites in acutely fasted and refed rats.

The mechanism responsible for the decrease in somatomedins (SM) with fasting and their increase with refeeding is poorly understood. To determine if these changes could be explained by modifications in liver responsiveness to $\mathrm{GH}$ and/or PRL, the concentration and affinity of their binding sites were measured in fasted and refed rats. Binding studies to liver homogenates were performed using $125 \mathrm{I}$-bovine GH and $125 \mathrm{I}$-ovine PRL. After fasting for $24 \mathrm{~h}$, the concentrations of GH and PRL receptors were respectively reduced by $63 \%(P<0.005)$ and $44 \%(P<0.05)$ when compared to fed rats (GH: $23 \pm 3 \mathrm{fmol} / \mathrm{mg}$ protein; PRL: $23 \pm 3$ fmol/mg protein; mean \pm 1 SEM; $n=10$ ). No further decrease was observed after $72 \mathrm{~h}$. Both receptors concentration in fasted and fed rats correlated significantly with plasma insulin (GH: $r=0.70 ; P<0.001$ and PRL: $r=0.62 ; P<0.01$. Refeeding, after fasting for 3 days, normalized the concentration of $\mathrm{GH} \mathrm{re}^{-}$ ceptors after $48 \mathrm{~h}$ and plasma insulin after $24 \mathrm{~h}$. In contrast, PRL receptors did not increase significantly, even after 4 days (10 $\pm 1 \mathrm{fmol} / \mathrm{mg}$ protein). The Ka for $\mathrm{bGH}\left(0.69 \pm 0.07 \mathrm{nM}^{-1}\right)$ and OPRL $\left(1.09 \pm 0.05 \mathrm{nM}^{-1}\right)$ showed no significant changes. In conclusion, modifications of liver $G H$ receptors may participate to the regulation of SM levels during fasting and refeeding. The discrepancy in the evolution of $G H$ and PRL receptors during refeeding suggests that their regulation is different. 
41 S A GREENE*, B TODO*, B CARTWRIGHT* J D BAUM*. A AYNSLEY-GREEN. University Department of Poediatrics, John Radel iffe Hospital, Headingt on, Oxf ord, U.K.

Metabolic response to moximum exercise in diabetic and nondiabetic children.

An incremental work load test, using a bicycle ergameter, was perfiormed on 7 diabetic (age $11.4-15.4 \mathrm{yrs}$ ) and 9 non-diabetic children (age 9.9-14.9 y rs). During the test to maximum work capacity, direct meosurement of oxygen consumption ( $\mathrm{VO}_{2}$ ) was obtained together with intermittent blood sompling for analysis of blood glucose, lactate, py ruvate and ketone bodies and plasma insulin, growth hormone and cortisol concentrations.

There was a significant difference in the maximum $\mathrm{VO}_{2}$ bet ween the two groups (Diabetic Max $\mathrm{VO}_{2}$ mean $33.0 \pm 5.5 \mathrm{mls} / \mathrm{kg} / \mathrm{min}$; nondiabetic Max $\mathrm{VO}_{2}$ mean $\left.42.5 \pm 8.9, \mathrm{p}<0.05\right)$. During the exercise there was also a significant difference in the change in the blood glucose with all diabetic showing a marked fall (diabetics mean change $3.55 \pm 2.28 \mathrm{mmol} / 1$; non-diabetics $0.23 \pm 0.16 \mathrm{mmol} / \mathrm{l}, p$ $<0.03)$. No significant differences between the two groups we re seen in the response of blood lactate, py ruvate and ketone bodies to maximum exercise.

Despite the marked fall in blood glucose concentrations and the reduced maximum oxygen uptake, the response of blood lactate, py ruvate and ketone bodies to exercise seems unimpaired in diabetics.

An analysis of the hormonal responses will be presented in relation to the blood glucose changes.

\section{S A GREENE*, J D BAUM*, A AYNSLEY-GREEN, University} Department of Paediatrics, John Radaliffe Hospital, Headingt on, Oxford, U.K.

The management of diabetes mellitus following total pancreatectomy in infancy.

Pancreatectomy is a rare cause of diabetes mellitus in infancy, and the optimum management of the hypergly caemia has not been defined. We report experience of four children who were subjected to total pancreatectomy because of neonatal nesidioblastosis, at 1, 4, 5, and 13 months respectively. All four families have exhibited signs of severe emotional stress, but despite this, growth and neurological development have been normal.

The children exhibit unusual aspects of the diabetes when compared with children with 'idiopathic' diabetes. All four children demonstrate insulin sensitivity leading to recurrent hypogly caemia. Mean daily insul in requi rement is 0.71 ( range $0.67-0.74 \mathrm{v} / \mathrm{kg}$ ). Blood glucose levels have been monitored by finger prick estimations made at home. 24-hour blood glucose profiles during treatment with a single daily injection of medium acting insulin, show less diurnal variation in blood glucose levels compared with children with idiopathic diabetes. Particularly noteworthy is the reduction in post-prandial peaks. Blood glucose concentrations rarely exced $10 \mathrm{mmol} / 1$ in these children. A practical approach to the management of children with post-pancreatectomy diabetes will be presented.

43

J. ILONEN, A. MUSTONEN, H.K. AKERBLOM and A. TILLIKAINEN. Nat1. Publ. Health Inst. Oulu, Depts. of Pediatrics and Med. Microbiol. Univ. of Oulu, Oulu, Finland. HLA-related epidemiological aspects of insulin-dependent diabetes (IDD).

To clarify the suggested heterogeneity of IDD, differences of HLA antigen frequencies were sought in regard to familiality, sex; age, season of the year and the calendar year at the onset of the disease. Among 245 children with IDD from the region of the University Hospital of Oulu, northern Finland, increased frequencies of $\mathrm{A} 9, \mathrm{~B} 8, \mathrm{~B} 15$ and $\mathrm{Bw} 16$ antigens were seen in patients, whereas $\mathrm{B} 7$ was decreased. Only a part of the patients were typed for D-locus: Increases of Dw3 and Dw4 associated with B8 and B15 were seen as well as a decrease of B7-associated Dw2. Bw16 appeared to be associated with an unidentified D-locus antigen. Among the $12 \mathrm{sib}-$ ling pairs with IDD $A 9$ and Bw 16 antigens were increased compared to single cases $(P<0.0006$ and $P<0.001)$. Between male and female patients there was a difference in the frequency of $\mathrm{Al}(28 \%$ in niales and $13 \%$ in females, $\mathrm{P}<0.05)$. In the group of patients diseased at the age of 9 years or moxe, the frequency of B15 was higher than in younger patients $(51 \%$ and $34 \%, \mathrm{P}<0.02)$. B8 positive patients were more of ten diseased at warm months ( $35 \%$ compared to $22 \%, \mathrm{P}<0.05)$. This difference was caused especially by the overpresentation of male patients with A1,B8 combination in those diseased in the summer. Patients with onset in the peak year 1981 showed an overpresentation of HLA-B40. Together, these results support the concept of heterogeneity in the pathogenesis of IDD associated with HLA linked genetic determinants.
T. TUVEMO,, M. GEBRE-MEDHIN ${ }^{*} \&$ U. EWALD". (Intr. by CG.Bergstrand). Department of Paediatrics, University Hospital, S-750 14 UPPSALA, Sweden.

The importance of different variables of control for vascular reactivity in diabetic children.

Decreased response to postischaemic hyperaemia is an early dysfunction of the small cutaneous vessels of diabetic children. Factors influencing the degree of decreased vascular reactivity can be expected to be of importance for the degree of long-term vascular changes.

Subjects and methods: Postischaemic hyperaemia after $4 \mathrm{~min}$ arterial occlusion was studied in 28 diabetic children aged 5-18 years using a conventional transcutaneous oxygen $\left(\mathrm{tcPO}_{2}\right)$ electrode (Dräger $\left.\mathrm{R}\right)$ at $37^{\circ} \mathrm{C}$. Fasting blood specimens were analysed for $\mathrm{HbAl}$, plasma glucose, serum lipids, serum magnesium and serum trace elements.

Results: Haemoglobin $A_{1}(r=-0.39, p<0.05)$, glucose excretion during the night preceding the test $(r=-0.59, p<0.01)$ and serum triglycerides $(r=-$ $0.40, p<0.05$ ) showed negative correlations to the postichaemic peak tcPO2. Fasting plasma glucose, serum cholesterol and daytime glucose excretion did not correlate significantly $(p>0.05)$ to this variable. Serum magnesium concentration correlated both to $\mathrm{tcPO}_{2}$ increase rate $(r=0.41, p<0.05)$, postichaemic peak tcPO2 $(r=0.40, p<0.05)$, and to the velocity of the return to normal tone after postichaemic hyperaemia $(r=0.58, p<0.01)$

Conclusion: Variables indicating bad long term and short term diabetic control correlated to reduced vascular reactivity. Low serum magnesium was closely correlated to decreased vascular reactivity, measured as postischaemic vasodilation capacity and posthyperaemic normalization of vascular tone.

\section{T.TORRESANI* ELISABETH SCHUSTER and RUTH ILLIG Department of Pediatrics, University of Zurich, Switzerland.}

Bioactivity of plasma LH: a longitudinal study in 6 children between the age of $0.5-60$ months.

LH was determined by an in-vitro microbioassay (BIO) using testosterone production by rat Leydig cells as reported earlier. Probands were normally growing healthy children with congenital hypothyroidism under optimal replacement therapy.

Individual results: BIO/RIA, LH standard LER $907, \mathrm{ng} / \mathrm{m} 1$

\begin{tabular}{|c|c|c|c|c|}
\hline age (months) & 0.5 & 8 & 24 & 40 \\
\hline girf (H.L.) & $384 / 64$ & $96 / 41$ & $35 / 10$ & $82 / 11$ \\
boy (G.R.) & $760 / 80$ & $250 / 55$ & $36 / 13$ & $46 / 21$ \\
\hline
\end{tabular}

All children tested so far show a similar pattern although there is a wide variation between individuals. $\beta$-HCG subunits were not detected in any sample. During the first months of life, $L H$ values in boys were higher than in girls. Later on sex difference disappears. Beyond the age of 3.5 years, BIO LH shows a tendency to rise as can be seen from our BIO LH data grouped according to age.

\begin{tabular}{|c|c|c|c|c|}
\hline age & boys & mean (SE) & girls & mean (SE) \\
\hline $9 \mathrm{~d}-7 \mathrm{~m}$ & $\mathrm{n}=5$ & $333(11 T)$ & $\mathrm{n}=5$ & $136(66)$ \\
$8 \mathrm{~m}-1 \mathrm{y}$ & 3 & $34(9)$ & 6 & $45(12)$ \\
$1.1 \mathrm{y}-3 \mathrm{y}$ & 4 & $23(5)$ & 4 & $23(5)$ \\
$>3.5 \mathrm{y}$ & $\mathrm{I}$ & 46 & 3 & $82 ; 44 ; 54 ;$ \\
\hline
\end{tabular}

In contrast to BIO LH, RIA LH values, at this age, were low. Supported: Swiss National Science Foundation Grant No. 3.894.080

\section{A.BELGOROSKY* and M.A.RIVAROLA* (Intr. by J. Perheen-} tupa). C.E.D.I.E., Buenos Aires, Argentina. Sex hormone binding globulin (SHBG) in arterial, and peripheral, hepatic and renal vein blood of children and adults.

SHBG is presumably secreted by the liver and its serum levels are under sex hormone control. We have measured SHBG in blood serum obtained during catheterization. Peripheral vein (PV) values, in nmol/liter, were (mean $+\mathrm{SD})$ : adult males, $31+13(\mathrm{n}=9)$, adult females, $71+32(n=9)$, pregnant women, $293+80(n=4)$, prepubertal children $(\mathrm{CH}) 80.1 \pm 43.7(\mathrm{n}=27)$. In $6 \mathrm{CH}$, SHBG increased from $44.4+5$ in arterial blood (AR) to $55.3+5$ in the hepatic vein $(\mathrm{HV})(\mathrm{p}<0.01)$ while it was $51.1 \pm 10.6$ in the renal vein (RV) ( $\mathrm{p}$ NS) and $51.8 \pm 12.8$ in PV ( $\mathrm{p} N \mathrm{NS})$. In 6 male adults, SHBG was $19.6+7.9$ in AR and $23.4+9.6$ in HV ( $p$ NS). Administration of androgens in 3 adolescent boys with anorchia decreased SHBG from 48(62-32) to $27(31-22)$ after one week. The estrogenization of the adult female does not influence SHBG, while the high estrogenic levels of pregnancy increase it markedly. In males, sexual maturation results in a significant decrease in serum SHBG. The arterio-venous difference observed in $\mathrm{HV}$ of $\mathrm{CH}$ supports the hepatic origin of SHBG. One of the chronic effects of androgens might be the inhibition of the hepatic secretion of SHBG. The mechanism of the acute effect has not been established. 
J.P. MIALOT*, J.E. TOUBLANC, M. THIBIER*, M. ROCER, M. CASTANIER*, P. CANLORBE, Ecole Nat, Vétérin., Lab. UNCEIA, Maisons Alfort, Fond. Recherche. Hormonologie Fresnes, Hôp. St-Vincent-de-Paul, Paris, France. Pubertal maturation in male dog - A longitudinal study.

A morphological, endocrine and Bone Age study was carried out in 22 fox breed male dogs in order to determine the timing of pubertal maturation. The body growth peak is reached by the 12 th-14th week. The testicular increment is maximum between 32 and 34 weeks. at which time the first spermatozoa appear in the ejaculate. Luteinizing hormone (cLH) Testosterone ( $T$ ) Androstenedione (A) Dehydroepiandrosterone (DHEA) were measured by RIA. $\mathrm{CLH}$ is in plateau until the 5 th week ( $5 \mathrm{ng} / \mathrm{ml}$ LER $1685-1, \mathrm{n}=22$ ) at which time pulses appear. The frequency and amplitude of $\mathrm{cLH}$ pulses ( $>30 \mathrm{ng} / \mathrm{ml}$ ) on a 24 hours period (samples every 20 and $60 \mathrm{mn}$, $\mathrm{n}=4$ ) are maximum between 21 and 44 veeks, without any nycthemeral differences. Pulses then decrease both in amplitude and frequency to initial values. The basal level of $\mathrm{CLH}$ remains unchanged throughout puberty. T, A and DHEA (ng/ml) rise from low levels before the 32 nd week $(T<1, A<0,5, D H E A<1)$ up to $T: 1.95, A: 0.75$ DHEA : 1 at 35 veeks and are in the adult range $T: 3.92, \mathrm{~A}: 1,48$ DHEA : 1.29 at week $44 \mathrm{th}$. cLH pulses are followed within $20 \mathrm{mn}$ by peaks of the 3 steroids. T, A and DHEA fell to almost undetectable levels after castration in 2 dogs aged 12 months. These data demonstrate that : $1 /$ there is an early initiation of cLH pulses $2 /$ the increase of the pulses promotes maturation of Leydig cells; 3 the events occur before DHEA rise. Dog may be an interesting
model for the onset of puberty.

\section{8}

M.A. ZHUKOWSKY ${ }^{\star}$ and T. SEMITSCHEWA ${ }^{*}$ (Intr. by J. Perheentupa). Institute of Experimental Endocrinology and Hormone Chemistry, Moscow, USSR.

Hypothalamo-pituitary relations and therapy in pubertas praecox.

Studies of pathogenesis and effectiveness of therapy were performed in 100 patients with pubertas praecox (PP). In addition to physical examination we obtained the basal levels of LH, FSH, PRL, $\mathrm{T}, \mathrm{E}$, diurnal $\mathrm{LH}$ rhythm, and LH and FSH responses to LHRH test. Wide individual fluctuations were observed in the basal levels, while the mean values were near to normal pubertal means. In LHRH test high peaks of LH and moderate peaks of FSH were typical whereas the level of PRL did not exceed the norm for age. Oxyprogesterone caproate and cyproterone acetate gave good clinical effect, but did not delay the skeletal maturation. This diagnostic approach allows to discard the term "idiopathic PP". LHRH test and diurnal LH rhythm offer best distinction between complete and incomplete PP. In premature adrenarche and thelarche hypothalamo-pituitary axis is immature with infantile type of LHRH responses. In true PP hyperreactivity of $\mathrm{LH}$ indicates a disturbance of the hypothalamo-pituitary system. Increased PRL levels in children with premature adrenarche suggest a regulating influence of PRL on the androgen production of the adrenals. Data of remote observation (during 20 years) of 256 patients with different forms of PP are presented.
R. KAULI, Z. BEN-ZEEV*, A.M. COMARU-SCHALLY*, A.V. SCHALLY* and Z. LARON. Inst. Pediat. \& Adolesc. Endocrinol. \& Dept. Pharmacy, Beilinson Medical Ctr., Sackler Sch. of Medicine, Tel Aviv Univ., Israel \& Endocr. \& Polypeptide Lab., Tulane Univ., New Orleans, USA.

Treatment of precocious puberty with D-TRP-6-LH-RH in combination with cyproterone acetate (CA).

Four girls with true central precocious puberty (PP) aged $38 / 12,54 / 12,63 / 12$ and 9 yrs were treated with D-TRP-6-LH$\mathrm{RH}$, an LH-RH agonist, 20-30 mcg daily by s.c. injection for periods of 6 to 19 mos., in the first weeks in combination with $C A$. Three had previousiy been unsuccessfully treated with $C A$ alone. Pubertal signs were slowed and arrested within 4-8 weeks and even regressed, with a blunting of the gonadotrophin (Gn) response to i.v. LH-RH. After discontinuation of CA pubertal arrest and $G$ suppression were maintained on D-TRP-6-LH-RH alone. Plasma $E_{2}$ levels decreased and remained prepubertal. Growth continued 2 at a prepubertal rate and bone maturation was markedly slowed. No side effects were observed. These observations indicate that the paradoxical inhibition of Gn secretion by long term administration of $\mathrm{LH}-\mathrm{RH}$ agonists for treating PP, with the initial stimulatory effect counteracted by the short term addition of CA is a useful therapeutic scheme. It is hoped that intra nasal spray or oral administration will be able to replace in the future the need of daily injections.
61 I.D. HAY*, H.N. COHEN*, G.H. BEASTALL* and G.G. KLEE* (Intr. by I. Hughes). University Dept. of Medicine, Glasgow, Scotland and Mayo Clinic, Rochester, USA. Immunoreactive melatonin in boys with idiopathic delayed puberty. It has been recently reported (Nature 202:301, 1979) that in normal schoolboys a pronounced fall in serum melatonin (M) levels occurs immediately prior to the onset of puberty. To determine whether this also applies to patients with delayed pubertal development, we examined serum immunoreactive $M$ levels in 30 boys (bone age 9-14, chronological age 14-18 yrs) who had idiopathic delayed puberty (IDP). The results were compared to a control group of 26 boys with non-endocrine disorders (age range 9-15 yrs). In controls mean serum $M( \pm S D)$ was $63 \pm 17 \mathrm{pg} / \mathrm{ml}$. In 42 sera from the IDP group it was significantly higher at $184 \pm 77$ $\mathrm{pg} / \mathrm{ml}(\mathrm{P}<0.0001)$. Within the IDP group no significant differences were found between levels in pre-puberty (Tanner Pl, Gl, testicular volume $\leqslant 4 \mathrm{ml}$ ) and those in early-mid puberty (P2-3, G2-3, TV 5-11 $\mathrm{ml}$ ). However, between early-mid and latex puberty (P4-5, G4-5, TV $\geqslant 12 \mathrm{ml}$ ), serum $M$ levels fell significantly $(P<0.025)$. When TV was $5-11 \mathrm{ml}$, mean $M$ level was $228 \pm 78 \mathrm{pg} / \mathrm{ml} \quad(\mathrm{n}=16)$ but with a TV $\geqslant 12 \mathrm{ml}$ the level was significantly lower at $140 \pm 65$ $\mathrm{pg} / \mathrm{ml} \quad(\mathrm{n}=16, \mathrm{p}<0.005)$. From our study we conclude that in boys with IDP serum M levels are elevated prior to the onset of pubertal changes, do not fall during early puberty and fall significantly only in the later stages of puberty. We would therefore suggest that, whilst melatonin may inhibit puberty, a fall in serum levels is not essential for the commencement of puberty in man.
G.SINNECKER*, R.P.WILLIG, N.STAHNKE, W.BRAENDLE*

Dept. of Pediatrics, University of Hamburg, FRG

Endocrine Studies in Sexual Precocity caused by ovarian Follicular Cysts.

In precocious puberty due to ovarian cysts high estrogen $\left(E_{2}\right)$ and low gonadotropin (LH, FSH) levels are found. In contrast a $6^{2} 11 / 12$ yrs. old girl is presented: Puberty stage $2-3$, height 3.8 SD above normal, height-age: $109 / 12$ yrs., BA $119 / 12$ yrs., menarche 6

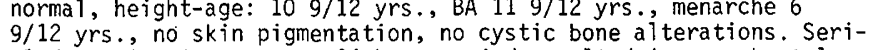
a1 determinations over a 24 hour period resulted in prepubertal LH $(<0.3-0.8 \mu \mathrm{g} / 1)$ and FSH $(0.3-0.6 \mu \mathrm{g} / 1)$ levels. Urinary gonadotropins were below detection limit. LH and FSH failed to rise in GnRH-test $\left(60 \mu \mathrm{g} / \mathrm{m}^{2}\right)$. Vaginal cytology showed distinct estrogen effects. $E_{2}$ ranged between 0 and $20 \mathrm{pg} / \mathrm{ml}$, urinary estrogens ranged between 3 and $6 \mu \mathrm{g} /$ day (infantile values). Testosterone, progesterone, cortisol, prolactin, HCG, 17-KS, 17-0HCS and pregnancy associated proteins were normal. - The girl's bilateral ovarian tumors were extirpated subtotally. Histologic examination revealed cystic ovaries with multiple follicular cysts, but no stimulation of theca cells, no luteinization. Cyst fluid contained $\rightarrow 1000 \mu \mathrm{g} / 1 \mathrm{E}_{2}, 0.5 \mu \mathrm{g} / 1 \mathrm{LH}, 0.2 \mu \mathrm{g} / 1 \mathrm{FSH}$, and $0.3 \mathrm{U} / 1 \mathrm{HCG}$. Following tumor extirpation precocity regressed, $E_{2}, L H$, and $F S H$ levels did not change but gonadotropin values responded adequately to GnRH (LH 0.3 to 1.5 and FSH 0.4 to $1.9 \mu \mathrm{g} / 1$ ). These findings suggest autonomous production of sexual steroids which showed no measurable elevation in serum and urine but produced symptoms of precocity. Despite normal estrogen levels, gonadotropin values were suppressed. It is likely that abnormal estrogens were produced or that the sensitivity of target organs was increased.

\section{W.V.PETRYKOWSKI ${ }^{*}$ and B.SCHMIDT* (Intr。by J. Perheentupa)Kinderklinik of Freiburg Uni- veralty, Federal Rep。of Germany High-dose conjugeted estrogens do not reduce Anti- thrombin III (AT III) concentration in tall girls. Estrogens alter blood flow and vessel walls, and produce measurable effects on the coagulation syotem. Deficiency of AT III is associated with increased risk of thrombosis and probably the only convincing laboratory evidence for a prethrombotic state.As es- trogens are claimed to reduce AT III, we have prospec- tively studied its concentration before and during high-dose $(7.5 \mathrm{mg} / \mathrm{day})$ conjugated estrogen treatment in 8 tall girls. In addition, partial thromboplastin time, prothrombin time,plasminogen, fibrinogen and its degradation products, bleeding time, platelet count and spontaneous platelet aggregation were followed.These parameters showed inconclusive, if any, changes as ex- pected.Mean AT III before therapy was $21.66 \mathrm{IU} / \mathrm{ml}$ with a SD of 2.09 and $22.38 \mathrm{IU} / \mathrm{ml} \pm 3.20$ during 3 or 6 months of treatment, an insignificant change. Conclusion: detection of AT III deficiency at present is the only rellable means of predicting a prethrom- botic state. Since this hereditary condition is very rare and high-dose estrogens do not reduce AT IIIcon- centration as previously claimed(Howie,1973), lack of thrombotic complications in about 1000 treated tall girls worldwide becomes plausible.}


Effect of cyproterone acetate (CPA) theraPy on 15 adrenal steroids in girls with precocious puberty (PP).

15 steroids were measured in $11 \mathrm{girls}$ with PP before and during CPA-treatment. Basal values (b) are compared to those after stimulation ( $s$ ) by hypoglycemia. "b" of progesterone $(P), 17-0 \mathrm{H}-$ progesterone (17-P), 17-OH-Fregnenolone (17-PI), corticosterone (B), desoxycortisol' (S), cortisol (F), dehydroepiandrosterone (DHEA) were decreased markedly; "s" was significantly reduced of pregnenolone $(\mathrm{PI})$ and $17-\mathrm{P}$. " $\mathrm{b}$ " of $(\mathrm{PI})$ was increased during CPAtreatment. Androstendione and testosterone showed moderate changes only. Mineralocorticoids were not influenced by CPA. Interpretations: a) CPA inhibits several adrenal enzymes, b) CPA affects (the activity of) more than one corticotrophic hormone and alters their activities differently but does not inhibit the angiotensin mediated stimulation.

\begin{tabular}{|c|c|c|c|c|c|c|c|c|c|c|}
\hline Median & & $P$ & PI & $17-P$ & $|7-P|$ & $\bar{B}$ & $S$ & $18-B$ & $F$ & DHEA \\
\hline PP $" b "$ & & 726 & 2 & 289 & & 7860 & 533 & 549 & 108500 & 648 \\
\hline PP "s" & B & 303 & 462 & 1200 & 4170 & 30000 & 465 & 1560 & 182500 & 1100 \\
\hline PT "b" & c & 562 & 60 & 60 & 179 & 1830 & 92 & 650 & 1550 & 47 \\
\hline PT "s" & 0 & 400 & 24 & 390 & 1690 & 15600 & 785 & 1790 & 132500 & 633 \\
\hline$A: C \quad P$ & & .005 & .05 & .001 & .05 & .025 & .05 & ns & .001 & .01 \\
\hline$B: D$ & $<$ & ns & .001 & .05 & ns & ns & .025 & ns & ns & ns \\
\hline
\end{tabular}

\section{L.AUDI, A. CARRASCOSA* and A. BALLABRIGA} (Intr. by M. T. Corvol). Clínica Infantil Seguridad Social, Barcelona, Spain.

Androgen metabolism by human fetal epiphyseal cartilage and their chondrocytes in primary culture.

Testosterone $(\mathrm{T})$ and androstendione $\left(\mathrm{A}_{4}\right)$ metabolism were de termined in epiphyseal cartilage (EC) $n=11(50,6 \delta)$ and their chondrocytes in primary culture $(\mathrm{Ch}) \mathrm{n}=5\left(3, \mathrm{q}^{+} 2 \mathrm{\sigma}\right)$ from human fetuses (9. a. 11-31 weeks) incubated in Dubelcco's medium during 24h. Metabolites were separated by bidimensional TLC and $\Delta_{4}$, dihydrotestosterone $(D H T)$ and $T$ recrystallized in 5 different solvent systems. EC was used qualitatively (results in \%) and $\mathrm{Ch}$ quantitatively (results in $\mathrm{Pm} / \mathrm{mg}$ Prot.). EC transformed $18.3 \mp 2.6 T\left(5 \times 10^{-8} \mathrm{M}\right)$ into $\Delta_{4} 7.5 \mp 1.5$, DHT $4.8 \mp 0.6$, andros-

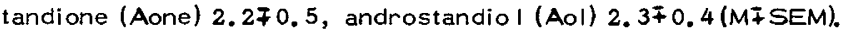
Ch metabolized $T$ into $\Delta_{4} 80.6 \mp 11.1$, DHT 13.7 1.8 , Aone 7.87

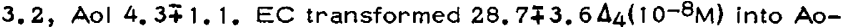

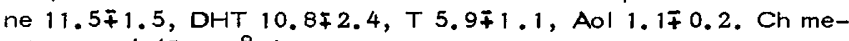

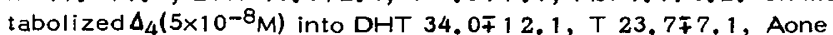
16.5 7.3, Aol 4.2 71.4 . Conclusion: $T$ and $\Delta_{4}$ have the same me tabolic patterns in EC and $C h$ and there was no difference accor ding to sex and gestational age. The main metabolite produced from $T$ by $E C$ and $C h$ is $\Delta_{4}$ in contr ast $w$ ith fibroblasts from genital and non genital skin of the same fe tuses whose principal metabolites were $5 \alpha$-reduced (DHT, Aol and Aone).

\section{5}

M. LEVIN ${ }^{\star}$, J.W. HONOUR ${ }^{\star}$, V. SHAH ${ }^{\star}$ and M.J. DILLON Hospital for Sick Children, London WC1 and Clinica Research Centre, Harrow, Middlesex, U.K.

Fatal low renin hypertension due to $11 \beta$ hydroxy-steroid dehydrogenase deficiency in a 5 month-old infant.

A 5 month old boy, the second child of healthy unrelated parents was found to have prolonged hyperbilirubinaemia in the neonatal period for which no cause was found. Aged 6 weeks an episode of apnoea followed by lethargy and irxitability possibly due to small subarachnoid haemorrhage. Plasma electrolytes were normal but $B P$ not recorded. Aged 5 months, following a 24 hour history of mild diarrhoea and vomiting, blood pressure was found to be $200 / 110 \mathrm{~mm}$ of $\mathrm{Hg}$. Hypokalaemic alkalosis was present $\left(\mathrm{K}^{+} 1.8\right.$ and TCO.2 $29 \mathrm{mmol} / 1$ ), urinary steroid excretion by gas chromatography-mass spectrometry revealed a pattern consistent with $11 \beta$ hydroxysteroid dehydrogenase deficiency. Treatment with Labetalol, Propranolol and Hydrallazine was only partly effective. Marked blood pressure fluctuation occurred and the child's condition deteriorated with acute cardiac decompensation followed by arrest. In spite of resuscitative efforts he died within 4 days and before the specific investigation results revealed the cause of his hypertension. A CMV infection was confirmed after death but not considered to be the cause of the hypertension although could have contributed to his terminal illness. This is the youngest patient known to have $11 B$ hydroxysteroid dehydrogenase deficiency and, as far as we are aware, the first fatal case.
Elevated plasma dehydroepiandrosterone DHA in mild 11ß-hydroxylase deficiency

Clinical and biochemical manifestation of $11 \beta$-hydroxylase deficiency is variable. Adrenal steroidogenesis may be impaired in either or both the pathways of 17-hydroxylated and 17-nonhydroxylated compounds. Based on recently established criteria of basal and ACTH stimulated urinary steroids (M. Zachmann et al., in press) mild $11 \beta$-hydroxylase deficiency was diagnosed in the present case. Our female patient whose mother is moderately hirsute had premature pubarche at age $4 y r s$, thelarche at $13 y r s$, menarche at 18yrs and persistent oligomenorrhea. Bone age advanced according to chronological age. The clinical findings were short stature, hirsutism, poor breast development and normal genitalia. Basal urinary steroids were unremarkable, but THS after ACTH i.m. was increased $(4.2 \mathrm{mg} / 24 \mathrm{H})$, while THDOC and DHA remained undetectable. Plasma DHA was markedly elevated (range 1000-2866 $\mathrm{ng} / 100 \mathrm{mI}$ ) and high levels were found for testosterone $(127-199 \mathrm{ng} / 100 \mathrm{ml})$, androstenedione $(645 \mathrm{ng} / 100 \mathrm{ml})$, DHAsulfate $(1250 \mathrm{ng} / \mathrm{ml})$. DHA and testosterone were dexamethasone suppressible and decreased with hydrocortisone treatment. It is concluded that high plasma DHA in hirsute girls may be a marker of mild $11 \beta$-hydroxylase deficiency.

\section{7}

K.E.PETERSEN, K.DANKJ ARR NIELSEN", S.BOLUND* and N.E. SKAKKERAX" The Children's Hospital Fuglebakken, Glostrup Hospital, Diakonissestiftelsen, Rigshospitalet, Copenhagen, Denmark.

Steroid 5- $\alpha$-Reductase Deficiency - studies in cases of Pakistani and Vietnamese Origin.

Two cases of male pseudohermaphroditism (46XY) were studied, a 16 year old Pakistani and a 22 year old Vietnamese subject. Both were brought up as females, but virilized at puberty and changed to a male gender role. In both subjects testosterone (T) to dihydrotestosterone (DHT) ratio was increased, urinary 5- $\beta-$ etiocholanolone/ 5 - $\alpha$-androsterone ratio elevated and hCG stimulation substantiated 5- $-\alpha$-reductase deficiency. Plasma LH and FSH were elevated. Very low urinary excretions of $5-\alpha$-reduced metabolites (allo-THF and allo-THB) were found: The deficiency in these patients therefore seems to have affected both hepatic and extra hepatic compartments. Surgical procedures for correction of the malformations were undertaken. Testicular biopsy showed in the first case a complete arrest of spermatogenesis at primary spermatocyte level and pronounced Leydig cell hyperplasia. In the second case a heterogenous pattern with incomplete arrest, including presence of late spermatides was found. Each patient had a sister: A 7 year old Pakistani female (46XX) had normal external genitalia, normal T/DHT ratio, but the urinary excretions of $5-\alpha-$ reduced metabolites were very low, demonstrating a reduced reductase activity in the hepatic compartment. A 12 year old Vietnamese female showed typical 5- - -reductase deficiency. Thus 5- $\alpha-r e-$ ductase deficiency is described in families from new geographical locations and the genetic heterogenity is illustrated.

58 J.W. HONOUR*, D.B. GRANT, N.F. TAYLOR* Aand D.A.PRICE MRC Clinical Research Centre, Harrow; Hospital for Sick Children.London \& Royal Manchester Childrens Hospital. Steroid Biosynthesis in Virilising Adrenal Tumours

In children (9F,3M) with adrenal tumours causing virilisation, the production of androgens was assessed by gas chromatographic (GC) determinations of steroids in urine. In 6 cases $(5 \mathrm{~F}, 1 \mathrm{M})$ aged 2.8 - 5.3 years, the high excretions of urinary 17-oxosteroids $(>30 \mu \mathrm{mol} / 24 \mathrm{~h})$ were attributable to excess production of DHA (dehydroepiandrosterone). Excretions of 16-oxygenated metabolites of DHA, steroids normally only significant in the perinatal period, were $2-60 \%$ of DHA excretion. in a female, aged $4.5 y, 16 \alpha$-hydroxyDHA was the main urinary steroid, and histology of the tumour showed fetal-type adrenocortical cells. Very large tumours with local invasion of the surrounding tissues were found in 3 infants, 2 of whom have died and one has multiple metastases. Small, wellencapsulated adenomas were successfully removed from the other three. In 5 cases $(4 \mathrm{~F}, 1 \mathrm{M})$ aged 0.8 - 5 years, $11 \beta$-hydroxyandrosterone was the major urinary steroid and 17-oxosteroid excretion was 8 - $18 \mu \mathrm{mol} / 24 \mathrm{~h}$. Well-encapsulated tumours were removed and all these infants are alive and well 1 - 6 years after surgery. In one boy, aged 7.8 years ( 17 -oxosteroids, $15.4 \mu \mathrm{mol} / 24 \mathrm{~h}$ ) the major steroj.ds in urine were metabolites of pregnenolone. GC profile analysis has thus revealed heterogeneous patterns of steroid biosynthesis in adrenal tumours with some showing profiles similar to those produced by the fetal adrenal cortex. 

plasma has been found, dependent on gestational and calender age. In case of athyroidism, no plasma Tg was observed, which suggests that $\mathrm{Tg}$-measurements can be used for this diagnosis. 6 patients with a deficient $\mathrm{Tg}$ synthesis showed also undetectable $\mathrm{Tg}$ plasma concentrations. In contrast to athyroid patients, they excreted in the urine iodinated material, containing iodohistidine ("I-his"), which was probably derived from proteolysis of "abnormal" jodoproteins in the thyroid. In 5 athyroid children undetectable plasma $\mathrm{Tg}$ concentrations wexe found and no urinary "I-his" excretions. Normal Tg concentrations without "I-his" excretion were found in 3 children with ectopic glands. 2 patients with abnormal $\mathrm{Tg}$ had normal Tg plasma levels and increased "Ihis" excretion. In 3 patients with an organification defect very high Tg plasma levels were found and no increased "I-his" excretion. In 9 neonates with a yet not identified defect high Tg plasma levels were found, without increased "I-his" excretion. In conclusion: determination of plasma Tg and urinary "I-his" concentrations can be used for the diagnosis of several thyroid defects, obviating the in vivo use of radioactive isotopes.

60 J.SACK, O.AMADO'), H.TENZER $\left.{ }^{+}\right)$ Neonatal hypothyroidism (NH) unit, Sheba Medical Center, Israel.

Should semum TSH be suppressed?

In 9 infants with $\mathrm{NH}$, detected by the screening, thyroid function was assessed each month in the first year. The infants were started on L-thyroxine $15 \mu \mathrm{g} / \mathbf{k g B} /$ daj. This dose was progressively reduced to $10.2-0.2$ at 2 months (mt), $5.9=0.2$ ( 5 mt) and $4.8 \pm 0.2$ ( $12 \mathrm{mt}$ ). Normal serum 4 conc. Were achieved in ali infants during the first month of treatment, in all infants during the first month of treatment, $\mu \mathrm{g} / \mathrm{dI}$ and remsined between $11.1 \pm 0.7$ and $11.9 \pm 0.9$ thereafter. In spite of normal $\mathrm{TH}$ and $\mathrm{T} 3$ conc., as well as normal catch-up growth and development, serum Tgr mt. Thereafter even minimal changes in serum T4 cenc. mt. Thereafter even minimal changes in serum T4 conc. $\mathrm{kg}$ ) was performed in $6 \mathrm{KH}$ children. Although serum $\mathrm{T}_{4}(12.4-0.3 \mu \mathrm{g} / \mathrm{dl})$ and $\mathrm{T3}(177-10 \mathrm{ng} / \mathrm{dl})$ were normal there was an exaggerated rise of TSH from $17-4$ to $84+26 \mu \mathrm{U} / \mathrm{ml}$. Conclusions: This regimen of therapy leads to normalisation of serum T4, $T 3$ as well as normal growth and derelopment. Serum TsH is elevated for a long period of time. The feedbeck and response of the thyrotroph is altered in $\mathrm{NH}$.

61 R. WuLiER, P. BOURDOUX*and A.M. ERMANS* Departments of Paediatrics and Radioisotopes. University of Brussels, Brussels, Belgium.

TSH response to TRH according to age.

Serum TSH response to TRH was studied in 205 children aged $3 /$ I2 to I6 years, evaluated for various clinical reasons and in whom no biological or endocrine anomaly were found subsequently. Blood was collected up to 2 hours after bolus $i . v$. injection of $200 \mathrm{~kg}$ synthetic TRH, with or without insulin and/or IHRH. Serum TSH was measured by RIA referring to WHO standard MRC 68/38. Serum T4, FT4, T3 and TBG were measured by RIA. Results were related to bone age. Basal serum TSH was comparable in all age groups (mean $\pm \mathrm{SD}: \mathrm{I} .8 \pm \mathrm{I} .0 \mu \mathrm{U} / \mathrm{ml}$ ). The mean peak TSH value at $30 \mathrm{~min}$. and the mean integrated area of the TSH response curve were significantly higher before than after 3 years of age :

\begin{tabular}{|c|c|c|c|c|}
\hline$\frac{\text { Age }}{(\mathrm{yx})}$ & $\underline{\mathrm{N}}$ & $\frac{\text { Peak sermm TSH }}{(\mu \mathrm{U} / \mathrm{mI}+\mathrm{SD})}$ & 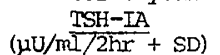 & $\underline{P}$ \\
\hline $.3-I$ & I4 & $I 7.0 \pm 4 . I$ & $I 442 \pm 339$ & $0.00 \mathrm{I}$ \\
\hline$I-2$ & 22 & $I 4 . I \pm 4.6$ & II64 \pm 394 & $0.00 I$ \\
\hline $2-3$ & 30 & II. $3 \pm 5 . \mathrm{I}$ & $884 \pm 373$ & 0.05 \\
\hline $3-6$ & 35 & $9.7 \pm 2.9$ & $784 \pm 269$ & NS \\
\hline $6-9$ & 35 & $9.4 \pm 2.8$ & $752 \pm 245$ & NS \\
\hline $9-I 2$ & 34 & $9.3 \pm 2.7$ & $737 \pm I 77$ & - \\
\hline $\mathrm{I} 2-\mathrm{I} 6$ & 35 & $9.2 \pm 2.7$ & $767 \pm 253$ & NS \\
\hline
\end{tabular}

There was no difference according to sex. Mean T4 and TBG slowly decreased with age. Mean FT4 and T3 did not vary significantly. We conclude that the hypothalamic-pituitary-thyroid feedback
loop is not fully mature until the age of 3 years.
V. Hesse G. Rönnefarth , U. Tarnofsk1* Department of Podiatrics, Fr.-SchillerUniv. Jona/GDR

Prevalence of goiter and lodine excretion in urine of newborns and children in a southern district of GDR (Gera region)

Results: 1. Goiter prevalence

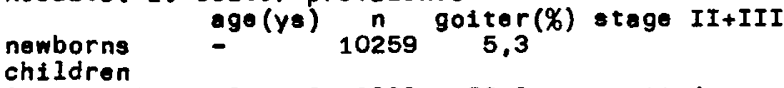

Gera region $12-162898 \quad 56,9 \quad 11,4$

children GDR 13 - $15 \quad 892 \quad 46,5 \quad 10,5$

2. Iodine excretion in the urine

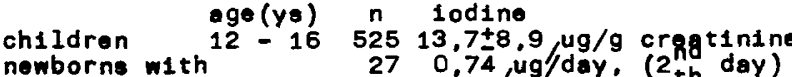

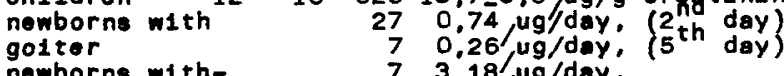

out goiter

7 3,18/ug/thay.

Iodine content of breast milk was analysed th 10 mothere in a longiłtinal tudy. Result $2^{\text {hd }}$ day

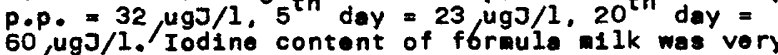
low $(0,45, u g J / 1$ and $1,3 \mathrm{ugJ} / 1)$. It is concluded that goiter is ondonic in children in GDR and iodine

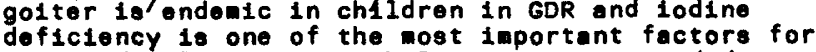
goiter development. Prophylaxis is recomended.

63 P.LAUTALA, R.PUUKKA, M.KNIP, M.PUUKKA and L.PERKKIL $\ddot{A}$ (Intr. by H.K. Akerblom).

Departments of Pediatrics and Clinical Chemistry, University of Oulu, Oulu, Finland.

Glucose tolerance in infants of diabetic mothers.

To study the glucose tolerance in infants of diabetic mothers (IDM) we measured blood glucose (BG), plasma immunoreactive, free and total insulin (IRI, F-IRI, T-IRI) and plasma C-peptide (IRC) in cord blood and in venous blood at the age of 2-1.4 days from IDM $(n=20)$. Also the binding of $125-I$-labelled insulin to erythrocytes of the blood samples was measured. Infants of healthy mothers matched for sex and gestational age served as controls $(C G, n=20)$. All the mothers of IDM had insulin dependent diabetes diagnosed before the onset of the pregnancy. BG was higher in cord blood of IDM compared to the CG, but was similar later on. Transient hypoglycemia was observed in 13 of the IDM and none of the CG on the first postnatal day. F-IRI and T-IRI were very high in IDM compared to IRI in the $C G$ in cord blood but decreased rapidly within the first two weeks. IRC was also high in IDM in cord blood compared to $C G$ but decreased to the control level. Maximal binding of insulin to the erythrocytes was similar in the two groups in cord blood but decreased significantly in IDM during the first two weeks of life. The results suggest that insulin receptors are inadequately regulated in the newborns of diabetic mothers contributing to hypoglycemic tendency.

\section{4}

K. ALBERTSSON-WIKLAND ${ }^{x}$, A. NIKLASSON ${ }^{x}$, R. OLEGARD ${ }^{x}$ and B. RYDGREN (Intr. by 0 . Westpha1).

Dept of Pediatrics I and II and Dept of Anestesia, University of Göteborg, Sweden.

Hypoglycemia in normal infants delivered by caesarean section.

The aim of the present study was to evaluate the influence of glucose infusion to healthy pregnant women during elective caesarean section on the glucose and lipid metabolism in the newborn. Material: 40 healthy women with normal pregnancies divided into four groups: 20 with general and 20 with epidural anestesia, given either Ringer-Glucose $(2.7 \%)$ or saline infusion. Blood samples were collected from the mother at delivery and from the newborn until an age of $4 \mathrm{~h}$ and analyzes of glucose, different hormones and carbohydrate and lipid metabolites were performed.

Results: In the group of women with general anestesia and RingerGlucose infusion, $50 \%$ of the infants bacame hypoglycemic (glucose $<1.7 \mathrm{mmol} / 1$ ) one hour after delivery while hypoglycemia only occurred in $20 \%$ of the infants when the mothers received saline infusions. The corresponding figures in the group of women with epidural anestesia were $60 \%$ and $20 \%$ respectively, but in these infants, the duration of the hypoglycemia was more pronounced. Conclusion: The general use of high volume of glucose infusion during caesarean section seems to cause hypoglycemia in the infant which almost could be prevented by using saline infusion. 
65

J.KNUDTZON* (Intr. by O. Trygstad). Pediatric Research Institute, Rikshospitalet, Oslo 1, Norway.

Acute effects of ACTH on plasma levels of glucagon, insulin and glucose in rabbits.

Corticotropin-like immunoreactivity has been demonstrated in pancreatic islets. Corticotropin (ACTH) is known to increase plasma levels of insulin, but there are no reports on any effects of ACTH on glucagon release. $25 \mu g^{1-24} \mathrm{ACTH}$, injected intravenously into 4 rabbits, gave increases in glucagon ( $p<0.05$ after $3 \mathrm{~min}$., maximum increase $432 \pm 154 \mathrm{pg} / \mathrm{ml}$ at 20 min.), insulin ( $p<0.05$ after $15 \mathrm{~min}$., maximum increase $8+1 \mu \mathrm{U} / \mathrm{ml}$ at $30 \mathrm{~min}$.$) and glucose (1.8 \pm 0.5$ mmol/l at 20 min $; 0$ p 0.05$)$ Similar increases were observed with $1-39_{\mathrm{ACTH}}$. 1-4 ACTH , $4-10_{\mathrm{ACTH}}, 1-10_{\mathrm{ACTH}}$ and $18-39$ ACTH (CLIP) did not influence plasma levels of glucagon and insulin. The increases observed with $1-24_{\mathrm{ACTH}}$ were inhibited by somatostatin. Infusion with phentolamine $(\alpha$-adrenergic blocking agent) augmented the ACTH-induced insulin increase $(111+12 \mu \mathrm{U} / \mathrm{ml}$ at $30 \mathrm{~min} ., \mathrm{p}<0.05$ after $5 \mathrm{~min}$.$) , near-$ ly abolished the glucagon increase and decreased blood glucose $(1.9 \mathrm{mmol} / 1$ after $60 \mathrm{~min}$., p N.S.). These results suggest that $\mathrm{ACTH}$ may suppress insulin release and increase glucagon and glucose through adrenergic mechanisms, probably by increasing plasma levels of epinephrine.

66 f. KURIZ*, Ph. JUNQ*, J.G. JUIF* (intr. by : R. RAPPAPORT) Unité d'Endocrinologie et de Diabétologie Pédiatrique CHU 67098 STRASBOURG HAUTEPIERRE Cédex (France)

Insulin and C-peptide secretion in normal and obese children during intravenous glucose tolerance tests.

Simultaneous mesurements of glycemia, plasma C-peptide immunoreactivity (CPR) and immunoreactive insulin (IRI) as indicators of beta-cell function were carried out in 18 normal and 33 obese children to define more precisely the changes in insulin levels during IV glucose stimulation $(0,33 \mathrm{~g}$ of glucose per $\mathrm{kg}$ body weight) and to see if CPR provided information beyond that furnished by $|R|$ alone. Statistical analysis was performed by analysing the variance.

Under basal conditions glucose levels were comparable, but in obese children IRI $(0,15 \pm 0,06 \mathrm{nmol} / \mathrm{I})$ and $\mathrm{CPR}(0,74 \pm 0,06 \mathrm{nmol} / \mathrm{I})$ were found to be greater than in healthy ones (IRI $0,1 \pm 0,01 \mathrm{nmol} / \mathrm{l}$ $p<0,01 ; C P R \quad 0,49 \pm 0,08 \mathrm{nmol} / \mathrm{l} p<0,025$ ).

During IVGTT, peak glucose values occured at the same time and were of the same amplitude in both groups, but subsequent glucose levels were higher in obese children. IRI and CPR were significantly higher in obese children at all times. Compared to basal levels, the increases in CPR were proportionally the same in both groups. However the $|R|$ were proportionally greater in obese patients and their $\mathrm{CPR} / \mathrm{R} \mathrm{R}$ ratios were lower.

In obese children there appears to be a state of hyperinsulinism partially related to insulin hypersecretion both in basal conditions and after IVGTT. The mean values of IRI in obese children are greater than would be expected from CPR. This may be due to diminished metabolic clearance of insulin.

67

J.M. GARAGORRI*, C. DUPONT*, M. DONNADIEU* M. COLLE* and J.L. CHAUSSAIN

Hopital Saint-Vincent de Paul, Paris, France. Insulin resistance in girls with acanthosis nigricans.

6 girls, aged 4 to 16 years, with acanthosis nigricans and hirsutism, were studied. Fasting and post glucose hyperinsulinism was present in the 5 older. In the youngest, a transitory diabetes with hyperinsulinism was induced by a cortisone therapy for hepatitis. Insulin resistance, suggested by the failure to significantly decrease blood glucose after insulin injection $(0.1 \mathrm{U} / \mathrm{kg})$, was demonstrated in 3 steps : $1 /$ patients' plasma failed to bind $125 \mathrm{I}$ insulin after a 5 days incubation followed by precipitation by antihuman globulin serum. 2/ Specific 125 I insulin binding to rat liver membranes was identical in the presence of patient's and control plasmas. 3/ specific $125 \mathrm{I}$ insulin binding to the erythrocytes of the 6 patients $(3.5$ to $7.0 \%)$ was significantly lower

$(\mathrm{p}<0.01)$ than in controls $(4.5$ to $19.5 \%)$. Moreover, the significant correlation present in controls between total bindings and reticulocytes counts ( $x=$ $0.824, \mathrm{p}<0.001$ ) was absent in the patients.

These data demonstrate that, in the juvenile type of acanthosis nigricans, insulin resistance which may preceed hyperinsulinism is not related to antiinsulin antibodies nor to antireceptor antibodies, but results from a primary defect of insulin receptors.
68 Y.L. DANON*, J. AURBACH*, M. KARP and Z. LARON. Div. Pediat. Immunol., Inst. Pediat. \& Adolesc. Endocrinol. Beilinson Medical ctr. \& Sackler School of Medicine, Tel Aviv University, Israel.

Immunoregulatory $T$ lymphocytes in insul in dependent diabetes mellitus (IDDM).

The status of immunoregulatory $T$ cells was studied in 4 newly diagnosed juvenile diabetics within 1 week of diagnosis. Monoclonal antibodies to $T$ lymphocyte cell surface antigens were used to characterize peripheral lymphoid population. Antibodies used were anti T4-helper-inducer cells, T8-cytotoxic-suppressor cells and anti DR. Cells were studied by indirect immune fluorescence. Suppressor $T$ cell function was assessed by the concanaval in $A$ induced suppression test. Patient 2 had positive islet cell antibodies at diagnosis.

\begin{tabular}{llcrccc}
$\begin{array}{l}\text { Pt. Leukocytes } \\
\text { No. per mm }\end{array}$ & $\begin{array}{c}\text { \% lympho- } \\
\text { cytes }\end{array}$ & $\begin{array}{c}\text { \% reactivity with } \\
\text { anti } \\
\text { T8 }\end{array}$ & $\begin{array}{c}\text { Con. A } \\
\text { DR }\end{array}$ & $\begin{array}{c}\text { suppress. with } \\
\text { PHA \% }\end{array}$ \\
\hline 1 & 6900 & 23 & 41 & 27 & 14 & 33 \\
2 & 6900 & 43 & 44 & 30 & 19 & 31 \\
3 & 7600 & 51 & 34 & 30 & 17 & 18 \\
4 & 3700 & 32 & 45 & 20 & 16 & - \\
Normal controls & & $44 \pm 8$ & $25 \pm 6$ & $11 \pm 6$ & $51 \pm 18$
\end{tabular}

Thus some newly diagnosed IDDM's may not exhibit immunoregulatory abnormalities in the early stages. Further longitudinal studies are needed in order to clarify the importance of $T$ cell subsets in the pathophysiology of autoimunity in IDDM.
69

T. MARKESTAD*, L. AKSNES*, R. STRANDJORD* M. ULSTEIN* and D. AARSKOG. Departments of Pediatrics, Neurology and Obstetrics, University of Bergen, Norway.

Vitamin D metabolites in maternal and cord blood in normal and epileptic pregnancy.

Vitamin D metabolites were determined in maternal cond serum pairs of 13 epileptic women treated with diphenylhydantoin (DPH) alone or in combinations with other drugs and of 22 normal pregnancies. Both groups were supplenented with 400 IU vitamin $\mathrm{D}_{3}$ per day.

Mean 25-hydroxyvitamin $D_{3}$ (25-OFD) concentration was lower in the epileptic women ( $34.5-14.0$ vrs. $47.0-15.5 \mathrm{ng} / \mathrm{ml}, \mathrm{p}<0.025)$. Cord levels were lower in the epileptics, but correlated with maternal values in both groups.

$1,25-(\mathrm{OH}){ }_{2} \mathrm{D}$ levels were considerably lower in maternal and cond blood in the epileptjcs (maternal: $43.3-20.6$ vrs. 85.3-25.6, cond: $20.6-12.1$ vrs. $41.7-10.5 \mathrm{pg} / \mathrm{ml})$.

Concentration ratios of $24,25-(\mathrm{OH}){ }_{2} \mathrm{D}$ to $25-\mathrm{OHD}$ tended to be higher, and ratios of $25,26-(\mathrm{OH})_{2} \mathrm{D}$ to $25-\mathrm{OHD}$ were significantly higher in maternal and cord blood in the epileptics.

Reduced 25-OHD levels are consistent with increased turmover rate of vitamin $\mathrm{L}$ during $\mathrm{DPH}$ treatment. The reason for reduced $1,25-(\mathrm{OH}){ }_{2} \mathrm{D}$ levels are uncertain. Increased relative concentration of $25,26-(\mathrm{OH})_{2} \mathrm{D}$ and possibly of $24,25-(\mathrm{OH}){ }_{2} \mathrm{D}$ may reflect an increased degradation of 25-OHD, or altered metabolic pathways.

70

K.KRUSE ${ }^{+}$and U.KRACHT ${ }^{+}$(intr. by W.G.SIPPELL). Dept. Ped., Univ. of Kiel, FRG.

Effect of intravenous calcium ( $\mathrm{Ca}$ ) on total urinary cyclic AMP (UcAMP) and hydroxyproline (OHP) in children with hypoparathyroidism (HP).

As increasing serum Ca inhibits parathyroid hormone (PTH) secretion one would expect a suppression of UcAMP and OHP after Ca infusion in subjects with normal parapatients with HP. To test this hypothesis $18 \mathrm{mg} / \mathrm{kg} / 3 \mathrm{hr}$ Ca was infused in 5 children with PTH-deficient and PTH-resistant HP, two of them being normocalcemic during the study. The results were compared to those of 4 controls (C) and 8 epileptic children (E). UcAmp decreased to (mean \pm SD) $82.1 \pm 5.5 \%$ of the baseline value in $C$ and to $69.8 \pm 9.7 \%$ in $E$, with an inverse correlation to the relative increase of serum $\mathrm{Ca}$ in both groups. In contrast, UCAMP increased to $118.7 \pm 14.9 \%$ in HP despite a comparable serum Ca increase. OHP decreased to $48.0 \pm$ $6.8 \%, 48.2 \pm 12.7 \%$, and $39.4 \pm 9.8 \%$ of baseline in $C, E$, and $H P$, resp. (C vs. $H, P>0.05$ ). In $H P$ the paradoxically UCAMP increase and the OHP decrease were probably due to the effect of the associated calcitonin increase which was much higher than in $C$ and $E_{\text {. Conclusion: }}$ The simple measurement of UcAMP before and after Ca infusion provides a diagnostic tool to identify patients with $\mathrm{HP}$ even in the normocalcemic state. In contrast, the determination of OHP does not discriminate these thyroid function but a diminished suppressibility in 
71 K.KRUSE ${ }^{+}$(intr. by W.G. SIPPELL). Dept. Ped. Univ. of Kiel, FRG.

Prolactin, a calcium-regulated hormone?

We have demonstrated an inhibitory effect of intravenous calcium ( $\mathrm{Ca}$ ) on serum prolactin (PRL) (Acta Endocrinol.98:339,1981). To clarify wether the PRL inhibition can be already produced by serum $\mathrm{Ca}$ levels with in the upper normal range, we examined PRL after an overnight fast and 3 hours following an oral Ca load (OCL) with $1 \mathrm{~g} / 1.73 \mathrm{~m}^{2}$ body surface in controls (C) as well as in children with absorptive $(\mathrm{AH})$ and renal ( $\mathrm{RH}$ ) hypercalciuria. Results ( $\mathrm{ng} / \mathrm{ml}$, median and range): $c_{(n=23)}$ AH $(n=12) \quad$ RH $(n=8)$

PRL, before 5.3(3.0-12.5) 11.5 (5.5-24.5)\&6.0(3.1-13.5)

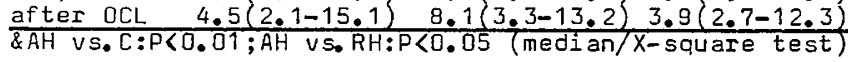
PRL decreased to 75.6 (median; mean:76.6) \% of the baseline level in the combined 3 groups $(n=43, P<0.05)$, with an inverse correlation to the serum $\mathrm{Ca}$ increase $(I=-0.51, P<0.01)$. Conclusions: 1. Changes in $\mathrm{Ca}$ homeostasis might affect serum PRL under physiological conditions. 2. Basal PRL should be determined during fasting, as Ca-rich meals may have a suppressive effect on this hormone. 3. The significance of increased fasting PRL in patients with AH deserves further studies, since PRL has been shown to be a physiological stimulus of intestinal $\mathrm{Ca}$ absorption in the rat.

72 V. NEMETHOVA ${ }^{*}$, B. LICHARDUS ${ }^{*}$ and V. LEHOTSKA (Intr. by J. Perheentupa). IInd Dept. Pediatrics, Komenský University Bratislava, Czechoslovakia.

Long term experiences with the administration of dDAVP for various indications in children.

After using dDAVP treatment since 1972 the authors conclude: 1) in children with central diabetes insipidus, one drop of dDAVP $2-3 \times$ daily $i . n$. normalizes urine flow without causing any untoward side effect. 2) in 56 patients with torpid nocturnal enuresis treated with 1 drop dDAVP per $1 / 2 \mathrm{~m}^{2} \mathrm{~b} . \mathrm{s}$. the rate of absolute success (disappearance of nocturnal mictions) was $59 \%$ and in a further $11 \%$ the frequency of enuresis was substantially reduced. 3) dDAVP may be used for rapid testing of the concentrating ability of the kidneys without water deprivation. According to experiences in 78 children, a urine osmolality $>900 \mathrm{mosm} / \mathrm{kg}$ in at least one of three hourly voidings after 1 drop dDAVP per . the necessity of a water deprivation test. Moreover, a study in 75 healthy 2 w -12 m-old infants revealed during the first 2 months of life an increase of osmolality by $100 \%$ in the course of $6 \mathrm{~h}$ after 2 drops of dDAVP. In the older infants an osmolality of $2700 \mathrm{mosm} / \mathrm{kg}$ was attained. 73 HILARY HOEY*, D B GRANT, M J DILLON and T M BARRATT** London, England.

Male pseudohermaphroditism associated with salt wasting and hyporeninaemia.

Investigation of a 4 week old infant with 'ambiguous' genitalia showed a $46 \mathrm{XY}$ karyotype, no significant rise in plasma testosterone after HCG stimulation, persistent hyponatraemia and hyperkalaemia with increased urinary sodium excretion, low plasma renin activity, and low plasma aldosterone. Rudimentary testes with absent Mullerian structures were found at laparotomy and feminizing genitoplasy was performed at 4 months. Subsequent investigation at the age of 18 months confirmed persistent hyperkalaemia, hyponatraemia and increased urinary Nat excretion in association with low PRA. Sonography, an IV urogram and renal function studies suggested renal dysplasia with a reduced GFR, but urine $\mathrm{Na}+$ loss was fully corrected with $9 \boldsymbol{\alpha}$ fludrocortisone $(100 \mu \mathrm{g} /$ day $)$. Infusion of angiotensin II produced a rise in plasma aldosterone from $90 \mathrm{pmol} / 1$ to $280 \mathrm{pmol} / 1$ after 2 hours, indicating potentially normal aldosterone secretion and thus suggesting that the hyponatraemia and hyperkalaemia were due to hyporeninaemia. The association of testicular dysgenesis with hyporeninaemia has not been previously described.
74 M.DUMIĆ*D.MARDEŠIĆ, $V$.PLAVŠIĆ*LJ.BRKLJAČIĆ, M. NOVAK:D.PAL ${ }^{\star}$ and A.KAŠTELAN" (Intr.by M.I. NEW) Dept. of Pediatr. Medicine and Tissue Typing Centre, Med.Faculty, Univ., Zagreb, Yugoslavia Coincidence of pseudohypoaldosteronism (PHA) with gluten enteropathy

A 21 months old boy with PHA associated with coeliac disease (CD) is reported. The diagnosis of PHA was made on the basis of hyponatremia (113-126-mol/1), hypekkalemia $(5,2-6,1 \mathrm{mmol} / 1)$ and large urinary salt losses (133-160 mol/dU) as well as high plasma renin activity $(58-64 \mathrm{ng} / \mathrm{ml} / \mathrm{h})$, high aldosterone levels $(2800-3100 \mathrm{pg} / \mathrm{mI})$ and increased urinary aldosterone excretion (68-112 ug/dU). Whereas mineralocorticoid therapy was ineffective, salt therapy has proved successful. CD was confirmed by the usual tests for malabsorption, jejunal biopsy and favorable response to gluten-free diet. The patient's HLA type was A1, B8, DR3, found in the majority of children with $\mathrm{CD}$. The combination of PHA and $C D$, not as yet described is probably a coincidence. It is suggested that other PHA patients be HLA typed in order to investigate the segregation between HLA type, PHA and CD.

75 W. BECK, P. STUBBE, G. PRINDULL $L^{X}, E$. JENTSCH ${ }^{x}$ and P.H. HEIDEMANN ${ }^{X}$ (Intr. by $P$. Stubbe)

Department of Paediatrics, University of Göttingen, Humboldtallee 38,3400 Göttingen, F.R.G.

Endocrinological studies following chemotherapy and/or irradiation in patients with malignant disorders.

In 43 patients, 23 giris and 20 boys, who had received chemotherapy and/or irradiation for different malignant disorders, the following functions were investigated: the sleep-related rhythms for FSH, LH and PRL, stimulating tests of the pituitaryadrenal and -thyroid axis, GH, pancreas (insulin, glucagon), testosterone, progesterone and estradiol. 17 patients had lympho-hematopoietic disorders, 26 had solid tumors. 10 patients demonstrated endocrinological abnormalities: 1 boy with hypergonadotropic hypogonadism and hyperglucagonemia (ALL), 2 boys with hyperglucagonemia (Hodgkin IIa and testicular adeno-CA), 1 with hyperinsulinism (haemangioepithelioma), 1 with extremely high ACTH-levels and hyperglucagonemia (Wilms-tumor), and 1 with primary hypothyroidism (lymphadenopathia); 2 girls with hypergonadotropic hypogonadism (Hodgkin IIIa and Reticulum-CA of the vulva), 1 with an impaired glucose-tolerance (Wilms-tumor) and 1 with high ACTH-levels and an impaired glucose tolerance (teratoid blastoma). Although all patients investigated were without any clinical symptoms these resuits emphasize the importance of following endocrinological functions.

76 I. HENRICHS*, A. WOLF*, K. MUSCH* and W.M. TELLER. Centers of Paediatrics and Gynaecology,

University of Ulm (Donau), F.R.G.

Release of human placental lactogen during in vitro placental perfusion with and without somatostatin.

Human placental lactogen (hPL) is produced by the syncytiotrophoblast and secreted almost exclusively into the maternal circulation. It acts mainly as a catabolic substance in order to supply the fetus with energy rich substrates. We examined the concentrations of hPL in maternovenous perfusates by a dual perfusion system of human placental cotyledones of 15 mature placentas by reestablishing the fetal and maternal circulation in vitro (according to a modified technique of $\mathrm{H}$. Schneider et al. Am.J.Obst.Gyn. 114, 822, 1972). The secretion rate of hPL in maternovenous perfusate was calculated. Besides, the effect of somatostatin on the release of hPL was tested. HPL was determined radioimmunologically by method of A.T. Letchworth ( $\mathrm{J}$. Obst.Gyn.Br.Commonw. 78, 535, 1971). Cyclic somatostatin was administered into maternal circulation in a concentration of $1.25 \mathrm{\mu g} / \mathrm{ml} / \mathrm{min}$. for 30 . min. Results:

1. After $20-40 \mathrm{~min}$. of perfusion in 8 mature placentas, the mean rate of $\mathrm{hPL}$ release was $1,77 \mu \mathrm{g} / \mathrm{g}$ placenta/min. \pm 0.229 $\mathrm{SEM}$. This rate was in the range of the in vivo calculated secretion of hPL (S.L. Kaplan et al., J.Clin.Endocr. 28, 1450, 1968). 2. Somatostatin did not change hPL release rate in 7 perfusion experiments $(1,36 \mathrm{~kg} / \mathrm{g}$ placenta/min. $\pm 0.049 \mathrm{SEM})$. 3 . The initial washing out effect after starting the perfusion was not changed by somatostatin. 
D B GRANT, M O SAVAGE, $R$ G G RUSSELL.. The Hospital for Sick Children, Great Ormond Street, London and Department of Human Metabolism and Clinical Chemistry, Sheffield, England.

McCune-Albright syndrome with severe progressive polyostotic fibrous dysplasia. Failure of experimental treatment with salmon calcitonin and dichloro-Diphosphonate.

The patient was borm in 1972 and was first admitted at the age of 5 months because of recurrent vaginal bleeding. There was extensive skin pigmentation and widespread fibrous dysplasia was evident on skeletal survey. Bilateral ovarian cysts were removed at laparotomy but vaginal bleeding recurred and treatment with cyproterone acetate was subsequently given. At the age of 23 months she was admitted with increasing bone deformity. Investigations showed hyperthyroidism, hypophosphataemia, and possible rickets. Treatment with carbimazole, dihydrotachysterol, and phosphate was begun. At the age of 3 years 10 months, following several pathological fractures, treatment with salmon calcitonin $(4 \mathrm{mg} / \mathrm{kg} /$ day) was given with no appreciable effect. At the age of 6 years she was admitted with cardiac failure following withdrawal of carbimazole. At this time the bone blood flow accounted for $39 \%$ of the cardiac output. When aged ? years she was treated with CIodronate Disodium ( $400 \mathrm{mg} /$ day) for 3 months: this had no effect on hydroxyproline excretion, alkaline phosphatase, or bone blood flow. She is now aged 9 years and 3 months and has increasing discomfort due to her progressive bone deformities.

78 A. KÖRNER* A. REGÖLY-MEREI* and L. BARTA* (Intr. by J. Perheentupa). First Department of Paediatrics, Semmelweis University Medical School, Budapest,

Hungary.

Klinefelter syndrome associated with other disorders.

The common feature of the three cases was that symptomatology was very poor and not too special for Klinefelter syndrome. The first boy developed a mild feminine type obesity without gynaecomastia, cryptorchidism or mental retardation. His karyogram was $47, \mathrm{XXY}$. Because of contradictory geno- and phenotypes, karyotype determination was performed in fibroblast culture of scrotal skin and testicular biopsy. Both supported Klinefelter syndrome. Besides the obesity the most striking feature of the second case was phokomelia. The boy was operated for unilateral cryptorchidism: a biopsy from the atrophic testis proved Klinefelter syndrome. Karyogram showed $47, \mathrm{XXY} / 46, \mathrm{XY}$ mosaicism. The third patient suffered from very unstable, insulin dependent diabetes. Besides obesity multiple lipomas occurred. Triglyceride level was markedly elevated. In his early childhood he was operated because of cryptorchidism. Karyogram showed 47, XXY/46, $\mathrm{XY}$ mosaicism. Conclusion: obesity associated with any anomaly seems to be an indication for karyotype determination.
80

M. LIPSANEN-NYMAN, J. RAPOLA and J. PERHEENTUPA. Children's Hospital, University of Helsinki, Finland. Mulibrey nanism: hypoplasia of the endocrine glands. We evaluated the endocrine system of 30 of the 46 patients wich Mulibrey nanism (Perheentupa et al, Lancet $2: 351$, 1973) known in Finland. Partial GH deficiency was diagnosed in 4 patients, 2 of them children, by repeated insulin-arginine testing. These children and 4 of 9 others who received GH therapy showed a good growth response. 2 children developed primaxy hypothyroidism. 1 patient had a thyroid cyst and another an adenoma. Adrenocortical responses to 2-h ACTH test were subnormal in 14 patients. 8 of them also had subnormal cortisol responses to insulin-induced hypoglycemia. One of these 8 had elevated plasma ACTH levels and a clearly deficient cortisol response to 4-day ACTH test indicating primary adrenocortical failure. 4 others showed no response in plasma ACTH to hypoglycemia, indicating deficient ACTH secretion. 9 patients had features of both primary adrenocortical failure and ACTH deficiency. In 4 of them the adrenocortical function was at first normal but then progressed to failure. At autopsy in 4 of 6 patients the adrenals were hypoplastic. In both sexes pubertal development was late and incomplete. The 8 postmenarcheal females were oligo- or amenorrheic and most of them had elevated post-GnRH LH and FSH levels. All had hypoplastic ovaries and 5 had ovarian tumours. In postpubertal males the testes were hypoplastic, all but 1 had elevated basal and post-GnRH LH and FSH levels and poor responses to HCG with normal basal testosterone levels. Sperm analyses showed aspermia or oligospermia.

\section{E.E. JOSS and K.A. ZUPPINGER}

Dept. of Pediatrics, University of Bern, $\mathrm{CH}$ oxandrolone in Turner's syndrome, a pairedcontrolled study up to final height. Thirty 1-year periods on Oxandrolone were studied in 20 patients with Turner's Syndrome. The mean bone age $(\mathrm{BA})$ at onset of therapy was $10.6 \pm 1.8$ years. control patients with Turner's syndrome were matched for $B A$ (max. diff. $=0.5$ yrs) and adult height prediction Bayley + pinneau (max, diff. $=3.0 \mathrm{~cm}$ ). On Oxandrolone $(0.1 \mathrm{mg} / \mathrm{kg} / \mathrm{d})$ height velocity increased from 2.9 to $5.0 \mathrm{~cm} / \mathrm{yr}(\mathrm{p}<0.001)$. The increase in height velocity was negatively correlated to the $B A$ at onset $(r=-0.49, p=0.01)$. The $B A$ velocity during the treatment period (including a 6 month off period) was $0.75 \mathrm{yr} / \mathrm{yr}$ in the treated, compared to $0.66 \mathrm{yr} / \mathrm{yr}$ in the untreated patients (ns). 15 of the 20 patients have reached $\mathrm{f}$ inal height. 7 of those with a mean $B A$ at onset of 12.1 years were treated for 1 year only and had - compared to the matched controls - a mean gain in final height of $2.5 \mathrm{~cm}$ (ns). 8 patients with a mean BA of 10.6 years were treated for $2 \times 1$ year and had a significant mean gain in final height of $5.2 \pm 4.1 \mathrm{~cm}(\mathrm{p}<0.01)$. Calculation of the adult height prediction by the IPH-method of Lenko et al. (Acta Paediatr Scand Suppl 277: 57, 1979) gave the same gain in final height.

\section{9} M.B.RANKE and J.R.BIERICH

University Children's Hospital, Tübingen, FRG

Gigantism of hypothalamic origin.

A 1;8 yrs old female infant (S.F.) - a product of a Clomiphene-induced pregnancy, delivered at term (b.w.3600 g)-presented with tail stature ( $96 \mathrm{~cm} ;+3.5 \mathrm{SD})$ Psychomotor development was retarded and the clinical appearance suggested Sotos' S. (weight 16.2kg; head circumf. $50 \mathrm{~cm}$; frontal bossing; high-set frontal hair; clitoral enlargement).E2,T, DHA,T4, LH and FSH (basal and after $\mathrm{LH}-\mathrm{RH}$ ) were normal. TSH basal $1.9 \mu \mathrm{U} / \mathrm{ml}-$ after TRH $3.3 \mu \mathrm{U} / \mathrm{ml}$. Basal $\mathrm{GH}$ levels were normal and suppressible by glucose. Maximum of $\mathrm{GH}$ after arginine $16.7 \mathrm{ng} / \mathrm{ml}$. CT of the scull revealed mild hydrocephalus intern., but no tumor masses. At age $2 ; 2$ yrs $(101 \mathrm{~cm}) \mathrm{GH}$ reached $60.4 \mathrm{ng} / \mathrm{ml}$ after arginine. Spontaneous $\mathrm{GH}$ secretion at night $(10255 \mathrm{ng} / \mathrm{ml} / 5.5 \mathrm{~h})$ and Somatomedin activity (porc.cart.) $(1.7 \mathrm{U} / \mathrm{ml})$ were grossly elevated. Pneumoencephalography revealed a tumor mass related to the hypothalamus suggestive for a hamartoma. This case of gigantism with GH hypersecretion is analogous to cases with precocious puberty and hamartoma. Stimulation of $\mathrm{GH}$ releasing hormone(s) or inhibition of SRIF may be the pathogenetic cause. The relation to cerebral gigantism - with its presumably low $\mathrm{GH}$ secretion - will be discussed.
82 E.M. de WIJN $^{*}$ and R. STEENDIJK.

Dept. of Pediatrics, Academisch Medisch Centrum Amsterdam, the Netherlands.

Growth and development in 5 patients with pseudohypoparathyroidism; a longitudinal study.

In 4 girls and 1 boy with pseudohypoparathyroidism growth and maturation were followed for 7-13 years until adult height was reached. Puberty occured early in each case (average age at menarche in the girls was 12.1 years) and as a result of their rapid development all patients were relatively shorter as adults than as children. Average height at age 8.0 years was -0.33 SDS; aver. adult height was -2.58 SDS. These observations offer an explanation for the finding in the literature that short stature is more common in adults than in children with this disease. Skeletal age was advanced in all cases and the development of the tubular bones of the hand was more advanced than the development of the round bones. At an average chronol. age of 9.9 years aver. skel. age (TW2) was 12.3 years. The difference between the radiusulna-short bone score and the carpal bone score had an average value of 2.2 years. It is possible that this difference resulted from inappropriately early closure of the epiphyseal discs of disproportionally short metacarpals and phalanges. On the other hand, this discrepancy may be an aspecific phenomenon of advanced skeletal maturation, since it has been found to occur also in true precocious puberty and in congenital adrenal hyperplasia. 
Biphasic growth surge in male but not female rats

Body weight and nose-tail length (NTL) together with $\mathrm{GH}$, Somatomedin activity (SM; proc.cart.), DHA, T and $\mathrm{E} 2$ in serum, were measured in male(M) and female(F) Wistar rats cross-sectionally every day (age day 15-90). The distance curves for weight and NTL in both sexes showed sigmoidal patterns although for $F$ the post-pubertal curves were smaller. Examination of the relationship between hormonal profiles and the auxological data revealed the followings:-1. The velocity curves for body weight and NTL recorded two peaks in $M$ (major day 30 , minor day 55) while $F$ had only one at age day 30.-2. The pattern of SM followed in course of the NTL velocity curve and coincided with peak one.-3. GH recorded a peak at age day 55 in both sexes when $T$ and $E 2$ demonstrated a rising milieu. -4 .DHA demonstrated a sex difference: in $F$ a peak occurred at age day 43 followed by a dropin $M$ a first peak was at age day 42 , followed by a drop and then rising again coinciding with increment of $T$. It is probable that the first peak in the growth velocity curve is primarily regulated by SM.With SM being low at this period it is plausible that SM activity is controlled by $\mathrm{GH}$ with insulin and/or by the changing sensitivity of the $G H$ target(s). The second peak in $M$ is the result of $\mathrm{SM}-\mathrm{T}$ interaction, therefore not seen in $\mathrm{F}$. with hypothalamic-pituitary disease.

4 healthy and 17 children with hypothalamic-pituitary disease (HPD) were given $40 \mathrm{mg} / \mathrm{kg}$ Metyrapone (M) intravenousiy in $400 \mathrm{ml}$ infusion during 4 hours in the morning. Before and after the infusion blood samples were taken into tubes contained $5 \mathrm{mg} \mathrm{Na}-\mathrm{EDTA}$ for estimation of plasma ACPH bJ CIS RIA kits andCortisol (C) by BIORAD RIA kits. - Resultg: RIA kitg $(\mathrm{pg} / \mathrm{m} I)$ before $M$ after $M$ CORTISOL ( $\mathrm{gg} / \mathrm{d} \mathrm{l}$ ) before $M$ after $M$ Cranio- $244.6 \pm 288.6$ (4) $554.8 \pm 319.6$ (5) $18.5 \pm 5.35 .3 \pm 0.2$

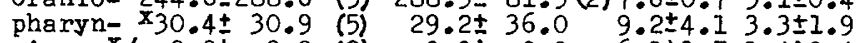
gioma $x / a \quad 0.0 \pm 0.0$ (2) $0.0 \pm \quad 0.0 \quad 6.1 \pm 1.7 \quad 1.4 \pm 0.4$ (cr) $x / b 50.7 \pm 37.0$ (3) $48.7 \pm 34.9 \quad 14.0 \pm 1.05 .3 \pm 0.2$ $\mathrm{HPD}=-30.6 \pm 5.5(3) \quad 15.3 \pm 10.1 \quad 4.5 \pm 0.72 .6 \pm 0.8$ 2 children with $\mathrm{Cr}$ had Iow $\mathrm{C}$ and high basal ACTH levelg without ACTH capacity (feed-back hypogengitivity? biological inactivity?). In cages of low (10 Mg/dI) $C$ and low ACTH levels there was no ACTH capacity. This is apecific of $\mathrm{Cr}$ (5 of 7 ) Subnormal ACTH capacity vels (5 of 8 ) and in $\mathrm{Cr}$ ( 3 of 7 ) gupporting thet steroid substitution is often unnecessary.
84 S. DAHLSTRÖMX and FINNISH STUDY GROUP (Intr. by H. K. Akerblom). Department of Paediatrics, University of Turku, Turku, Finland.

Current skinfold values of Finnish children aged 3 to 18 years of age and the assessment of obesity.

The objective of present multicentre study was to obtain information on risk factor levels for coronary heart disease and their determinents in children. The field study was carried out on a random representative sample of 3596 children, aged $3,6,9$ 12 , 15, and 18 years, from different parts of Finland, in 1980 . The data concerning nutritional status and obesity included height, weight, skinfolds, puberty ratings, blood pressure, blood lipids and insulin, also interview data of food intake, socioeconomic conditions, psychological factors and physical fitness. Triceps and subscapular skinfolds were measured according to IBP. Age- and sex-specific skinfold values, hitherto not available in Finland, were computed, together with their correlations and interdependences with other relevant variables. Subscapular skin fold proved to be better correlated to weight than triceps or sum of skinfolds, and could thus be a good criterion for obesity, independent of height. In the majority of children subscapular skin fold values were lowest at 6 and 9 years, rising thereafter up to 18 years of age. In the light of present cross-sectional data, in about $10 \%$ of girls and $5 \%$ of boys skinfold data show a continuous rise after. 3 years of age. The absolute values of these children at 3 and 6 years are $\geqq 10 \mathrm{~mm}$ for girls and $\geqq 9 \mathrm{~mm}$ for boys. It may be possible to find obese children with skinfold measurements already at ages of 3 and/or 6 years.

A AYNSLEY-GREEN, J A MACPARLANE*, University Department

Screening for chnomal growth in children.

Growth Hormone deficient children in G.B. are beginning treatment at an unacceptably advanced age because of delayed investiga tion (1). GH deficiency is but one condition causing abnormal growth where early treatment is essential to protect the final adult height. We hove onalysed 226 children in the Oxford Growth $\mathrm{Clinic}$ in order to assess the age of referral for growth disorders, and to consider ways to improve eorlier diagnosis. $87 \%$ ( 126 boys and 71 girls) were seen for short stature. The mean and modal age of referral for genetic short stature (4\$\% of short children) were 10 and 6 years respectively, but one third were not referred unt il $>12$ years. $49 \%$ of short children had recognisable disorders, with hy pothyroidism ( 9 cases), Turner's Syndrome ( 14 girls) and GH deficiency ( 11 cases) presenting at mean ages of $9,11.5$, and 7 years respectively. The modal age of referral for Turner's Syndrome was 16 years, and 9 ye ars for GH deficiency. Mean ages of referral of 29 children ( 17 boys and 72 girls) with tall stature were 10 and 14.75 years respectively. We conclude that most children with pathological growth could have been detected earlier. To improve early detection we have manufactured a full sized percentile wall chart for height against which the child stands. Abnomal stature can be recognised instantly. The use of these charts to screen populations of children for abnomal growth will

be demonstrated. Health Trends 1975; 7: 61-65.
87 T.E. ROMER, B. KLUCZYNSKA* and K. SACENOWSKA* Child's Health Center, Warsax, Poland.

Normal or high level of glucose stimulated serum imunoreactive insulin in hyposonatotropic dwarf(HD) goes with less growth deficiency.

In $33 \mathrm{fD}$ an oral glucose tolerance test was performed and serum insulin assayed. In 20 patients the peak value of insul in was below normal (group $A$ ) and in 13 was normal or high (group B). Group A included 5 patients and group B 6 patients with an organic lesion. There was no significant difference in bone age/chronological age $x$ 100 (BAI) and in SD helght score (SDHS) between the $\mathrm{HD}$ with idiopathic and organic disease. The mean SDHS was $-5,09 \pm 1,3$ in groum $A$, and $-3,89 \pm 0,9$ in group $B_{\text {. The }}$ mean BAI was $41,0-18,4$ and $70,0 \pm 19,9$, respectively. The differences were significant. There were also significant differences in SDHS and BAI between the subgroups with an organic lesion in group $B$ and $B$. The existence of differences in insulin level and growth within the subgroup of HD with organic disease contradicts the speculation that patients with high stimulated insulin level secrete a defective GH molecule with preserved effect on carbohydrate netabolisa. Better growth perpend on higher residual GH secretion, which may be not neasurable, or on insulin itself.

\section{P.E. GARNIER, P. DESIX and M. ROGER}

Fondation de Recherche en Hormonologie, Paris, France. Effect of Ethinyl-Estradiol (EE) on growth hormone (GH) response to exogenous stimuli in low responding children and true hypopituitary dwarfs.

Sixty two dwarf children (mean -3.5 SD) aged from 2 to 16 years (48 males and 14 females) having a GH peak response below $8 \mathrm{ng} / \mathrm{ml}$ (mean $5.1 \pm$ SEM $0.27 \mathrm{ng} / \mathrm{ml}$ ) to at Teast two stimuTation tests using insulin, arginine and/or ornithine were re-studied with at least one of these stimulation tests after administration of EE $100 \mu \mathrm{g} /$ day for 3 days. 17 had ascertained pituitary deficiency resulting from a known cause, gross hypothalamo-pi tui tary lesion, breech delivery, familial hypopituitarism or multiple idiopathic pituitary defect: mean \pm SD peak GH values were $3.4 \pm$ $2.36 \mathrm{ng} / \mathrm{ml}$ before and $2.9 \pm 1.98 \mathrm{ng} / \mathrm{ml}$ after EE. Among 45 wi thout prior evidence of pituitary deficiency, 34 responded normally after $\mathrm{EE}$, with $\mathrm{GH}$ peak values ranging from 10.1 to $45 \mathrm{ng} / \mathrm{ml}$ (mean $18.3 \pm$ SD $8.5 \mathrm{ng} / \mathrm{mI}$ ). In 11 others, EE was not followed by a normalization of the $\mathrm{GH}$ response: mean $\pm \mathrm{SD}=4.9 \pm 1.7 \mathrm{ng} / \mathrm{ml}$ before and $6.4 \pm 2.3 \mathrm{ng} / \mathrm{ml}$ after EE, thus leading to suspect an isolated GH deficiency. 7 of these were then treated with $\mathrm{hGH}$ which significantly improved their growth rate from mean $\pm S D$ $3.8 \pm 1$ to $8.1 \pm 1.9 \mathrm{~cm} /$ year. It may thus be suggested that $\mathrm{EE}$ is usefur to distinguish cases of true isolated GH deficiency among children with growth retardation and low GH response to stimulation test. 
L. FRYKLUND*, G. EKETORP, H.FLODH, K. FHÖLENHAG A. SKOTTNER-LUNDIN* B, STRINDBERG $A$. WICHMAN* and K.G. THORNGREN ${ }^{*}$ (Intr. by K. Hall). KabiVitrum $A B$, Stockholm and Univ。 of Lund, Lund, Sweden. Development of human growth hormone produced in recombinant bacteria as a therapeutic agent.

Human growth hormone (somatotropin, hGH) is used tnerapeutically for the treatisent of children with pituitary deficiency. The hormone is a protein of MW 22.000 which is isolated from human pituitary glands. The gene for human somatotropin has been inserted into the plasmid $\mathrm{PBr}$ in Escherichia coli K12 by recombinant DNA techniques. The recombinant bacteria have been grown in batch culture and the hGH extracted from the disintegrated cells. Conventional biochemical separation methods such as ion exchange and gel chromatography have been used for purification on a scale suitable for industrial production. The biosynthetic hGH appears to be identical to the pituitary hormone with regards to molecular weight and sequence with the exception of an N-terminal methionine. No contaminating proteins of bacterial origin are present. Biological activity, determined in hypophysectomized rats by increase in epiphysial width of tibia, weight gain, and sulfate incorporation into connective tissue appears to be identical to that of the pituitary hormone. One month toxicity studies in rats and $\operatorname{dog} s$, in doses more than one hundred times the normal therapeutic dose have revealed no toxic effects. A two week safety study in man has indicated no adverse effects and several clinical trials in both hypopituitary children and adults are in progress.

90 K.W.KASTRUP and J.S.CHRISTIANSEN, Endocrine Clinic, Fuglebakken and Steno Memorial Hospital, Copenhagen, Denmark.

Comparison of growth response to human growth hormone after subcutaneous and intramuscular injection in growth hormone deficient childxen.

Previously we have demonstrated that daily subcutaneous (s.c.) injections of human growth hormone (hGH) could mimic normal physiological levels and thereby present a more rational schedule of treatment. Twenty children participated in a study where hGH (Nanormon ${ }^{R}$ ) was given s.c. at night by patients or parents. Two were newly diagnosed, whereas 18 had been treated with hGH on $i$. m. schedules. In 6 children 1 IU hGH was followed by 2 IU six times per week. Growth veiocity (cm/year) was $3.6 \pm 1.8$ and 6.8 \pm 2.0 (mean \pm SD) respectively. In 9 children conventional treatment with $4 \mathrm{IU} \times 3 / \mathrm{wk}$ i.m. was compared to $2 \mathrm{IU} \times 6 / \mathrm{wk}$ s.c.

Growth response was $4.8 \pm 1.0$ and $7.2 \pm 2.5 \mathrm{~cm} /$ year respectively. $(p .=0.02)$. These patients all showed a decreased growth response to conventional treatment. Growth response in the newly diagnosed patients was markedly increased. Local reactions or antibody formation was not observed during treatment. Somatomedin A values were decreased in some patients on i.m. treatment and was restored to normal on s.c. treatment. Subcutaneous treatment is well accepted and represents an alternative to conventional intramuscular treatment.

91 crinology, University Children's Hospital "Het Wilhelmina Kinderziekenhuis", Utrecht, the Netherlands.

Plasma somatomedin activity and urinary hydroxyproline excretion during acute and long term administration of human growth hormone in children with short stature.

In 15 children with short stature and a wide range of growth hormone (GH) levels, growth velocities and clinical features, baseline somatomedin activity (SM-act) and total urinary hydroxyproline excretion (THP) and their responses to $1.6 \mathrm{U}, 3.2 \mathrm{U}$ and $6.4 \mathrm{U} \mathrm{hGH} /$ $\mathrm{m}^{2} /$ day for 7 days consecutively were studied and compared to SMact, THP and height acceleration during 1 year of hGH therapy ( $4 \mathrm{U}$ biweekly). Baseline SM-act correlated with height velocity in patients without special features. All patients showed a dose-related icrease of SM-act and THP. SM-act at 1.6 and $3.2 \mathrm{U} / \mathrm{m}^{2} / \mathrm{day}$ correlated positively with weight-for-height. Two patients with a low increase of SM-act during short term GH administration subsequently showed low height acceleration. On hGH therapy growth rate increased with 1.8 to $13.6 \mathrm{~cm} /$ year. SM-act and THP were higher than before therapy, without much fluctuation during the year. Height acceleration correlated positively with the difference of SM-act during and before chronic treatment. In conclusion: 1 . in our patients initial increases of SM-act and THP are only indicative for height acceleration on therapy; 2 . the study of the GHSM-THP-growth axis allows a better understanding of the contribution of different factors, such as GH deficiency, the nutritional status and the endorgan sensitivity, to the variation of individual growth patterns.

I. GIL-AD*, TOPPER E.*, Z. JOSEFSBERG*, MAMET R.*, Y. BAR-YOSEF* and Z. LARON. Inst. Pediat. \& Adolesc. Endocrinol., Beilinson Med. Ctr. and Sackler School of Med., Tel Aviv University, Israel.

Plasma beta endorphin during insulin hypoglycemia and after oral clonidine.

The possible role played by beta endorphin in the secretion of $\mathrm{hGH}$ was investigated by concomitant measurements of plasma beta endorphin, hGH and cortisol during insul in hypoglycemia $(0.1 \mathrm{U} / \mathrm{kg} \mathrm{i} . \mathrm{v}$.$) or clonidine \left(0.075 \mathrm{mg} / \mathrm{m}^{2} \mathrm{p.o}.\right)$ after an overnight fast. Two groups of 9 and 10 children ( 13 boys and 6 girls) aged 6-15 yrs were studied at $0,30,60,90$ and 120 mins after drug administration. Hypoglycemia stimulated beta endorphin from $9+1$ (m+SE) to $25.5+5 \mathrm{pm} / 1$. Clonidine decreased beta endorphin in 6 patients from $8 . \overline{8}+2$ to $4.4+0.7 \mathrm{pm} / 1$ and in 4 basal levels were not modified. $h G H \overline{i n c r e a s e d} \overline{t o}>20 \mathrm{ng} / \mathrm{ml}$ in all subjects except one after clonidine. Cortisol increased from a mean of 9.2 to $24.2 \mathrm{ug} / \mathrm{dl}$ during hypoglycemia and decreased from a mean of 12.3 to $3.9 \mathrm{ug} / \mathrm{dl}$ after clonidine. Our data provides further evidence of a good correlation between beta endorphin secretion and ACTH respectively cortisol secretion, but no correlation between beta endorphin and $\mathrm{hGH}$ secretion even though opiates are considered hGH stimulators.

Supported by a grant from the Chief Scientist's Office, Ministry of Heaith.

93

R. ESHET* S. PELEG* and Z. LARON. Inst. Pediat. \&

Adolesc. Endocrinol., Beil inson Medical Ctr. \&

Sackler Sch. of Medicine, Tel Aviv Univ., Israel. Direct visualization of $h G H$ binding to receptors of $I M-9$ human cultured lymphocytes.

Human hGH receptors were studied by investigating the binding of fluorescent labelled hGH (F-hGH) to IM-9 human cultured lymphocytes. The binding activity of the F-hGH analog was determined by a radioreceptor assay using human liver microsomes. F-hGH competed with 125 I-hGH for its specific receptors to the same extent as unlabelled hGH. IM-9 lymphocytes were incubated with F-hGH for $60 \mathrm{~min}$. at $37^{\circ} \mathrm{C}$ and visualized with a sensitive video intensification microscopic system which enables to directly observe the location of the fluorescent hormone on the surface of the cells. The hormone receptor complexes were found aggregated into patches on the cell surface and formed a single cap on one pole of the cell. The use of F-hGH provides a visual method to study the binding of the hGH molecule to its specific receptors. The role of the aggregation step in the mechanism of action of $h \mathrm{GH}$ remains to be elucidated.

Supported by a grant from the ESPE-Nordisk Grant for the Study of Growth Retardation.

\section{R. ESHET*, Z. LARON, A. PERTZELAN and M. DINTZMAN*.}

Inst. Pediat. \& Adolesc. Endocrinol. \& Dept. Surgery

$A$, Beilinson Medical Ctr. \& Sackler Sch. of Medicine Tel Aviv University, Israel.

Defective $h G H$ receptors in the livers of 2 patients with Larontype dwarfism (LTD).

Liver tissue was obtained by biopsy from 2 male LTD patients aged $4 \& 26$ yrs (approved by the hospital ethical committee). As control liver tissue served 6 heal thy kidney transplantation donors ( $m$ age $24 \mathrm{yrs}$ ). 100,000g microsomal pellets were prepared from each specimen for analysis. The results were as follows:

\begin{tabular}{|c|c|c|c|c|}
\hline \multirow{2}{*}{$\begin{array}{l}\text { Liver } \\
\text { Microsomes }\end{array}$} & \multirow{2}{*}{\multicolumn{2}{|c|}{$\begin{array}{r}125 \text { I-hGH } 125 \text { I-insulin } \\
\% \text { specific binding per } \\
12 \mathrm{mg} \text { microsomal protein }\end{array}$}} & \multicolumn{2}{|c|}{ Pìasma } \\
\hline & & & $\begin{array}{c}\mathrm{nGH} \\
\mathrm{ng} / \mathrm{m}\}\end{array}$ & $\begin{array}{r}\text { Insul in } \\
\mu \mathrm{U} / \mathrm{m} \text { l }\end{array}$ \\
\hline $\begin{array}{r}\text { LTD - Pt. } 1 \\
\text { Pt. } 2\end{array}$ & $\begin{array}{l}0.5 \\
0.1\end{array}$ & $\begin{array}{r}33.4 \\
7.1\end{array}$ & $\begin{array}{l}45 \\
20\end{array}$ & $\begin{array}{l}1 \\
5\end{array}$ \\
\hline
\end{tabular}

Normal: 31 assays of 6 livers

Range $7.9-24 \quad m=14$

In contradistinction to the nomal liver specimens, the liver of the LTD patients showed no specific binding of hGH. There was, however, normal binding of insulin. Circulating antibodies against hGH receptors have not been found in the 2 and other 4 LTD patients. The results are interpreted as evidence for a basic and specific defect in hGH receptors in the liver of LTD patients leading to an inability of somatomedin generation. It is possible that this abnormality is generalized and not limited to the liver. 


\section{READ BY TITLE}

95 S. BALABANOVA*, F. POHLANDT*', I. HENRICHS*, and W. M. TELLER. Center of Paediatrics, University of Ulm, Federal Republic of Germany.

Feto-maternal transfer of calcitonin in himan placental perfusion model.

Most recently we have shown fetal secretion of calcitonin and higher concentrations in fetal than in maternal plasma. In this study we investigated the permeability of placenta for calcitonin in an in vitro human placental perfusion model. Complete separation of maternal and fetal side in this model was proved by dextran-blue. Calcitonin was infused into the fetal artery during 20 minutes. Perfusate samples from fetal vein and maternal vein were taken at intervals of 3 and 5 minutes over a period of 30 minutes following start of perfusion. CT-concentrations were measured by CT-RIA.

Results: Minutes following start of perfusion

\begin{tabular}{lcccccccc}
\hline 0 & 3 & 6 & 9 & 12 & 15 & 20 & 25 & 30 \\
\hline Fetal vein & \multicolumn{7}{c}{ CT $(\mathrm{pg} / \mathrm{ml})$} \\
0 & 120 & 110 & 110 & 115 & 115 & 130 & 170 & 27 \\
\multicolumn{2}{l}{$\begin{array}{l}\text { Maternal vein } \\
0\end{array} \quad 0$} & 32 & 45 & 57 & 52 & 55 & 55 & 57
\end{tabular}

The appearance of $C T$ in the maternal circulation showed - at least in the perfusion model - permeability of placenta to fetal CT at physiological concentrations.

96 S. Balabanova ${ }^{*}$, F. POHLANDT ${ }^{*}$, I. HenRICHS ${ }^{*}$, and W. M. TELLER. Center of Paediatrics, University of U/m, Federal Republic of Germany.

Materno-fetal transfer of parathyroid hormone in an in vitro human placental perfusion model.

In general, polypeptide hormones are not thought to cross primate placenta. The present study was undertaken to investigate the passage of PTH from maternal to fetal circulation across the placental membrane in an in vitro human placental perfusion model. Bovine parathyroid extract was infused into the maternal artery during $20 \mathrm{mi}-$ nutes. Perfusate samples from maternal vein and fetal vein were taken at intervals of 3 and 5 minutes over a period of 40 minutes following start of perfusion. To validate PTH assay for use in the presence of perfusate a typical standard curve for assay of beef PTH was obtained in parallel with assay tubes containing added perfusate. Completeseparation of maternal and fetal side in this model was proved by dextran-blue.

Results:

\begin{tabular}{|c|c|c|c|c|c|c|c|c|c|c|c|}
\hline 0 & 3 & 6 & 9 & 12 & 15 & 18 & 21 & 26 & 31 & 36 & 41 \\
\hline
\end{tabular}

$\begin{array}{llllllllllll}0.5 & 9.0 & 40 & 42 & 45 & 74 & 66 & 47 & 39 & 21 & 9.8 & 8\end{array}$

$\begin{array}{llllllllllll}\text { Fetal vein } & & & & & & & & \\ 0.5 & 0.5 & 0.7 & 1 & 1.4 & 1 & 2.3 & 1.4 & 1.2 & 0.8 & 1.0 & 0.9\end{array}$

Appearance of PTH in fetal circulation showed permeability of pla-

centa to maternal PTH at high concentrations.

97 M.BORKENSTEIN" (Intr. by H.Gleispach) Dept. of Pediatrics, University of Graz, Austria.

Cinical application of intranasal administration of $\mathrm{TRH}$.

The release of TSH and PRL after intranasally applied TRH was investigated in ten healthy prepubertal children. Informed consent was obtained. $500 \mu \mathrm{g}$ of synthetic TRH in aqueous solution were insufflated in one nostril. Blood samples were obtained before, and $30^{\circ}, 60^{\circ}, 90^{\prime}$, and 120' after the TRH administration. Sérum ievel's of TH, TH, TSH and PRL were all in the normal range. Intranasal' TRH induced the release of TSH and PRL in all children with a peak rise within 30'. $\triangle \mathrm{TSH}: 7,9 \pm 1,3 \mu \mathrm{U} / \mathrm{ml} ; \triangle \mathrm{PRL} 16,9 \pm 3,6 \mathrm{ng} / \mathrm{ml}$ $(\bar{x} \pm S E M)$. TSH values were still significantily higher at $120^{\prime}(p<0.025)$ whereas the PRL values did not differ. A dose dependent TSH release following intranasal sprayed $T R H$ was shown. $\triangle T S H$ was higher $(\mathrm{p}<0.025)$ in children receiving $>10 \mu \mathrm{g} / \mathrm{kg} \mathrm{TRH}$ than in children receiving $<10 \mu \mathrm{g} / \mathrm{kg}$. Differences in PRL release were not shown.

Intranasal insufflation of TRH seems to be a harmless and valuable tool for the evaluation of the hypothalamo-pituitary system and thyroid gland function.
J.H. BRAMMSWIG ${ }^{*}$, G. SCHELLONG ${ }^{*}$,

R.P. MÜLLER (Intr. by K.E. v. Mühlendahl) University Children's Hospital and Department of Radiology, University of Münster, West-Germany.

Clinical computerized tomography (ССT) in girls with isosexual idiopathic precocious puberty.

With the introduction of CCT there have been occasional reports on soft tissue densities in the suprasellar region in boys with precocious puberty. In girls, isosexual precocious puberty is still considered to be idiopathic in the majority of cases.

Since February 1980 we have performed CCT in 7 girls with "idiopathic precocious puberty". In four of these patients we were able to demonstrate a soft tissue density in the suprasellar region, possibly a hamartoma. The mass could be further delineated in the area of the interpeduncular cistern by intrathecal contrast studies with metrizamide. All four patients had the onset of symptoms before the age of 4 years. In the remaining 3 girls signs of puberty occurred between 4.5 and 6.75 years with a hydrocephalus in one. We conclude that CCT's should be performed in all girls with so-called idiopathic precocious puberty, especially in patients with the onset of symptoms before the age of 4 years.

99

C. DACOU-VOUTETAKIS, M.MANIATI *, A.CHRONOPOULOS AND N.SCORDIS*.A' Dept.Pediat.Athens University, Athens, Greece.

The response of plasma prolactin ( $\mathrm{Pr})$ growth hormone (GH), LH and FSH to L-DOPA in the obese child (OC).

The hypothalamo-pituitary responsiveness to L-DOPA in the OC was studied.Plasma Pr, GH, LH and FSH were determined priox to, and $30,60,90,120$ minutes post L-DOPA, in 6 OC and 6 normal weight (NW), prepubertal children, aged 6-12 years. There was more intense suppression of $\mathrm{Pr}$ in $\mathrm{NW}$ than in $\mathrm{OC}(69 \%$ versus $41 \%$ drop at 120 minutes). An earlier and higher rise in $G H$ was observed; the mean GH values $\pm S D$ at $30,60,90$ minutes post L-DOPA in NW and OC were $20.3+5.72$ and $1.13+0.27$, respectively $(p<0.01)$. There were no differences in FSH and LH values in the two groups. The findings may be attributed to depressed hypothalamo -pituitary responsiveness to dopaminergic stimuli in the obese child, although other mechanisms cannot be excluded.
100

C.DACOU-VOUTETAKIS, M.MANIATI *, CH.THEODORIDIS AND G.KREATSAS*. A' Dept.Pediat.Athens University, Athens, Greece.

A case of "precocious menarche"

A girl now aged 9.2 years presented monthly vaginal bleeding, of 3-4 days duration, regularly from age 2.5 to 32 months, and irregularly from 8.3 years until now. Other pubertal manifestations were absent except for pubic hair Tanner II, which developed recently. At age 30 months, plasma FSH and $\mathrm{LH}$ values, determined every $2 \mathrm{hrs}$ for $24 \mathrm{hrs}$, ranged from $1.6-3.2 \mathrm{mIU} / \mathrm{ml}$. Urine estrogens were $3 \mathrm{\mu g} / 24 \mathrm{hrs}$. At the age of 8.5 years vaginoscopy showed the blood to come from the cervical orifice which looked normal.Coagulation studies were normal.Plasma estradiol was $<22 \mathrm{pg} / \mathrm{ml}$. FSH and LH peak values during sleep were 2.8 and 2.2 $\mathrm{mIU} / \mathrm{ml}$, respectively. Post LHRH, FSH rose from 2 to 11.2 $\mathrm{mIU} / \mathrm{ml}$ and $\mathrm{LH}$ from 1.1 to $2.8 \mathrm{mIU} / \mathrm{ml}$. Linear growth and osseous maturation showed no accelaration.Mentality was normal. We consider this case as precocious menarche, an entity analogous to precocious thelarche, and it is most likely caused by increased end organ sensitivity. 
F. DE LUCA*, G. MAGazZU1*, C. SFERLAZZaS*, G. DI PASQUale*, E. PAN DULL $0^{*}$ and F. TRIMARCHI* (Intr. by G. Giovannelli) - 2nd Department of Pediatrics, Policlinico Universitario, Messina, Italia.

Serus zinc levels and thyroid economy changes in Cystic Fibrosis ( C F ).

Changes in thyroid econony are known to occur in $C F$, but the results of previous reports are conflicting ( $\mathrm{cfr}$. Segall-Blank, J. Pediatr. 98, 218, 1981). In the present study 10 iodide untreated CF children (aged $0.5-12$ yrs), as compared to 84 healthy children $(1-12$ yrs $)$, exhibited lower mean ( + S.D. $)$ values of se run $14(6.8 \pm 1.3$ vs $9.3 \pm 2.3 \mu \mathrm{g} / \mathrm{dl} ; \mathrm{p}<0.001)$, rT3 $(22 \pm 8$ vs $33 \pm 11 \mathrm{ng} / \mathrm{dl} ; \mathrm{p}$ $<0.001)$ and $\mathrm{rBPA}(18+4$ vs $24+8 \mathrm{~g} / \mathrm{dl} ; \mathrm{p}<0.05)$. Serun TSH $(4.8+1.3$ vs $2.3 \pm$ $1.7 \mu \mathrm{U} / \mathrm{ml})$ and $\triangle \mathrm{ISH}(38 \pm 14$ vs $18 \pm 6 \mu \mathrm{U} / \mathrm{ml})$ after i.v. TRH $(5 \mu \mathrm{g} / \mathrm{Kg})$ were significantly $(p<0.01)$ higher in CF than in controls. Circulating $T 3$ and TBG concen trations were not different in the 2 groups. In CF group a significant relationship was found between $T 4$ and $r T 3$ values $(r=0.65)$, which were both negatively correlated to $\triangle$ ISH $(r=-0.54$ and -0.64 , respectively). No correlation was observed between T4 and TBPA levels. Such a biochemical pattern is consistent with a compensated hypothyroid status. Recent reports indicate that thyroid function way be influenced by zinc plasma concentrations (Hartona, Nutr. Metab. 23, 294, 1979). Nevertheless, no significant correlation $(r=0.33)$ was found in our CF patients between thyroid function tests and serum zinc levels, which were lower in CF than in controls ( $94+11$ vs $114+19 \mu \mathrm{g} / \mathrm{dl} ; \mathrm{p}<0.01)$, according to other reports ( cfr. Gordon, J. Pediatr., 99, 341, 1981 ).

102

F. DE LUCA*, F. TRIMARCHI*, M. GEMELLI*, G. BARBERI0*, G. DI PASQUA LE* and G. Magazzu'* (Intr. by G. Giovannelli). - 2nd Department of Pediatrics, Policlinico Universitario, Messina, Italia.

Thyroid function impairment in Coeliac Disease $(\mathrm{CD})$

Tertiary hypothyroidism (Vanderschueren et al., Clin. Endocr., 6, 361, 1977) and low T3 syndrome ( $T$ rimarchi et al., Ann. Endocr., 39, 149, 1980) were occasionally reported in $C D$. In the present report thyroid status has been investigated in 14 coeliac children ( $1-10$ yrs), diagnosed by ESPGAN criteria. Only 5 of them presented normal thyroid function tests. Two exhibited the typical biochemical pattern of primary hypothyroidism ( 143.3 and $4.3 \mu \mathrm{g} / \mathrm{dl}$, respectively; 1350 and $75 \mathrm{ng} / \mathrm{dl}$; TSH 22 and $10 \mu \mathrm{IU} / \mathrm{ml}$ ) reversible on gluten-free diet. Serum ISH hyperresponsivity to i.v. TRH $(5 \mu / \mathrm{gg})$ was the only biochemical abnormality in 5 patients ( $\triangle T S H 29$ to $51 \mu \mathrm{IU} / \mathrm{ml}$ ). In the other 2 enhanced TSH pituitary reserve ( $\triangle \mathrm{TSH} 46$ and $55 \mu \mathrm{IU} / \mathrm{ml}$ ) was associated to marginally high basal TSH values (11 and $9.4 \mu(\mathrm{U} / \mathrm{m} 1)$ and to low-normal serum $T 4$ concentrations. In a 7 yrs old girl, referred to our Unit because of short stature, such biochemical findings initially suggested the diagnosis of mild primary thyroid impairment, but thyroxine treatment was uneffective to improve growth rate throughout a 2-year period. As diagnosis of CD was successively assessed on the basis of small bowel biopsy result and gluten-free diet was started, growth spurt and normalization of thyroid function tests were observed, parallely with the gut mucosa damage recovery.

103

Z. DICKERMAN, R. PRAGER LEWIN* and Z. LARON. Inst. Pediat. \& Adolesc. Endocrinol., Beilinson Medical Ctr. \& Sackler School of Medicine, Tel Aviv University, Israel.

Low immunoreactive gonadotrophins (IR-Gn) in normal puberty.

Inappropriately low basal levels of IR-Gn and a low response in consecutive ( $q 6 \mathrm{mos}$ ) LH-RH tests $\left(50 \mathrm{mcg} / \mathrm{m}^{2}\right.$, i.v.) corresponding to prepuberty, were observed in 7 boys with normal puberty.

\begin{tabular}{|c|c|c|c|c|}
\hline $\mathrm{mea}$ & $\pm S D$ & H $(\mathrm{mIU} / \mathrm{m}$ & & \\
\hline & Basal & Peak & Basal & Peak \\
\hline $\begin{array}{l}\text { Repeated } \mathrm{z}^{\mathrm{H}-\mathrm{RH}} \text { tests } \\
\left(50 \mathrm{mcg} / \mathrm{m}^{2} \text {, i.v. }\right.\end{array}$ & $0.6 \pm 0.4$ & $1.7 \pm 0.7$ & $0.8 \pm 0.4$ & $1.2 \pm 0.6$ \\
\hline $\begin{array}{l}\text { LH-RH infusion } \\
(500 \mathrm{mcg} / 3 \mathrm{hrs})\end{array}$ & $0.7 \pm 0.4$ & $2.2 \pm 0.5$ & $0.6 \pm 0.2$ & $1.5 \pm 0.2$ \\
\hline
\end{tabular}

The basal plasma testosterone $(T)$ levels and its response to HCG tests $(1500 \mathrm{U} \times 3)$ were appropriate for the clinical stage of puberty. In 4 boys in their final pubertal stages, an LH-RH infusion test ( $500 \mathrm{mcg}$ over $3 \mathrm{hrs}$ ) did not increase the IR-Gn level over that found in the standard $\mathrm{LH}-\mathrm{RH}$ tests, but the T level increased from $399+89$ to $525+125 \mathrm{ng} / \mathrm{d} 1$ ( $\mathrm{p} 0.01$ ) indicating normal sensitivity of the Leydig cells to endogenous LH. This rare phenomenon possibly due to an altered set point of Gn regulation and action is of diagnostic interest and practical importance.
104 B. GODÓ ${ }^{*}$, CS. FAZEKAS ${ }^{*}$ and E. SÓLYOM ${ }^{*}$ (Intr. by H.K.A. Visser). Dept. Pediatr. Municip. Hosp. Békéscsaba and Miskolc, Hungary.

Adrenal stimulation test for the detection of heterozygous carriers of 21-hydroxylase deficiency (congenital adrenal hyperplasia; CAH)

The frequency of heterozygous carriers of $\mathrm{CAH}$ in various parts of the world has been studied. In Switzerland for example it is $1: 62$, in Maryland $1: 125$ and in Alaska $1: 19$. In the majority of the cases the enzyme defect is localized in the steroid 21-hydroxylase. Some data have been published on the plasma 17-hydroxyprogesterone levels (17-HP) observed in obligatory heterozygotes after ACTH stimulation: Compared to normal controls, 17-HP in carriers rises to higher concentrations. We studied six set: of parents (age: 18-31 years) of children with CAH due to 2l-hydroxylase deficiency. At the time of this investigation they did not receive any medication. Blood samples were obtained before the $i . v$. injection of synthetic ACTH (Cortrosyn) and at $t=30,60$ and 90 min following ACTH administration. Plasma 17-HP and cortisol levels were measured by radioimmunoassay. The ratio of 17-HP/ cortisol also has been calculated. Compared to literature data on normal controls, we found in six gene carriers (from six families) elevated 17-HP levels. The basal levels of 17-HP in the other six gene carriers were normal, but after ACTH loading increased sharply.

A.GRtगTERS* , P.BEYER* , G.ETBS* S.KORTH-SCHUTZ and 105 B. WEBER.Children's Hospital, Free University of Berlin (Wesc), Germany.

Changes of DS,Cortisol and Thyroxine Levels in Sick Premature and Fullterm Infants.

Dehydroepiandrosteronsulfat (DS), Cortisol (F) and Thyroxine (T4) were measured in 44 sick premature and fullterm newborns. In 10 newborns a longitudinal study from day 1 to day 55 of life was possible. We wanted to correlate the stress response of the fetal adrenal cortex(DS), of the adult adrenal cortex(F) and of the thyroid gland $\left(\mathrm{T}_{4}\right)$ to gestational age.DS levels showed a negative correlation to gestational age,but exceeded at any time of the longitudinal study the values found in non-stressed newborns.F levels showed no correlation to gestational age and did not exceed the values found in healthy newborns.

\begin{tabular}{cccccccccc} 
Cest.Age & \multicolumn{2}{l}{$27-29 \mathrm{w}$} & $30-34$ & $\mathrm{w}$ & \multicolumn{2}{l}{$35-37$} & $\mathrm{w}$ & \multicolumn{2}{c}{$38-40 \mathrm{w}$} \\
\hline Day & DS & F & DS & F & DS & F & DS & F \\
$1-5$ & 5157 & 40,3 & 3366 & 27,5 & 3967 & 39,8 & 3612 & 46,5 \\
$10-15$ & 2539 & 21 & 1843 & 9,2 & 1975 & 25,3 & 972 & 35,6 \\
$25-30$ & 2383 & 21 & 1827 & 13 & 2290 & 30 & 646 & 41 \\
$40-50$ & 2023 & 30 & - & - & 964 & 18 & - & - \\
\hline
\end{tabular}
were more sustained in the prematures and correlated well with changes in the clinical status. $T_{4}$ levels were very low $(k 5 \mathrm{~g} / \mathrm{dl}$ ) during the first two weeks of life, but increased with improvement of illness. We conclude, that in premature and fullterm infants the adrenal can respond adequately to stress,but there is a lack of $\mathrm{T}_{4}$ secretion in severe non-thyroid illness.

\section{D.GUPTA,N.MUNSTER ${ }^{+}$and R.LAICHINGER ${ }^{+}$} Department of Diagnostic Endocrinology, University Children's Hospital, 74 Tübingen,FRG

Endocrinological correlates of prenatal alcohol exposure in male rats when pubertal and adult.

Since the pioneer investigations of Stockard(1912, $1916,1918,1932$ ) with regard to in utero exposure to alcohol in mammals the issue continues to foster large number of studies and has gathered new dimension because of observed malformations in human offspring. The present protocol involved a model to examine:1) two different periods (from 15 day before to throughout pregnancy, and only during the pregnancylof alcohol administration, 2) two selected doses of alcohol $(2 \mathrm{~g} / \mathrm{kg}$ and $6 \mathrm{~g} / \mathrm{kg} \mathrm{b.w.),3)} \mathrm{examination} \mathrm{of} \mathrm{body} \mathrm{weight,} \mathrm{testicular}$ weight, serumLH,FSH, TSH, T and DHT in male of $f$ springs when pubertal ( 35 day) and adult ( 90 day). The results show the teratogenicity and embryotoxicity in the rat do not parallel those observed in human situation. For testes wt, body wt and gonosomatic index only the pubertal group with low dose of alcohol exposure shows significant $(p<0.01)$ decline while the other groups do not show any difference. Serum concentrations of $\mathrm{LH}$ and $\mathrm{T}$ are also significantly $(p<0.01)$ lower in the pubertal group than those in the control group. Serum FSH and TSH in the pubertal group, and all the parameters in the adult groups remain normal indicating neither hormonal irregularities nor any"superior types"(Stockard,1922) among the offsprings. 
R. HATIER* and G. GRIGNON* (intr. by M. PIERSON) . Laboratoire d'Histologie-Embryologie-Cytogénétique, Facul té de Médecine, B.P. 184, 54505-Vandoeuvre-lesNancy, France.

Sertoli cell development in the absence of germinal cells in the rat.

When rats are irradiated at the end of the foetal life, the seminiferous tubules whose lumen appear lately (at the end of the 5 th week of post-natal life) contain only Sertoli cells; these cells differentiate normally during the first month: junctional complexes, size and aspect of the nucleolus, endoplasmic reticulum, mitochondria, Golgi apparatus...etc: however they present an unusual development of the cytoplasmic apical processes with numerous microtubule bundles.

The height of the Sertoli cell diminishes after this period, the processes are retracted. Cell organelles are less numerous while the elements of the endoplasmic reticulum are dilated and the number of microfilaments in the basal cell part and around the nucleus is increased. The basal lamina of the seminiferous epithelium appears multilayered. The myoid cells of the tunica propria are bordered by very thickened basal ] aminae.

These observations suggest that the differentiation of the Sertoli cells is independent of the presence of germinal cells during the first post-natal month while the plasmatic FSH rate is not yet increased. The observed a] terations happen in contrary at the same time as the increasing of the FSH rate.

108 I.D. HAY*, A.W. ROOT* and A.B. HAYLES* (Intr. by I. Hughes). Mayo Clinic, Rochester, Minnesota and All Children's Hospital, St Petersburg, Florida, USA. Defective pituitary gonadotropes in the pubertal failure syndrome associated with $x$-linked congenital adrenal hypoplasia.

Patients with $\mathrm{X}$-linked congenital adrenal hypoplasia (XCAH) fail to spontaneously enter puberty (Axch Dis Child 56:715, 1981) because of an associated hypogonadotropic hypogonadism (HH). Although luteinising hormone-releasing hormone (LRH) deficiency has been implicated, the anatomic location of the defect is unknown. To further investigate we studied two affected brothers both by a repetitive LRH infusion protocol (JCEM 48:864, 1979) and by measuring urinary immunoreactive (i) LRH-like material (JCEM 52:1150, 1981). In both subjects (at ages 21 and 18 years) mean basal serum LH was $2.7 \mathrm{mIU} / 1$ (normal 3-18). After iv LRH maximal LH increments were 1.1 and 0.0 . After 7 days of LRH infusions serum testosterone in both was detectable at 2.3 and $2.6 \mathrm{nmol} / 1$ (normal basal >10.5); basal LH levels (mIU/l) were 4.4 and 2.8. Repeat LRH testing revealed LH increments of 2.8 and 5.4 (normal 20-110). Basal urinary excretion of iLRH-like material was 10.19 and $8.03 \mathrm{ng} / 24 \mathrm{~h}$. Although $\mathrm{LH}$ responsiveness increased after repetitive LRH infusions, the LH incremental responses were clearly not normalised. Moreover, the levels of iLRH-like material found in the boys' urines were in the range for normal adult males. It would therefore appear unlikely that in XCAH hypogonadism results from LRH deficiency. Rather, it is probable that the primary defect in gonadotxopin secretion resides at the level of the pituitary gland.

109 P.H.HEIDEMANNX, P. STUBBE, G. and C. MOLLER-ECKHARDTX. Depts. of Pediatrics and Clin. Immunology, University of Göttingen and Giessen, FRG.

Hashimoto's thyreoiditis (HT): Incidence in children and in Turner's syndrome and possibie association with HLA-DR5 antigen. HT is an autoimmune disease caused by a dysfunction of immune response regulation. HT is a rare disease in childhood, but its incidence is known to be high in Turner's syndrome for unknown reasons. Recentiy, Weissel et a1. (Tissue Antigens, 1980) reported on an association between HLA-DR5 and HT in adults. In a study of 1718 boys and girls, aged 6-16 years, we found the overall incidence of the hypertrophic variant of HT to be $0.29 \%$ with a clearly female preponderance. $9(27,2 \%)$ out of $33 \mathrm{pa}-$ tients with Turner's syndrome exhibited elevated autoantibodies against thyroglobulin and/or microsomal antigen indicating HT. 7 had euthyroid, symptomless HT whereas 2 had hyperthyroid goiters and HT proven by biopsies. HLA-A, B, C and DR typing was carried out by standard lymphocytotoxicity tests in a tota? of 14 goitrous girls with HT (group I) and 25 patients with Turner's syndrome including 6 with HT (group II). In group III we enclosed the 14 girls of group I and 6 patients with positive thyroid autoantibodies and Turner's syndrome. We could not find any significant correlation between various HLA antigens and HT, but the frequency of HLD-DR5 antigen appeared to be increased in HT. The frequency of HLA-DR5 was $25.5 \%$ in heal thy controls $(n=206), 42.8 \%$ in group I, $20.8 \%$ in group II and $45.5 \%$ in group III. Further studies in children are necessary to conf irm the data published by Weissel et al..

\section{K. HERKNER*, H. FRISCH and W. SWOBODA}

LBI for Paediatric Endocrinology, Vienna, Austria.

The Androgen Excretion Pattern of Cryptorchid Boys After hCG Stimulation.

21 boys (age 0.5 to 18 yrs) with crytorchidism (uni- and bilateral) and with "anorchia" received a 3 days hCG stimulation test (2000 to 5000 IU i.m. per day). $24 \mathrm{hrs}$ urine collections were examined by capillary gas chromatography (multi column system). 12 compounds, mainly steroids of testicular origin and their metabolites, were determined. Plasma testosteron ( $T$ ) and dihydrotestosteron (DHT) were measured by RIA before and at the end of the hCG stimulation. Based on the excreted amounts of $5 \beta$-androstane$3 \alpha, 17 \beta$-diol ( $\beta$-diol), DHT and the combined amount of $T$ and androstenedion $(A)(T+A=$ "androgenic pool"), before and after $h C G$ stimulation, 3 groups of patients could be separated: (1) Significant increase of $\beta$-diol (coeffic. 1.5 or more), DHT and $T+A$ remained in normal range. (2) Increase of $B$-diol moderate (coeff. 1-1.5), DHT as well as $T+A$ excretion rising slightly above normal, and (3) no increase of $\beta$-diol (coeff. below 1), but higher excretion of DHT and $T+A$. Correlation of these findings with plasma T values was usually but not always good. Correlation with clinical findings suggested, that group 1 (mild unilateral testicular retention) might give a good prognosis, while group 2 could be called "intermediate", and the cases of so-called "anorchia" were found in group' 3 . We conclude that our findings might be of significance for clinical prognosis of these patients.

111 M. MIKATI* K. YUNIS* and S. NAJUAR Department of Pediatrics, American University of Beirut - Lebanon

Multiple daily insulin injections through a subcutanecusly implanted needle.

To achieve near normal glycemia, improve compliance, and obviate the inconveniences, cost and inherent dangers of the newer "pump" devices, multiple daily injections of insulin through a subcutaneously (sc) implanted needle as described by Slama etal. (Lancet $1980 i$ 1078) was used. This consisted of the adninistration of short, with or without, intermediate acting insulin preparations before breakfast, lunch and dinner. Twenty one patients with Insulin Dependent Diabetes Mellitus (IDDM), 6 newly diagnosed (NC) and 15 previously classically treated (OC), were offered this form of therapy. Six OC and one NC, all boys, stopped using it after a short trial period, the mean follow up was 6 months (range 2-14 months). Control of IDDM was assessed by concentrations of glycosylated hemoglobin in plasma $\left(\mathrm{Hb}_{\mathrm{t}}\right)$ every 2 to 3 months. Near normal levels were maintained in the newly diagnosed patients, HbA, $\bar{x} 8.7 \%$, range $5.3-13.2 \%$ (the $\bar{x}$ before treatment was $12.8 \%$, range 8.9-16.6\%). In the $O C \mathrm{BDA}$, dropped from $\bar{x}$ of $12.3 \%$ (range $9.5-$ $15.5 \%$ ) to $\bar{x} 9.8 \%$ (range $6.9-14.3 \%$ ) $(P<0.005)$. Minor local reactions in the form of erythema at the site of the needle in most, and multiple small s.c. abscesses in two, occurred, but were obviated by changing the needle every other day without the use of antibiotic therapy. Our data suggest that the use of a sc implanted needle is a cheap and convenient altemative to achieve long term control in some patients with DDM.

112 P.J.OERTEL*, K.LICHTWALD* and W. RAUH Depts. of Pediatrics and Pharmacology, Univ. of Heidelberg, F.R.G.

Plasma gonadotropins and gonadal hormones in prepubertal boys with chronic renal failure (CRF).

Delayed pubertal development in boys with CRF may primarily be due to gonadal dysfunction, increased plasma binding of testosterone (T), and disturbance in the hypothalamo-hypophyseal axis. We studied basal plasma

gonadotropins, $T$, percent free $T$, dihydro-T (DHT), and the response of LH and FSH to LRH $\left(50 \mu \mathrm{g} / \mathrm{m}^{2}\right)$ in 17 prepubertal boys (5-12 years) with preterminal CRF (serum creatinine $4.7 \pm 2.2 \mathrm{mg} / \mathrm{dl}, \mathrm{M}+\mathrm{SD}$ ). Controls (C) consisted of 21 prepubertal boys with constitutional short stature. Basal LH was elevated in CRF compared to $\mathrm{C}(1.1+0.5 \mathrm{vs} .0 .5+0.2 \mathrm{ng} / \mathrm{ml}, \mathrm{p}<0.01) ; \mathrm{FSH}$ did not differ significant $\overline{t y}$. In CRF $T(9.3+7.5 \mathrm{ng} / \mathrm{ml})$ was slightly lower than in C (n.s.). Percent free T (CRF: $2.4+0.5 \%$ ) and DHT (CRF: $5.2+3.8 \mathrm{ng} / \mathrm{ml}$ ) were similar in both groups. After LRH the difference between basal and peak values and the calculated stimulation areas were significantly smaller in CRF. Conclusions: In $\mathrm{CRF}$, low $\mathrm{T}$ in the presence of increased $\mathrm{LH}$ indicates Leydig cell dysfunction already before puberty. In addition blunted LH and FSH response to LRH suggests a hypothalamo-hypophyseal disturbance. Despite dysproteinemia in CRF the plasma binding of $\mathrm{T}$ is unchanged. 
Retarded testicular descent and hypophyso-gonadal axis in premature newborns.

Premature newborns provide a model to study the changes of LH,FSH and testosterone secretion in relation to testicular descent.15 cryptorchid premature newborns (gestational age 28-35 weeks), who had testicular descent before 6 month of age,were compared with a control group of 15 premature of the same gestational age. The serum levels of testosterone, LH and FSH were evaluated longitudinaly by RIA at 12-14 hours, 1-4 weeks, 5-8 weeks, 9-12 weeks and 16-2O weeks of age.No difference was observed in the behaviour of LH and FSH between the two groups.Significantly(p<0.001)higher levels of testostcroric were observed at 1-4 weeks in the control group (1.699$0.720 \mathrm{~g} / \mathrm{ml}$ ) than in cryptorchids patients $(1.183-0.656)$. After this time the two groups had no significant difference in the mean levels of testosterone too. In both groups the serum levels of testosterone and LH were significantly(control $r=58.83 \%, p<0.01$; cryptorchids $r=27.99 \%, p<0.05$ ) correlated.

In conclusion the delayed descent of testicle observed on most premature newborns may be correlated to their lower testosterone serum levels in the early weeks of life.

114 F. PÉTER, J. KOVÁCSX and L. BLATNICZKYX Buda Children's Hospital and "Heim Pál" Children's Hospital, Budapest, Hungary

Blunted growth hormone release after insulin-induced hypoglycemia(IIH) in children with defective galactose metabolism and growth retardation.

The cause of the growth retardation in disorders of galactose metabolism is obscure. We have studied $\mathrm{GH}$ responses to provocation in 13 children with abnormal galactose tolerance, as measured with Phadebas HGHPRIST and a galactose oxydase method. All children had significant growth $(2,4-4,1$ SD) and bone age ( $1-4 \mathrm{Jr}) \mathrm{re-}$ tardation and thin radial metaphyseal band width (Pediat Res.15:90,1981). All children increased plasma GH levela $>7 \mathrm{ng} / \mathrm{ml}$ in one of two provocative teats. However, 8 of 13 children failed to respond to IIH despite mean blood glucose concentration of $1,8 \mathrm{mmol} / 1$ at $30 \mathrm{mi}-$ nutes, and severe symptoms in 6 cases. GH response in 11 children was normal in a combined Somatogtatin-DOPA test(Pediat.Reg.12:1094,1978). Bagal GH level in 4 patients was $>7 \mathrm{ng} / \mathrm{ml}$. Conclusions: 1 . Repeated spontaneous attacks of hypoglycemia may cause a failure of GH secretion after IIH. This test is not useful in patients with conditions leading to recurrent hypoglycemia. 2. GH deficiency cannot be the explanation for growth retardation in children with defective galactose metabolism.

\section{R.PUUKKA, M. PUUKKA ${ }^{X}$, M.KNIP ${ }^{X}$, P.LAUTALA ${ }^{X}$ and L.PERKKILA ${ }^{X}$} (intr. by H.K.Akerblom). Departments of Clinical Chemistry and Paediatrics, University of Oulu, Finland Erythrocyte insul in binding in normal infants, children and adults To establish normal insulin-binding cri ieria, we studied the binding of insulin to erythrocytes from normal subjects (16 term deliveries, 32 infants, 32 prepubertal and 16 pubertal children, and 20 adults). Insul in binding to cord erythrocytes or to erythrocytes from infants (aged 2-7 days) was significantly higher at tracer and physiological insul in concentrations than was binding to cells from children (aged 1-16 years) and adults. In infants aged 1-12 months the maximum insulin binding capacity of erythrocytes was significantly higher than that of erythrocytes from children. In infants there was a negative correlation between age and both maximum insulin binding and receptor concentration. Insulin binding to erythrocytes from pubertal children was significantly lower than that in adults. Erythrocytes from men bound significantly higher amounts of insulin than did those from women.

The major change in erythrocyte insulin binding occured during the first year of 1 ife, although there was an overall nenative correlation between the maximum insulin binding and age in the subjects studied. The increased insulin binding to cord erythrocytes and to erythrocytes from infants appeared to be due to both increased receptor concentration and to an increase in receptor affinity, while differences in erythrocyte insulin binding between adult men and women were a result of changes in receptor affinity.
Child's Heelth Center, Varsay, Poland. Growth hormone (GH) autoregulation in uremic patients.

Growth hormone was estimated after oral clonidine by double isotope technique in 7 growth retarded nonhyposomatotropic hildren /group AT, in 5 patients with uremia, serm creatinine $>5 \mathrm{mg} / \mathrm{dl}$ (group B), in 12 growth retarded non-hyposomatotropic children with elevated basel GH level matchig the basal values found in patlents of group B (group C).All examinations meet local ethical committee approval. Following mean values were obtained (ng/ml):

$\begin{array}{lccccr}\text { minutes } & 0 & 30 & 60 & 90 & 120 \\ \text { group A } & 1,5 & 2,3 & 14,5 & 11,5 & 8,3 \\ \text { group B } & 10,2 & 16,2 & 14,9 & 11,1 & 9,6 \\ \text { group C } & 11,0 & 4,8 & 7,6 & 13,0 & 11,9\end{array}$

The $30-$ and $60-\mathrm{min}$ values in the urenic children are significantly higher than the corresponding values in the patients of group $C$. In all uremic patients there was an increase of GH value as soon as 30 minutes after clonldine administration. This 18 not the case in group $A$ and 18 contrary to findings in group $C$. The decrease of 30 min value and late peak value in group $\mathrm{C}$ is attributed to the $\mathrm{GH}$ autoregulation mechanism. Early increase of GH level in groum B suggests an abolishment of this mechanism in uremia.

\section{G.F.RONDANINI*,F.FOCARILE*,A.BARTOLUCCI*and G.CHIUMELLO taly} Free thyroid hormones: a better index to monitor the "thyroid state" in hypothyroid children.

Free thyroid hormones (FTH) have been shown in actults as the best indicators of thyroid function. We have investigated 29 congenital hypothyroid children, involved in a follow-ip program, based on hormonal monitoring of therapy and endocrine, neurological, psycological, $\propto$ culistic and audiometric periodic controls, all directed to a better assessment of substitutive therapy and a precocious detection and treatment of disease-related sequelae. We have found: 1) a low con relation between FT3 and T3, FT4 and T4, FT4 Index (10 x T4/TBG) and FT4. Since FIH are the major determinants of the "thyroid state", the low correlation found between "free" and "total"hormones show that T3 and T4 measurements cannot be considered an adequately sensitive index of thyroid state, while FTH may be . 2) In patients "adequately treated" (as shown by the follow-ip program assessment) with high ISH levels, FTH were in the low-nomal range; in patients with nonmal TSH levels FTH were in the high or nombl-high range; the difference was significative $(p<0.001)$. Total homones did not vary in the two groups. In other words FTH correlated inversely with TSH levels, while total homones did not at all. This suggests that total hormones do not show an adequate picture of the thyroid state of the patients, being unable to distinguish between high and normal TSH levels in patients adequately treated, thus leading to an overtreatment (as shown by FTH levels). Moreover in patients clinically undertreated with high TSH but normal total hormones levels, low FTH concentrations confirmed an inadequate substitutive therapy.

\section{W.ROSENDAHL ${ }^{+}$,M.B.RANKE, J.R.BIERICH} Children's Hospital, University of Tübingen, FRG

Improvement of height with anabolic steroids in Turner's syndrome?

It is suggested that treatment with mild androgens improves height prognosis in Turner's syndrome(TS) by stimulating growth velocity without unduely advancing bone age(BA). An assessment of this approach to treatment thus depends on an accurate determination of $B A$.

15 patients with TS $(45, \mathrm{XO}, \mathrm{N}=6 ; 9$ variants $)$ aged 8.1 15 years were treated with methenolone for 6 to 39 months. BA were determined by two trained persons independently according to Greulich-Pyle (GP) and TW2 (RUS) : Growth velocity(GV) improved in all girls under 15 years of age during the first year of treatment and decreased thereafter.GP-BA were systematically below RUS $(-15,7 \pm 8,1$ months; $N=88)$. The TW2 method allowed a more precise determination of small changes in bone maturity with a variability between investigators of $3,22+2,89$ months compared to GP with $5,88+6,24$.During treatment GV per GP-BA year were increased, but unchanged based on RUS-BA.

Conclusions: Structural abnormalities in bones of patients with TS render BA determinations difficult. The application of the GP method appears questionable. The beneficial effect of anabolic steroids may be virtual and a result of difficult BA determinations. 
119 J. SACK, Z. KRAIEM ${ }^{*}, M \cdot$ LISSON $^{*}, M$. BRISH $^{*}$, Sheba Medical Center and Carmel Hospital, Israel.

Serum cortisol levels in fullterm, premature and overweight newborns.

Our recently developed micromethod for the radioimmunoassay of cortisol in heel-prick blood samples collected on filter paper enabled the determination of cortisol concentrations in full term, premature and overweight $(>4 \mathrm{~kg})$ neonates. Serum cortisol levels $(\mu \mathrm{g} / \mathrm{d} \mathrm{l})$ at various intervals following birth were (mean \pm SEM, $n)$ : Fullterm: $\frac{1}{2} \mathrm{hr}: 17.2 \pm 1.7(n=16)$; $1 \mathrm{hr}: 16.4+1.3(n=20) ; 2-4 \mathrm{hr}: 10.4+1.0^{-}(n=9) ; 4-8 \mathrm{hr}:$ $11.2+1.1(n=16) ; 8-16 \mathrm{hr}: 9.8+0.87 \mathrm{n}=15) ; 16-24 \mathrm{hr}:$ $8.7 \pm 0.8(n=23) ; 24-36 \mathrm{hr}: 9.7 \mp 0.9(n=8) ; 36-48 \mathrm{hr}:$ $9.5 \pm 1.5(n=8) ; 3-10$ days: $9.0 \mp 1.0(n=27)$. Premature: $\frac{1}{2} \mathrm{hr}: 19.7 \pm 2.3(n=12) ; 1 \mathrm{hr}: 15.1 \pm 2.1(n=12) ; 16-24 \mathrm{hr}$ : $10.7 \pm 1.2(n=14) ; 3-10$ days: $7.9 \pm 0.8(n=10)$.

Overweight: $4-8 \mathrm{hr}: 8.7 \pm 0.8(n=26) ; 16-24 \mathrm{hr}: 5.7 \pm 0.4$ $(n=30)$. The data demonstrate that: 1. The high transient cortisol levels in the fullterm neonate drop abruptly

$(p<0.001) 1-2 \mathrm{hr}$. postnatally and remain essentially unchanged $(p>0.05)$ thereafter. 2. No significant difference $(p>0.05)$ in cortisol levels was found in premature compared to fullterm newborns. 3. Cortisol levels were significantly lower $(p<0.01)$ in overweight newborns.

\section{D.C.L.SAVAGE, J.H.BAOUGRE J.DRAKEFORD*and} J.WADSWORTH: Bristol Royal Hospital for Sick Children. Bristol, U.K.

Effects of fibre, beans and exercise on diabetic control. 21 insul in-dependent diabetic children completed four different breakfasts, given in rando order. Three diets differed in fi bre content. The fourth diet contained soys beans as part of the dietary fibre souree. Children collected capillary blood samples onto filter paper strips which were analysed for blood glucose content. Each morning children exercised vigorously for an hour and rested for an hour, resulting in comparable rest and exercise perlods for each child. Yean inftial blood glucoses on the four diets were not significantly different. The low fibre diet resulted in higher blood glucoses af ter breakfast than the medium and high fibre diets. Blood glucose on the high fibre diet did not differ from that on the medium fibre diet. The bean diet produced lower mean blood glucoses than with other diets up to 2 hours af ter breakfast; the smallest drop in blood glucose in the hour before lunch occurred on this diet. All the children found the bean diet unacceptable. Most of them liked the hich and medium fibre diets, and the low fibre diet was the most popular. Brercise had no effect on blood glucose. The potentially major benefits from beans are linited by their unpalatability. The more acceptable cereal fibre produces a relatively smaller benefit.

\section{E.SCHOBER* , H.FRISCH, H.VIERHAPPER* W.WALDHÄUSL*. PaediatriC Dept., 1.Med.Dept., LBI Paed.Endocrinology University Vienna, Austria.}

Plasma renin concentration (PRC) in patients with "non-salt losing" virilizing adrenal hyperplasia ( $C A H)$.

To evaluate a possible minute derangement in sodium balance and hence the possible necessity for mineralocorticoid substitution, PRC (supine and 2 hours upright) was determined in 9 sodium loaded $\left(232 \mathrm{mmol} / \mathrm{m}^{2} / d\right)$ patients with $C A H$, aged 5.1-13 yrs. patients were clinically classified as non-salt losers. PRC was determined radioimmunologically and expressed as Goldblatt Units (GU) $\times 10^{-4} \mathrm{ml}^{-1}$. Informed consent for the studies was obtained from the parents. In patients off cortisol replacement therapy for four days $P R C$ was highex than in 8 age matched healthy controls (supine: $3.3 \pm 0.5$ vs. $1.2 \pm 0.2(\bar{x} \pm$ SEM), pro.001; stimulated: $8.6 \pm 2.5$ vs. $2.4 \pm 0.4$, p 0.05 ). Upon treatment with dexamethasone $\left(1 \mathrm{mg} / \mathrm{m}^{2} / d\right)$ patients with $\mathrm{CAH}$ presented with a fall in basal $(2.1 \pm 0.5)$ but not in stimulated $(8.8 \pm 2.6)$ $P R C$. When dexamethasone-therapy was supplemented by $9 \times$ fluorohydrocortisone $10.1 \mathrm{mg} / \mathrm{m}^{2} / d$ for three days and $0.2 \mathrm{mg} / \mathrm{m}^{2} / \mathrm{d}$ for three days) both supine $(0.9 \pm 0.1)$ and stimulated $(1.6 \pm 0.3)$ $P R C$ was suppressed into the normal range. These results argue against a mineralocorticoid resistance and for subclinical. ACTH-dependant sodium loss as an explanation for the elevation of PRC in "non-salt losing" CAH. Mineralocorticoid therapy may therefore be advocated in patients with non-salt losing CAH and high PRC.

\section{S.M. SHALET and D.A. PRICE}

Christie Hospital and Royal Manchester Children's Hospital, Manchester, Engl and

HCG-secreting pineal tumour and precocious puberty.

Ten year old boy presented with headaches, vomiting and moderately advanced pubertal maturation (pubic hair stage 4; genitalia stage 3 ; testes $4 \mathrm{mls}$ ). CAT scan showed an enhancing lesion suggestive of a tumour in the region of the pineal gland. At craniotomy the tumour was biopsied only. Germinoma of the pineal was diagnosed histologically. Primary therapy consisted of a course of whole CNS irradiation. Before irradiation he had an advanced bone age, very high BHCG level (1255 iu/L), raised $\propto$ foetoprotein level of 84 units/ml and a testosterone level $(28.4 \mathrm{nmol} / \mathrm{L})$ in the high normal adult male range. By the end of his radiation course the CAT scan showed no evidence of abnormal enhancement, the BHCG, $\alpha_{\text {foetoprotein }}$ and testosterone levels had fallen to $<1 i u / L,<12$ units/mi and $1.7 \mathrm{nmol}$ respectively. The basal FSH and LH levels were $<2$ and $4 i u / L$ and rose to 3 and 11 $\mathrm{iu} / \mathrm{L}$ after LHRH. It is now 1 year post-irradiation and the boy is in excellent health. The BHCG and < foetoprotein levels remain undetectable but the testosterone level has risen to $13 \mathrm{nmol} / \mathrm{L}$ consistent with his pubertal development. We conclude that 1) germinomas of the pineal are exquisitely radiosensitive and radiotherapy is the treatment of choice for this lesion. 2) In a boy with a pineal lesion and precocious puberty a high BHCG level predicts the diagnosis and surgery is unnecessary unless a shunt is required. 3) Tumour products such as BHCG and $\alpha$ foetoprotein provide excellent markers for monitoring the patient's progress.

\section{N.STAHNKE, E.STENZEL*,G.SINNECKER*,H.H.HELLWEGE* Dept. of Pediatrics, University of Hamburg, FRG Thyroid function in sick newborn infants}

31 sick newborn infants were studied so far :15 infants with respiratory-distress syndrome (RDS) (gestational age 31-35 weeks, birth weight 1180-277o g), 6 infants with fetal erythroblastosis (FE) (gestational age 34-42 weeks, birth weight 2370-3810 g) and 10 small-for-gestational age (SGA) infants (gestational age 34-40 weeks, birth weight 1210-2345 g). $\mathrm{T}_{3}, \mathrm{~T}, \mathrm{TBG}$ and TSH were measured by RIA and the TA/TBG ratio was calcufated. Blood samples were obtained from umbilical cord and at 24,72 hours and at 1,2,3 and 4 weeks following parturition. Age-matched well newborn infants served as control subjects.Laboratory hormone results were correlated with clinical data.

In infants with $F E$ there was a reduction in $T_{4}$, TBG values and $T_{4} / T B G$ ratios and an increment in TSH levels. - Following the first few days of life $S G$ A infants exhibited diminished $T_{4}$ values and $T /$ TBG ratios compared to age-matched controls.

During first days after birth R D S - infants showed a marked decrease in $\mathrm{T}_{4}$ and $T B G$ levels, thereafter these values rose aga in. For 3 weeks these patients had significantly lower $\mathrm{T}_{4}$, TBG Tevels and $T_{4} / T B G$ ratios compared to control group. $T_{3}$ values were likewise reduced. TSH levels were significantly above control values. -The difference between patients' and control hormone data was gradualiy getting smaller.

The depression of thyroid hormone levels in RDS-infants seems to be due to severe illness of hyaline membrane disease.

\section{P.G.F. SWIFT and J.M.S. JOINSTONE* (Intr. by:} D.C.L. Savage) Dept. Paediatrics and Paediatric Surgery, Leicester, England.

Controlled trial of GnRH for incomplete descent of the testis.

There has only ever been one double-blind controlled trial or hormone treatment for incompletely descended testes (Illig, 1977, Lancet). In that trial the four collaborating centres produced widely discrepant success figures ranging from $15 \%$ to $60 \%$. We have completed a randomised double-blind controlled trial on 22 prepubertal boys using an intranasal spray containing either active GnRH or inactive aerosol. The dose of GnRH administered was $300 \mu \mathrm{g}$ bd for 2 weeks, followed by $600 \mu \mathrm{g}$ bd for 1 week. Treatment with active GnRH spray on 11 abnormally placed palpable testes was associated with apparently improved position in four, no change in six and higher position in one. Inactive spray was associated with apparently improved position in five, no change in five and higher position in one. After receiving inactive spray the control group received the GnRH spray with apparent improved position in one,
no change in nine and higher position in one. The results suggest that $\mathrm{GnRH}$ in this dosage was not responsible for the apparent change in position of the testes and that the widely differing claims for success in the past might be explained on the basis of difficulties in evaluating testicular position! 
TATO' L., AVANZINI S.*, ROMELLI P.B.*, PENNISI F.* Pediatric Clinic, CASMT, University, Verona, RIA Department, Lepetit SPA,Milano - Italy.

Urinary thyroxine(T4) and triodothyronine(T3)excretion in congenital hypothyroidism( $\mathrm{CH})$

Renal excretion of $T 4$ and $T 3$ has a weak correlation to corresponding free hormone concentration in serum. To investigate further 7 $\mathrm{CH}$ newborns aged 20 days were studied before and after treatment with l-thyroxine $\left(150 \mu \mathrm{g} / \mathrm{m}^{2}\right)$. The $24 \mathrm{~h}$ urinary excretion of T3(UT3) and T4(UT4) and serum levels of FT4 and FT3 were determined by RIA before and after 3 days, 7 days and 1 month of treatment. Before After

$\begin{array}{lcccc} & & 3 \text { days } & 7 \text { days } & 1 \text { month } \\ \text { UT3 } \mathrm{ng} / 24 \mathrm{~h} & 69.17^{ \pm} \pm 22 & 78.32 \pm-15.37 & 86.94-20.76 & 139.06-30 * \\ \text { UT4 } \mathrm{ng} / 24 \mathrm{~h} & 89.57^{ \pm}-36 & 101.99 \pm 33 & 98.16-30 & 141.32-57.04 * \\ \text { FT3 } \mathrm{pg} / \mathrm{ml} & 2.98-1.4 & 4.9 \pm 1.2 * & 6.19 \pm 1.29 * * & 6.59 \pm 1.00 * * \\ \text { FT4 } \mathrm{pg} / \mathrm{ml} & 3.53^{ \pm}-1.7 & 3.04 \pm 3.94 * & 13.32 \pm 2.66 * * & 17.6 \pm-2.97 * *\end{array}$
After l-thyroxine a significant rise of FT3 and FT4 was obser since the third day. On the contrary a significant change in UT 3 and UT4 was seen only after 1 month of treatment. Serum and urine values were not significantly correlated. In conclusion our data suggest that thyroid hormones might promote maturation of their postulated tubular secretion system. $(* p<0.05 * * p<0.01)$
E. VICENS-CALVET, M.GUSTÑE, N. POTAU, L. AUDI, L. IBAÑEZ, M. ALBISU and A.CARRASCOSA. (Intr. by J. Perheentupa). Children's Hospital, Barcelona, Spain.

The effects of cyproterone acetate (CA) in precocious puberty (PP). 20 patients with $\mathrm{PP}(18$ of central origin and 2 of probable ovarian origin) were treated with $\mathrm{CA}$ in a mean dose of $102 \mathrm{mg} / \mathrm{m}^{2}$ body surface/day $(S D \pm 20)$ during $0.8-6.2$ yrs $(M=2.1 \quad S D \pm 3.2)$. The children were aged $1.4-8.3$ yrs.at the start of treatment $(M=5.1 \quad \mathrm{SD} \pm 2.2)$ and the sex distribution was 17 girls $/ 3$ boys. In all cases treatment was started during the first yr. of the appearance of clinical signs. The beneficial effects of $\mathrm{CA}$ on clinical signs (CS), height age/bone age (1), SDS. bone age-SDS. height (2), gonadotrophin secretions in the LH-RH test and the side-effects on the hypophyseoadrenal axis (cortisol and ACTH values after ACTH and metyrapone) were studied. CA exerted a clear be iefical effect on the CS. The parameters (1) and (2) remained at the same values or improved slowly throughout the treatment. The LH peak in LH-RH test decreased significantly in central cases. The cortisol increase after ACTH was normal in $18 / 20$ cases and the ACTH peak post metyrapone was normal in $15 / 20$ cases. Therefore using the above mentioned dose a beneficial effect is to be expected in PP without development of the adrenal insufficiency which has been observed by functional tests after a higher dosage of C.A.
126 M. THOMAS*, S. de MUINCK KEIZER*, S. DROP and H.J. DEGENHART. Sophia Children's Hospital, Gordelweg 160, Rotterdam, Netherlands. Effects of oral testosterone-undecanoate treatment in boys with delayed puberty.

8 boys with delayed puberty were studied. Age: 14,117,5 years; bone age: $12-13$ years; Tanner staging: $\mathrm{P}_{1} \mathrm{G}_{1}$; testisvolume: $2-3 \mathrm{ml}$. An LH-RH test showed a prepubertal response in $6 / 8$ patients; 2 patients had early pubertal responses. Testosterone undecanoate (TU) was given during 3 months $(1$ month $40 \mathrm{mg} / \mathrm{d} ; 2$ months $80 \mathrm{mg} / \mathrm{d}$ ). Serial plasma concentrations were measured of Sex-Hormone-Binding Glubulin (SHBG), testosterone (T), androstenedione, free testosterone and DHEAS. Dihydrotestosterone (DHT) was also measured using a novel separation technique for $T$ and $D H T$. SHBG showed a distinct decrease. The absolute values of the androgens showed wide variation but were found to be within the normal range. At the end of the $3 \mathrm{rd}$ month Tanner staging ranged from $\mathrm{P}_{2} \mathrm{G}_{2}-\mathrm{P}_{3} \mathrm{G}_{3}$ while testis volume had increased in $6 / 8$ patients to $4-6 \mathrm{ml}$. After TU was stopped, $7 / 8$ patients showed growth acceleration with further progression of puberty. SHBG values increased but androgen levels remained unchanged. It is concluded that oral TU in boys with delayed puberty is able to induce puberty. It has a distinct androgen effect, producing plasma $\mathrm{C}_{19}$-steroids within a physiological range.

127

VANELLI M*, BERNASCONI S., VIRDIS R.*, :OORI G.*, VOLTh $\mathrm{C}^{*}$, TORELli $\mathrm{F}^{*}$, GIOVANNElli G. - Dept. of Paediatrics University of Parma, Italy.

Micropenis treatment: topical vs systemic testosterone therapy.

Twelve prepuberal children (C), 3-14 yrs old, with penile stretch lenght (PL) $2.50+0.10 \mathrm{~cm}(\overline{\mathrm{x}}+\mathrm{SE}$ il) were treated with topical (1st group) or i.m. (2nd group) Testosterone (T).

1st group (6C): $5 \%$ T-propionate oil applied directly to the penis ( $8 \mathrm{mg} /$ day for 4 weeks).

2nd group (6C): $30 \mathrm{mg}$ of T-enanthate i.m. every 15 days to reach a $\mathrm{PL} \geq 3.5 \mathrm{~cm}$ (average dose: $45 \mathrm{mg}$ ).

RESULTS: Both topical and systemic $T$ therapy produced an increase of PL in all cases. At the enr uf therapy PL was similar in both groups $(3.87 \pm 0.35$ and $4.4 . \pm 0.11 \mathrm{~cm}) ; 6$ months later, however; it was greater in the and than in the 1st gioup $(4.53 \pm 0.28$ vs $3.35 \pm$ $0.17 \mathrm{~cm} ; p<0.002)$. Undesirable side effects were minimal and transitory in all cases. Serum $T$ values were higher in the 2nd jruup than in the 1 st ne $(1.60+0.06$ vs $0.43+0.13 \mathrm{ng} / \mathrm{ml} ; \mathrm{p}<0.002)$.

CONCLUSIOivS: By i.r. therapy a more longlasting effect has been observed which apsears to be correlated with the higher $x$ levels obtained initially.
129 E.M.WHITEHEAD, S.M.SHALET, C.G.BEARDWELL, D.A.PRICE Christie Hospital and Royal Manchester Children's Hospital, Manchester, England.

Pituitary gigantiga: a disabling condition.

Ten pituitary giants have been seen in hospitals in the Manchester region between 1939 and 1980 , nine of whom are still alive. The clinical and hormonal features have been studied in 8 of these cases. In 6 the diagnosis was made between the ages of 10-17 years and the other 2 in young adul thood. At presentation 6 had large pituitary adenomas with suprasellar extension. Neuro-surgical removal of the adenoma was attempted in 5 of the 6 with successful clearance of the whole tumour in only 1 case. Six patients received external pituitary irradiation and 4 received Bromocriptine. Four patients developed a severe pronounced kyphosis and 2 have gross osteoarthrosis. Four patients have had considerable psychological problems including suicidal tendencies whilst attempting to adjust to this condition. The disabling long-term sequelae of untreated or inadequately treated pituitary gigantism has led uo to believe that an aggressive approach to the treatment of this condition is justified. Patients in whom the pituitary adenoma is confined to the fossa should undergo transsphenoidal microsurgery. In those patients with a large pituitary adenoma with extrasellar spread, total tumour removal should be attempted, despite the risk of panhypopituitarism. 